University of Arkansas, Fayetteville

ScholarWorks@UARK

Graduate Theses and Dissertations

$12-2012$

\title{
Community Structure and Ecological Specialization in Plant-Ant Interactions
}

Paola Barriga

University of Arkansas, Fayetteville

Follow this and additional works at: https://scholarworks.uark.edu/etd

Part of the Biology Commons, Entomology Commons, and the Plant Biology Commons

\section{Citation}

Barriga, P. (2012). Community Structure and Ecological Specialization in Plant-Ant Interactions. Graduate Theses and Dissertations Retrieved from https://scholarworks.uark.edu/etd/625

This Dissertation is brought to you for free and open access by ScholarWorks@UARK. It has been accepted for inclusion in Graduate Theses and Dissertations by an authorized administrator of ScholarWorks@UARK. For more information, please contact scholar@uark.edu. 
COMMUNITY STRUCTURE AND ECOLOGICAL SPECIALIZATION IN PLANT-ANT INTERACTIONS 
COMMUNITY STRUCTURE AND ECOLOGICAL SPECIALIZATION IN

PLANT-ANT INTERACTIONS

A dissertation submitted in partial fulfillment

of the requirement for the degree of

Doctor of Philosophy in Biology

By

Paola A. Barriga

Pontificia Universidad Católica del Ecuador

Bachelor of Science in Biology, 2000

December 2012

University of Arkansas 


\begin{abstract}
Positive associations among species have contributed to the maintenance of biodiversity. These interactions are typically studied in pairwise fashion where two interacting organisms are the focus. This dissertation uses network theory to analyze positive plant-ant associations in three Neotropical forests. Obligate plant-ant mutualisms were used, where plants host the ants in domatia and provide food bodies while the ants protect the plants and can feed them. A network approach was used to depict all obligate plant-ant interactions within a community. The main questions asked at the community level were: 1) Do network structure and levels of specialization change geographically and, 2) What is the level of resilience of these associations if plants become extinct? I found that network structure and levels of specialization in three forests do not vary and that these associations are not resilient to host plant loss. In a second project I explored if traits of plants that host ants change between lowland and pre-montane tropical forests and if the differences impact plant-ant associations. Stable isotope analyses of plants and ants, in addition to plant measurements such as specific leaf area, trichome number, nitrogen per area and leaf thickness, were used. Plant traits differed by locale and by plant species. Location, but not ant species, affected herbivory. Finally, I explored the influence of ant metamorphosis, fat body and diet on stable isotope measurements. Stable isotope analysis is commonly used in ecological studies to determine trophic structure. However, the physiology of organisms analyzed can influence the results obtained. Fire ant colonies were used to explore if metamorphosis, fat body extraction and diet type impact isotopic signatures. Laboratory reared fire ant colonies were maintained with cricket and a sucrose diet. The addition of tuna to the diet was tested on additional colonies. Ant fats were dissolved using hexane-isopropanol or 95\% ethanol. Metamorphosis had a significant effect only on $\delta^{15} \mathrm{~N}$ and the availability of tuna
\end{abstract}


produced further shifts in isotope ratios for all developmental stages. Treatment with organic solvents had no effect on $\delta^{13} \mathrm{C}$, but resulted in enriched $\mathrm{d}^{15} \mathrm{~N}$ values. 
This dissertation is approved for recommendation to the Graduate Council.

Dissertation Director:

Dr. Cynthia L. Sagers

Dissertation Committee:

Dr. William J. Etges

Dr. Gary R. Huxel

Dr. Phyllis D. Coley 


\section{DISSERTATION DUPLICATION RELEASE}

I hereby authorize the University of Arkansas Libraries to duplicate this dissertation when needed for research and/or scholarship.

Agreed

Paola A. Barriga

Refused

Paola A. Barriga 


\section{ACKNOWLEDGMENTS}

Funding for this dissertation came from WWF's (World Wildlife Fund) Russell E. Train Education for Nature Program, the Organization for Tropical Studies (Glaxo Fund), Sigma Xi Grants-in-Aid, and a Dissertation Research Award, Fulbright College of Arts and Sciences, University of Arkansas to PB, and NSF Office of International Science and Education grant \# 0813594 to C. Sagers and N. Garwood. Support as a Teaching Assistantship was granted from the Department of Biological Sciences at the University of Arkansas.

I acknowledge J. Trager, A. Wild, D. Donoso, J. Longino, W. Mackay for ant identifications/verifications, C. C. Berg, F. Michellangeli, D. Penneys, H. van der Weff, J. Gonzalez and J. P. Latorre for plant identification/verification. G. Alvia, E. Bellota and, R. Gonzales for field assistance, A. Smith for barcode cooperation, K. Kunn for her observations on Myrmelachista flavocotea at La Selva and A. Barragán, H. Navarrete, OTS-Peru, OTS-Costa Rica, and staff at these research stations for help with logistics and collecting permits. I also wish to thank my colleagues of the University of Arkansas Stable Isotope Lab for sample processing and to A. Dowling for the use of his equipment.

I thank N. Blüthgen, P. Guimarães, P. Jordano, R. Colwell, E. LeBrun, L. Hart, S. Letcher, J. Stenken, T. Brenes-Arguedas, J. L. Hamrick, and M. Pires for discussion, comment and advice, and my graduate committee, W. J. Etges, G. R. Huxel, P. D. Coley, C. L. Sagers for their input. K. Polasky took care of my fire ant colonies. I thank to E. Gbur, J. Ludlam, C. Dormann, S. Lehnen, K. Thompson and G. Petris for statistical and programming advise. The Ministerio del Ambiente in Ecuador, the Ministerio de Agricultura in Perú and the Ministerio de Ambiente y Enegía in Costa Rica approved permits to do this research. Finally, special thanks go out to my family and friends. 


\section{DEDICATION}

The journey to obtain this degree is dedicated to my grandparents Estuardo and María Esthela, my parents Víctor Hugo and Martha Susana, to Connie Tharel, William Eklund, my siblings and my sweet protector. 


\section{TABLE OF CONTENTS}

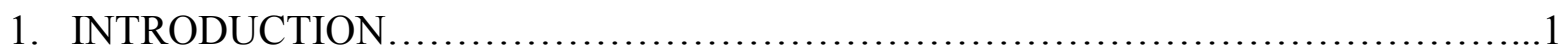



2. Community structure and ecological specialization in plant-ant interactions ............13

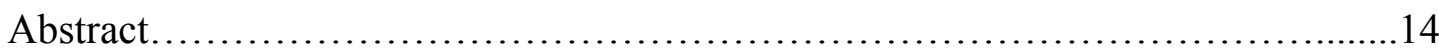





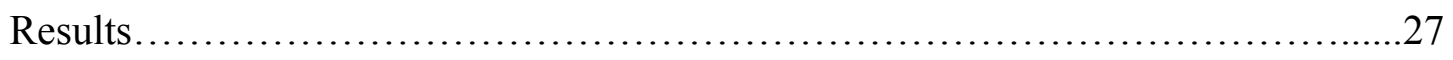

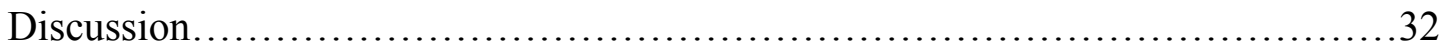

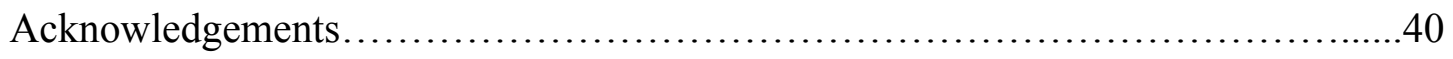

Literature cited.............................................................. 41

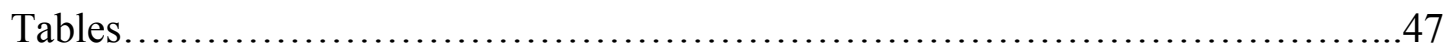

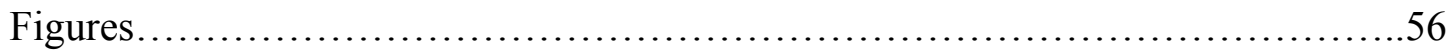

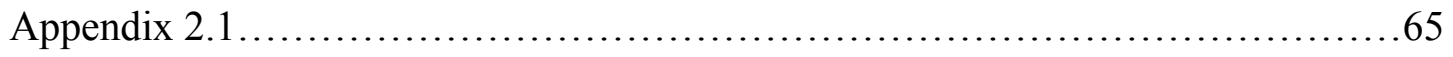

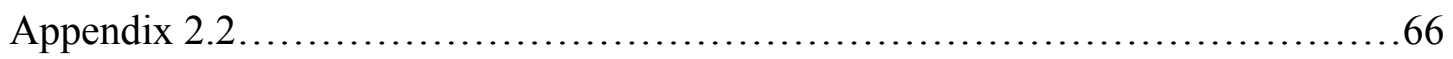

3. Functional trait variation and ant specialization in two plant-ant species in Costa Rica...67

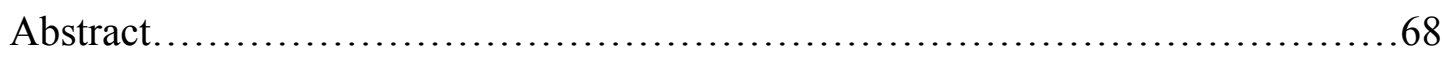

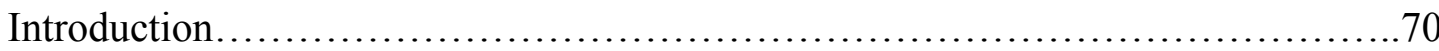

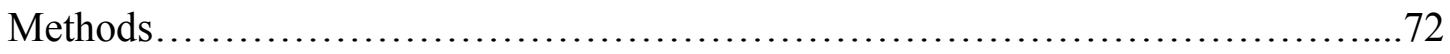

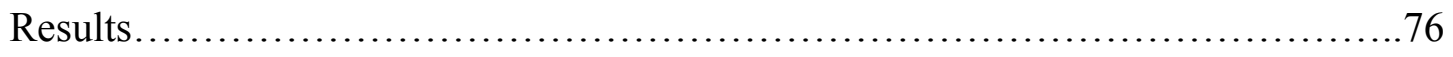

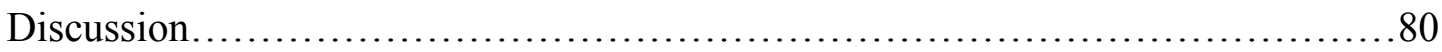



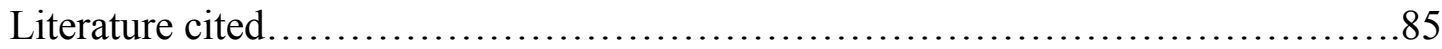


Tables.

Figures........................................................... 94

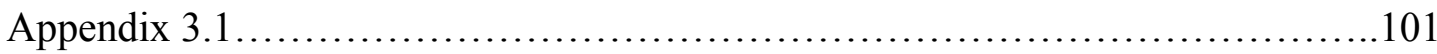

4. Stable isotope enrichment in laboratory ant colonies: effects of

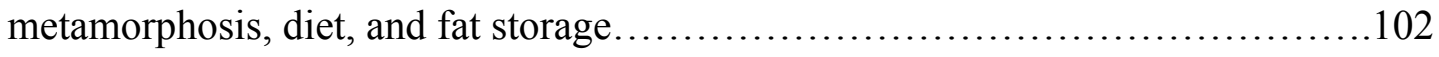



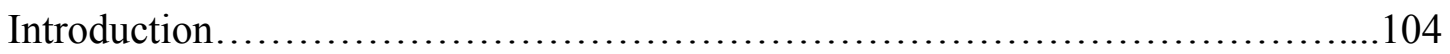

Methods............................................................... 106

Results................................................................ 110

Discussion........................................................ 114

Acknowledgements.................................................. 117

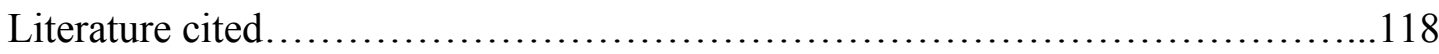

Figures............................................................. 122

Tables.............................................................. 124

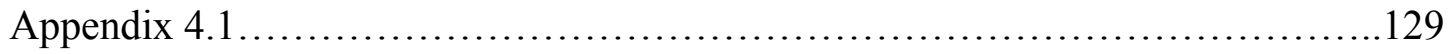

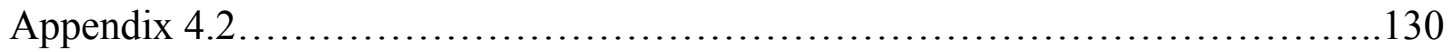

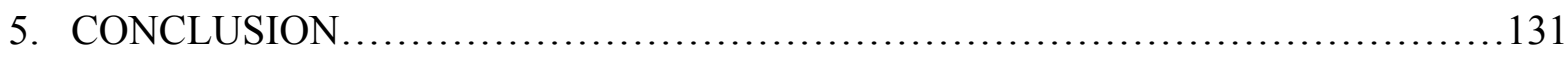

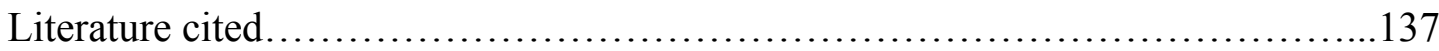




\section{INTRODUCTION}

Ecological interactions are important biotic factors that shape ecosystem biodiversity (Bascompte and Jordano 2007; Memmott et al. 2007; Palmer et al. 2008). After decades of research, a main focus of ecological studies has involved negative interactions among organisms such as competition and predator-prey dynamics (Stadler and Dixon 2008), but mutualistic associations have recently become more appreciated for their positive impact on the earth's biodiversity (Bascompte and Jordano 2007; Bastolla et al. 2009). Traditionally, mutualistic associations were underrepresented in population and community ecology studies due to a lack of models that allow their study (Stadler and Dixon 2008). Improvement in our understanding of mutualistic interactions has occurred with the dynamic view that ecological interactions can be understood as a continuum from antagonistic to mutualistic (Bronstein 1994; Thompson 1994; Stanton et al. 1999). Concurrently improved Lotka-Volterra type of models have become available to analyze these interactions (Stadler and Dixon 2008). An important advance, the implementation of network theory into ecological reasoning, has produced better understanding of the role that mutualistic associations have in ecosystem biodiversity and organization (Memmott et al. 2007).

Network theory has been mainly used in food webs to visualize who eats whom. Analyses of bipartite networks, networks that depict the association between two organisms, allow the visualization of interactions within entire communities. This has allowed better understanding of mutualisms than studying a particular mutualism in an isolated fashion from the other mutualisms occurring in a particular habitat (Thompson 1994). Organisms in communities interact directly and indirectly with one another and a network approach allows better resolution of the complexity of these interactions (Donatti et al. 2011). Complexity in interactions could 
influence the likelihood of species coexistence in equilibrium, how fast communities can recover from disturbances, the response towards species invasions and the stability and persistence of community composition (Fortuna and Bascompte 2006; Montoya et al. 2006; Rezende et al. 2007; Tylianakis et al. 2007). The network approach allows the evaluation of the impact of complexity and the loss and gain of species in communities.

In addition to the ecological background that network studies have produced, networks can be seen as structures that are the evolutionary product of species interactions (Thompson 2005). Analysis of network structure has shown that there are sets of traits that are the core of those structures. For example, plant-pollinator networks have traits such as flower shape and pollinators with a range of traits that allow them to pollinate those flowers. Plants and pollinators of different families or genera, can, as a product of coevolution, develop those traits and be part of the networks. Independent of the species identity, traits that characterize those networks are under selection independent of geographic area, producing similar final network structures in different locales. Because ecological characteristics that promote mutualistic interactions and the core traits that define those interactions are found worldwide, it has been suggested that interaction networks should evolve towards specific structures where the interacting species can be geographically interchangeable (Thompson 2005). If so, network topology or structure should not vary geographically and species identity should not affect network structure.

This phenomenon has been observed in free-living mutualisms where nested networks are reported independently of the identity of the interacting species (Jordano et al. 2003). In a nested network the most common species interact with several species and the least common species interact with a subset of the most common species. Similarly, symbiotic obligate mutualisms, where one of the interacting organisms is a symbiont that remains in intimate 
contact with the host over long periods of time, present compartmentalized networks (Fonseca and Ganade 1996; Guimarães et al. 2007). Those interactions form compartments or modules of species interacting that do not interact with the other subsets of species in the network (Lewinsohn et al. 2006). Therefore, the structure of a network is thought to be predictable depending on the type of mutualistic interaction (i.e. free-living or symbiotic obligate associations) and should not vary geographically. The aim of this dissertation is to determine if the structure of symbiotic obligate plant-ant networks vary geographically.

The first chapter focuses on the effect of geographic location on the network structure of obligate plant-ant associations' network structure. Here, plant and ant species are represented as nodes and their interactions as links joining these nodes. The frequencies of those interactions allows calculation of plant and ant dependences on each other (Bascompte et al. 2006). For example, to understand the dependence of plant species $i$ on animal species $j$, one can calculate the fraction of all animal visits coming from ant $j$ to plant $i$. Using the dependences between plants and ants, one can also calculate asymmetries in their relationships. Link distribution and asymmetry distribution have been used as measurements to analyze network topology. Therefore, I chose link distribution and asymmetries in the associations as topology metrics. Three obligate plant-ant communities were sampled: Yasuni National Park (Ecuador), Los Amigos Biological Station (Peru) and La Selva Biological Station (Costa Rica). Specific indices for specialization were developed for entire networks and for each specific node, or individual species, in the network (Blüthgen et al. 2006; Blüthgen et al. 2007; Blüthgen et al. 2008). I analyzed the distribution of the specialized indices for each locale to see if there were significant differences across locations. Additionally, I simulated the impact of plant extinctions on ant 
survival to determine whether network structure is related to community stability and resistance to disturbance.

Another important contribution to the study of ecological interactions came from the understanding that the outcome of ecological interactions can vary geographically. Species composition can vary geographically and between habitats resulting in a variety of ecological interactions from parasitic to mutualistic. For example, ecological interactions between small flower woodland-star, Lithophragma parviflorum (Hook.) Nutt. (Saxifragaceae), and the moth Greya politella (Walsingham) (Lepidoptera: Prodoxidae) that feeds and oviposits on this plant varies among habitats from parasitic to mutualistic (Thompson and Cunningham 2002). Greya politella is a relative of yucca moths and in a similar fashion they pollinate flowers while they oviposit on them. In four of the habitats studied, the plant relied on the moth as pollinator and the moth relied on the plant for their larvae to feed on the seeds. In these locations $\sim 59-69 \%$ of the fruits were aborted, but only $2-4 \%$ of them had Greya eggs showing that even though Greya larvae eat the seeds, at these locations a mutualistic association between them occurs. However, in four other habitats plants that had Greya as a pollinator were not more likely to produce seeds, but Greya eggs ate the seeds making this association a commensalism. The last four locations showed that plants selectively aborted fruits that had Greya eggs; therefore, in those locations this association was antagonistic (Thompson and Cunningham 2002).

Similar to the geographic variation in outcomes for species interactions, we expect to see geographic variation in the degree of specialization of interactions (Thompson 1994). The genetics of each individual interacting, in addition to the ecological factors characterizing a particular locale, produce a dynamic outcome in the level of specialization. For instance, physiological plant traits such as epidermis thickness, $\delta^{13} \mathrm{C}$ and $\delta^{15} \mathrm{~N}$ are known to vary 
geographically throughout their natural distributions (Cregg and Zhang 2001; Xu et al. 2003; Trimble and Sagers 2004).

Variation in plant physiological traits can affect ant associations when ants live in symbiosis with their host and feed on specific resources offered by the plants (Trimble and Sagers 2004). For example, six Cecropia Loefl. (Urticaceae) species were exposed to a high light regime of $30 \%$ full sun and a low light regime of $10 \%$ full sun to study the effect of light on trichilia development (Folgarait and Davidson 1994). Trichilia are dense indumentum formed of trichomes that Cecropia plants produce at the base of petioles of adult leaves (Berg and Franco Rosselli 2005). Ants inhabiting the trees collect food bodies, enriched in glycogen, from the trichilia (Rickson 1971). Cecropia polystachya Trécul developed trichilia at a lower leaf number, earlier plant developmental stage, under high light conditions than under low light (Folgarait and Davidson 1994). Even though this was the trend for the other species, differences were not statistically significant.

When plant-ant interactions are intimate and food bodies produced by the plants are an important food resource of the ant, plant trait variation and its influence in ant defense can be explored with the use of stable isotopes (Trimble and Sagers 2004). Carbon and nitrogen isotopes are usually used to track plant isotopic signatures in ant bodies. Ants that rely almost solely on food bodies from plant hosts are expected to have isotopic signatures that are close to plant values (Trimble and Sagers 2004). Ants that are very specialized are expected to protect the plant more efficiently than ants that are not as plant-dependent. The aim of the second chapter of this dissertation is to explore how plant trait variation influences the level of ant specialization.

Cecropia obtusifolia Bertol and C. insignis Liebm. are found at La Selva and at Las Cruces Biological Stations in Costa Rica. La Selva is a lowland tropical wet forest and Las 
Cruces is a pre-montane wet forest. Studying ant-plant relationships at these two locales offer the opportunity to observe if these plant species show variation in traits associated with adaptation to these locales. Nine plant traits including trichome number, leaf thickness, specific leaf area, grams of nitrogen per area, $\delta^{13} \mathrm{C}, \delta^{15} \mathrm{~N}, \% \mathrm{C}, \% \mathrm{~N}$ and $\mathrm{C}: \mathrm{N}$ ratio were were analyzed per plant species. Ant species inhabiting each plant were collected, placed in ethanol, identified and stable isotope analyses were performed on the paired plant and ant samples. ANOVAs were performed to determine if trait differences were found in each locale and by ant and plant species. Leaf photographs were analyzed to estimate herbivory and an ANOVA was performed to determine if herbivory differed by locale or ant species or a combination of both.

Stable isotope analyses have been used in ecological studies and one of the most common areas of use has been during diet analyses (Layman et al. 2007). This tool has proven useful, but interpretations of isotope analyses have relied on several simplifying assumptions. For example, in general, little enrichment (0-1\%) in $\delta^{13} \mathrm{C}$ between the diet and animals has been observed (DeNiro and Epstein 1978; Peterson and Fry 1987). In contrast, nitrogen enrichment has been shown to vary from -0.5 to $+9.2 \mathrm{~m}$ with a mean of 3.4\%o (DeNiro and Epstein 1981; Minagawa and Wada 1984; Post 2002) in a wide range of animals independent of habitat, type of nitrogen excreted, and growth rate (Minagawa and Wada 1984).

These findings offered the opportunity to use a nitrogen enrichment of $3 \%$ to determine trophic levels and diets in communities. However, this assumption has been challenged with the discovery that diet quality (Vanderklift and Ponsard 2003), nutritional status (Hobson et al. 1993), type of nitrogenous waste in excretion (Vanderklift and Ponsard 2003) water stress (Ambrose and Deniro 1987), life history stage (Patt et al. 2003; Doi et al. 2007; Tibbets et al. 2008) and the type of ecosystem being studied (Vanderklift and Ponsard 2003; Spence and 
Rosenheim 2005) can significantly influence carbon and nitrogen isotopic composition generating variation in isotopic enrichment (Sagers and Goggin 2007). Such variation in isotopic signatures and the mechanisms and the factors causing it remain poorly understood.

To adopt isotope approaches in studying the structure and function of ecological communities requires understanding the specific isotopic variation that could occur in each system (Tooker and Hanks 2004; Spence and Rosenheim 2005; Doi et al. 2006). The final chapter of this dissertation focuses on analyzing the effect of metamorphosis, diet and fat body removal in laboratory reared fire ants' isotopic signature. Five ant colonies were provided daily with crickets and a solution of cane sugar. Five additional colonies received this diet supplemented with tuna. Tuna was provided because it is enriched in ${ }^{13} \mathrm{C}$ and ${ }^{15} \mathrm{~N}$ relative to crickets. To analyze the effect of fat body on isotope signature, fifteen to twenty minor workers were haphazardly selected from sixteen colonies and assigned to each of three treatments: 1) control, 2) $95 \%$ ethanol, and, 3) a mixture of 1:1 (v/v) hexane-isopropanol. We used randomized complete block designs in an ANOVA to determine separately the effects of the solvents and metamorphosis on $\delta^{13} \mathrm{C}$ and $\delta^{15} \mathrm{~N}$ ratios. Metamorphosis was initially analyzed only with colonies that received the control diet. ANOVA in split plot designs were used to evaluate separately the effect of developmental stages, and diet on $\delta^{13} \mathrm{C}$ and $\delta{ }^{15} \mathrm{~N}$.

In summary, this dissertation contributes to understanding the effects of species composition on the structure of obligate plant-ant interaction communities. I analyzed the impact of changes in plant traits throughout geographic locations and any subsequent effect on the plantant interaction and the benefits the plants receive. Finally, I explored the effects on stable isotope values of ant bodies after metamorphosis, diet and absence of fat body and their possible influence on diet analyses' interpretations. This dissertation provides a broad view of the 
structure of communities of specialized plant-ant associations, characterizes the variability pairwise interactions at a regional scale, and explores the effects of physiology and diet for the interpretation of results of stable isotopic composition, useful common approach in ecological studies. 


\section{Literature cited}

Ambrose SH, Deniro MJ (1987) Bone nitrogen isotope composition and climate. Nature 325:201

Bascompte J, Jordano P (2007) Plant-animal mutualistic networks: the architecture of biodiversity. Annual Review of Ecology, Evolution, and Systematics 38:567-593

Bascompte J, Jordano P, Olesen JM (2006) Asymmetric coevolutionary networks facilitate biodiversity maintenance. Science 312:431-433

Bastolla U, Fortuna MA, Pascual-García A, Ferrera A, Luque B, Bascompte J (2009) The architecture of mutualistic networks minimizes competition and increases biodiversity. Nature 458:1018-1021

Berg CC, Franco Rosselli P (2005) Cecropia. The New York Botanical Garden Press, New York

Blüthgen N, Frund J, Vazquez DP, Menzel F (2008) What do interaction network metrics tell us about specialization and biological traits. Ecology 89:3387-3399

Blüthgen N, Menzel F, Blüthgen N (2006) Measuring specialization in species interaction networks. Bio Med Central Ecology 6:1-12

Blüthgen N, Menzel F, Hovestadt T, Fiala B (2007) Specialization, constraints, and conflicting interests in mutualistic networks. Current Biology 17:341-346

Bronstein JL (1994) Our current understanding of mutualism. Quarterly Review of Biology 69:31-51

Cregg BM, Zhang JW (2001) Physiology and morphology of Pinus sylvestris seedlings from diverse sources under cyclic drought stress. Forest Ecology and Management 154:131139

DeNiro MJ, Epstein S (1978) Influence of diet on the distribution of carbon isotopes in animals. Geochimica et Cosmochimica Acta 42:495-506

DeNiro MJ, Epstein S (1981) Influence of diet on the distribution of nitrogen isotopes in animals. Geochimica et Cosmochimica Acta 45:341-351

Doi H, Kikuchi E, Takagi S, Shikano S (2006) Selective assimilation by deposit feeders: experimental evidence using stable isotope ratios. Basic and Applied Ecology 7:159-166

Doi H, Kikuchi E, Takagi S, Shikano S (2007) Changes in carbon and nitrogen stable isotopes of chironomid larvae during growth, starvation and metamorphosis. Rapid Communications in Mass Spectrometry 21:997-1002 
Donatti CI, Guimarães PR, Galetti M, Pizo MA, Marquitti FMD, Dirzo R (2011) Analysis of a hyper-diverse seed dispersal network: modularity and underlying mechanisms. Ecology Letters 14:773-781

Folgarait PJ, Davidson DW (1994) Antiherbivore defenses of myrmecophytic Cecropia under different light regimes. Oikos 71:305-320

Fonseca CR, Ganade G (1996) Asymmetries, compartments and null interactions in an Amazonian ant-plant community. Journal of Animal Ecology 65:339-347

Fortuna MA, Bascompte J (2006) Habitat loss and the structure of plant, animal mutualistic networks. Ecology Letters 9:278-283

Guimarães PR, Rico-Gray V, Oliveira PS, Izzo TJ, dos Reis SF, Thompson JN (2007) Interaction intimacy affects structure and coevolutionary dynamics in mutualistic networks. Current Biology 17:1797-1803

Hobson KA, Alisauskas RT, Clark RG (1993) Stable-nitrogen isotope enrichment in avian tissues due to fasting and nutritional stress: implications for isotopic analyses of diet. Condor 95:388-394

Jordano P, Bascompte J, Olesen JM (2003) Invariant properties in coevolutionary networks of plant-animal interactions. Ecology Letters 6:69-81

Layman CA, Arrington DA, Montana CG, Post DM (2007) Can stable isotope ratios provide for community-wide measures of trophic structure? Ecology 88:42-48

Lewinsohn TM, Prado I, Jordano P, Bascompte J, Olesen JM (2006) Structure in plant-animal interaction assemblages. Oikos 113:174

Memmott J, Gibson R, Carvalheiro LG, Henson K, Heleno RH, Lopezaraiza M (2007) The conservation of ecological interactions. In: Stewart AJA, Lewis OT, New TR (eds) Insect Conservation Biology. CABI Publishing, Wallingford, UK, pp 226-244

Minagawa M, Wada E (1984) Stepwise enrichment of ${ }^{15} \mathrm{~N}$ along food chains: Further evidence and the relation between $\delta^{15} \mathrm{~N}$ and animal age. Geochimica et Cosmochimica Acta 48:1135-1140

Montoya JM, Pimm SL, Solé RV (2006) Ecological networks and their fragility. Nature 442:259-264

Palmer TM, Stanton ML, Young TP, Goheen JR, Pringle RM, Karban R (2008) Breakdown of an ant-plant mutualism follows the loss of large herbivores from an African savanna. Science 319:192-195 
Patt JM, Wainright SC, Hamilton GC, Whittinghill D, Bosley K, Dietrick J, Lashomb JH (2003) Assimilation of carbon and nitrogen from pollen and nectar by a predaceous larva and its effects on growth and development. Ecological Entomology 28:717-728

Peterson BJ, Fry B (1987) Stable isotopes in ecosystem studies. Annual Review of Ecology and Systematics 18:293-320

Post DM (2002) Using stable isotopes to estimate trophic position: models, methods, and assumptions. Ecology 83:703-718

Rezende EL, Lavabre JE, Guimar PR, Jordano P, Bascompte J (2007) Non-random coextinctions in phylogenetically structured mutualistic networks. Nature 448:925

Rickson FR (1971) Glycogen plastids in müllerian body cells of Cecropia peltata-a higher green plant. Science 173:344-347

Sagers CL, Goggin FL (2007) Isotopic enrichment in a phloem-feeding insect: influences of nutrient and water availability. Oecologia 151:464-472

Spence KO, Rosenheim JA (2005) Isotopic enrichment in herbivorous insects: a comparative field-based study of variation. Oecologia 146:89-97

Stadler B, Dixon T (2008) Mutualism. Ants and their insect partners. Cambridge University Press, New York, USA

Stanton ML, Palmer TM, Young TP, Evans A, Turner ML (1999) Sterilization and canopy modification of a swollen thorn acacia tree by a plant-ant. Nature 401:578-581

Thompson JN (1994) The Coevolutionary Process. University Of Chicago Press

Thompson JN (2005) The Geographic Mosaic of Coevolution. The University of Chicago Press, Chicago

Thompson JN, Cunningham BM (2002) Geographic structure and dynamics of coevolutionary selection. Nature 417:735-738

Tibbets T, M, Wheeless L, A., Martínez del Río C (2008) Isotopic enrichment without change in diet: an ontogenetic shift in $\delta^{15} \mathrm{~N}$ during insect metamorphosis. Functional Ecology 22:109-113

Tooker JF, Hanks LM (2004) Trophic position of the endophytic beetle, Mordellistena aethiops Smith (Coleoptera: Mordellidae). Environmental Entomology 33:291-296

Trimble ST, Sagers CL (2004) Differential host use in two highly specialized ant-plant association: evidence from stable isotopes. Oecologia 138:74-82 
Tylianakis JM, Tscharntke T, Lewis OT (2007) Habitat modification alters the structure of tropical host-parasitoid food webs. Nature 445:202-205

Vanderklift MA, Ponsard S (2003) Sources of variation in consumer-diet $\delta^{15} \mathrm{~N}$ enrichment: a meta-analysis. Oecologia 136:169-182

Xu Z, Prasolova N, Lundkvist K, Beadle C, Leaman T (2003) Genetic variation in branchlet carbon and nitrogen isotope composition and nutrient concentration of 11-year-old hoop pine families in relation to tree growth in subtropical Australia. Forest Ecology and Management 186:359-371 


\section{COMMUNITY STRUCTURE AND ECOLOGICAL SPECIALIZATION IN PLANT-ANT INTERACTIONS}

Barriga, Paola A.* and Sagers, Cynthia L.

Department of Biological Sciences,

University of Arkansas

Fayetteville, AR, USA

72701

*Corresponding author

email: pbarrig@uark.edu

phone: (479) 575-6349

Fax: (479) 575-3251 


\begin{abstract}
Species diversity and composition in communities have an effect on species interactions, their structure and degree of specialization. Because species diversity and composition vary geographically, we must study the structure of species interactions, specialization, and their resistance to disturbance across their distributions. Network theory provides a way to assess the structure of species interactions and the degree of specialization at the community and species levels. Simulations of sequential species removals allow an understanding of the effect of disturbances on species interaction networks. Obligate plant-ant interactions are ideal model systems to assess how geographic variation in community composition affects network structure, specialization, and its robustness to disturbance. We assessed the following hypotheses: do network structure and does species specialization vary geographically, and does removal of the best-connected and least abundant plant species have similar affects in different localities? We sampled at least 10 plants for the 30 species that host ants in their domatia in Ecuador, Peru and Costa Rica. Ants were collected in $95 \%$ ethanol and identified. We found that networks in the three locales were compartmentalized, had sub-webs and the distribution of the frequency of interactions among countries was not different. We found higher diversity in the interactions in Ecuador than in Peru or Costa Rica, and interaction evenness showed little variation in interaction frequencies across these three communities. The degree of specialization for the entire network in all three locales showed that these plant-ant interactions were highly specialized. The distribution of the degree of species specialization did not vary geographically, but niche breath changed geographically for ants in the Azteca alfari complex. This complex played a more important role connecting plant species in Ecuador and Peru than in Costa Rica. Plant extinction simulations showed that the sequential removal of plant species with more
\end{abstract}


connections towards the ones with fewer connections caused the lowest ant survival in the three locales while the removal of plants that were not abundant towards the more abundant produced higher ant survival. Understanding network structure in plant-ant interactions and their resistance to species loss adds a new perspective into conservation efforts.

Key words ants, plants, symbiosis, networks, geographic areas 


\section{Introduction}

Ecological interactions play an important role in species maintenance and diversity in ecosystems (Ehrlich and Raven 1964; Memmott et al. 2007). These interactions can be complex because species within the same environments are connected directly or indirectly with one another (Montoya et al. 2006). Interaction complexity often influences the likelihood of species coexistence in equilibrium, how fast a community can recover from disturbance, response towards species invasions, and the stability and persistence of community composition (Fortuna and Bascompte 2006; Montoya et al. 2006). The composition and diversity of natural communities are fundamental ecological factors that influence species interactions, their degree of specialization and their complexity (Jordano 1987; Davidson et al. 1989).

Interaction complexity and community organization can be described using a network approach (Olesen et al. 2007; Blüthgen et al. 2008; Ings et al. 2009; Donatti et al. 2011). In networks, species are represented as nodes and the interactions among them as links (Bascompte and Jordano 2007). Compartments or modules (Olesen et al. 2007) are subsets of species that interact only among themselves and not with other subsets of the community network (Lewinsohn et al. 2006). Some networks have sub-webs or isolated interacting species pairs that are not connected with the rest of the network (Guimarães et al. 2007). Depicting species interactions as networks provides insights concerning ecological and evolutionary dynamics occurring in communities (Rezende et al. 2007) and their geographic variation. The aim of this study is to determine if there is spatial variation in the structure of symbiotic obligate plant-ant networks and in resistance to plant species loss.

Symbiotic obligate plant-ant associations are interactions where plants offer domatia or spaces where ants can nest (Janzen 1966b; Davidson 2005). The most common domatia found in 
plants are hollowed stems or leaves or petiole pouches. Several plant hosts also offer food to the ants in the form of food bodies with high contents of proteins and lipids (Rickson 1971; Heil et al. 1998a; Fischer et al. 2002). In return, ants patrol their hosts protecting them from herbivores and encroaching vegetation (Linsenmair et al. 2001). In several instances, nitrogen found in ant carcasses, stored in the plant domatia, was incorporated by the plants into new tissue (Treseder et al. 1995; Sagers et al. 2000; Fisher et al. 2003).

Symbiotic obligate plant-ant communities are ideal mutualistic associations to test hypotheses developed with a network approach. Among the hypotheses to test in these types of communities are that interacting species converge and specialize for particular traits that characterize a mutualistic association rather than evolve unique traits in association with specific species (Thompson 2005). Adapting to a specific set of traits becomes a stable strategy when species richness increases in the communities (Thompson 2005). Because ecological characteristics that promote mutualistic interactions and the core traits that define those interactions are found worldwide, it has been suggested that interaction networks should evolve towards specific structures where the interacting species can be geographically interchangeable (Thompson 2005). Therefore, species identity should not influence community structure because the structure will be maintained if the species in the community play one of the roles (e.g. generalists, specialists) generally found in networks. This rationale does not include the role of competition among species of the same trophic level in the community structure. This hypothesis emphasizes that understanding species interaction dynamics and persistence requires knowledge of species across their distributional gradients (Thompson 2005); however, few data exist concerning spatial and/or temporal variation in interaction stability (Diaz-Castelazo et al. 2010). 
Several quantitative and qualitative metrics have been developed to study network structure (Bascompte and Jordano 2007). Indices designed to determine specialization at the network and species level have been developed (Blüthgen et al. 2006; Blüthgen et al. 2007; Blüthgen et al. 2008). These indices use frequency data, how many times an interaction between two organisms occur, and are robust to variation in sampling effort, matrix sizes and shapes because they describe deviations from a neutral organization of interactions (Blüthgen et al. 2006; Blüthgen 2010). By calculating values of specialization for each node we can obtain for each species in a network a distribution of ranges of specialization values. These values can be compared among networks.

Network structure and organization can be used to study network stability or resistance to species extinction. Network stability can be inferred by the simulated sequential removal of species from the network, either more connected to least connected, least abundant to more abundant species, or by random removal of individuals (Dormann et al. 2008). However, rarefaction analyses applied to networks, to species and the exclusion of rarely observed species have been suggested as options for producing more reliable analyses. Fewer efforts have been seen to simulate extinctions in obligate mutualisms or if those outcomes vary geographically.

Free-mutualistic networks, mutualisms where organisms interact with many individuals of the other species during their lifetime, have received more attention, particularly plant-pollinator and plant-seed disperser interactions. Free-mutualistic associations differ from symbiotic obligate associations because the associates do not live in intimate contact during their lifetime and they interact with a variety of species (Thompson 2005). Free-mutualistic associations have been characterized mainly by being nested, generally modular, and heterogeneous (Bascompte et al. 2003; Blüthgen 2010; Donatti et al. 2011). A nested network has a core of common species 
that interact among themselves and with species that are not as common (Bascompte et al. 2003). Networks are heterogeneous because the majority of species have few interactions, but a few species have more connections than are expected by chance (Bascompte and Jordano 2007).

Symbiotic obligate mutualisms differ from free-living associations in that one of the organisms interacting could be a symbiont that remains in intimate contact with the host over long periods of time (Thompson 2005). In this case, because the interaction is more intimate, mutualistic networks in these obligate mutualisms tend to be compartmentalized, with subsets of species interacting only among themselves and not with other parts of the network, and with subwebs or isolated interacting species-pairs that are not connected with the rest of the network (Fonseca and Ganade 1996; Guimarães et al. 2007). Thus, compartmentalized structures have been seen in free-mutualistic associations and in symbiotic obligate interactions, the latter often being more compartmentalized.

We studied three communities of symbiotic obligate plant-ant associations in three Neotropical forests. We examined the complexity in their structure to determine if these interactions produce similar network structures independently location. Additionally, we produced simulations to evaluate the stability of networks in the event of plant extinction at each locale. We specifically predicted that:

1. Network structure will not vary geographically among the symbiotic obligate plant-ant communities in Yasuni (Ecuador), Los Amigos (Peru) and La Selva (Costa Rica).

2. Distribution of the degree of specialization of individual species present in these three communities will not vary geographically.

3. Sequential removal of better to less connected plant species from plant-ant obligate networks will cause higher percentages of simulated ant extinction than sequential 
removal of random or less abundant plant species, and this result will not vary across the three communities studied.

\section{Methods}

\section{Study sites and field collections}

This research was carried out in three localities: 1) Yasuní Research Station (S $00^{\circ} 40.55^{\prime} \mathrm{W} 76^{\circ} 23.85^{\prime}$ ) in Yasuní National Park, Ecuador, 2) Research and Training Center at Los Amigos River (CICRA) (S12 33.30' W 70 $\left.06.47^{\prime}\right)$, the Madre de Dios area, Peru, and, 3) at La

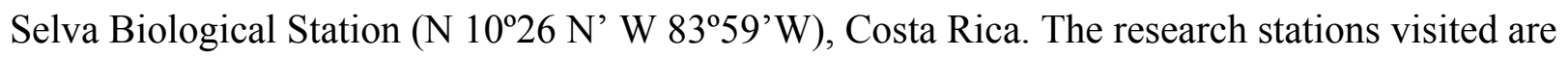
in lowland tropical rain forest.

The Yasuni National Park and Biosphere reserve has an annual average rainfall of 3081 $\mathrm{mm}$ (1995-1999) (Valencia et al. 2004). The park is 200-300 m above sea level (Tuomisto et al. 2002). The wettest months are April-May and October-November and generally no months with less than $100 \mathrm{~mm}$ of rainfall. Annual average temperature is $35^{\circ} \mathrm{C}$ (Valencia et al. 2004). Soils in Yasuni are typically clayey and acidic, rich in iron and aluminum and poor in nutrients (Korning et al. 1994). Los Amigos Biological Station is located $\sim 6 \mathrm{~km}$ upstream from the confluence between the Madre de Dios river and Los Amigos river at $268 \mathrm{~m}$ above sea level (Hamilton et al. 2007; Pitman 2008). Rainfall varies from $\sim 1200-3300 \mathrm{~mm}$ with drier periods during June to September (Hamilton et al. 2007). Daily temperatures vary between $21-26{ }^{\circ} \mathrm{C}$ and the highest temperature registered since 2000 was $39^{\circ} \mathrm{C}$ (Pitman 2008). Soils at Los Amigos vary dramatically, but generally are characterized as ultisols and inceptisols (Pitman 2008). La Selva Biological Station has about 55\% primary forest and the rest is a combination of young secondary forest, early successional pasture and abandoned plantations (McDade and Harsthorn 1994). The station is $35 \mathrm{~m}$ above sea level. The annual average rainfall from 1963-2010 at $\mathrm{La}$ 
Selva is $4375 \mathrm{~mm}$ with no apparent dry season (Cadol and Wohl 2010;

OrganizationforTropicalStudies 2012). The average temperature is $31^{\circ} \mathrm{C}$ (1982-2009). Soils at La Selva are alluvial and their fertility has the same degree of variation seen in other lowland wet tropic sites (McDade and Harsthorn 1994).

We attempted to sample at least 10 individuals of each known myrmecophyte (Table 1) with a minimum distance of $100 \mathrm{~m}$ between individuals. In some cases, due to host rarity, less than five individuals per host species were sampled (Table 1). Vouchers of Cecropia Loelf. (Urticaceae) plants and all ant species were deposited in cooperating museums in each country and in the Smithsonian National Museum of Natural History in Washington, DC, USA. We did not collect vouchers of other myrmecophytes. Those were identified in situ, or with the assistance of local natural historians, or pictures were taken for posterior identification. Only ant species from established colonies (e.g., presence of numerous workers and/or larvae and pupae) inside the domatia of the myrmecophytes were considered in this study. This procedure was followed to avoid collecting ants that were foraging opportunistically. These collecting procedures were used at each field site in Ecuador and Peru in January and February, 2009 and in Costa Rica during May 2010.

\section{Ant identification}

All collected ants were mounted and labeled. Azteca Forel (Formicidae: Dolichoderinae) identifications were confirmed following J. Longino’s Costa Rican Azteca key (http://academic.evergreen.edu/projects/ants/genera/azteca/key.html) and taxonomic revisions for Azteca in Costa Rica (Longino 1991b; 2007). Other ant genera were identified with help from A. Wild at the University of Illinois. W. Mackay verified the identities and morphological groups 
in Camponotus Mayr. and D. Donoso verified groupings in Crematogaster Lund, Myrmelachista Roger and Cephalotes Latreille.

After initial Azteca identification, specimens were directly compared with those at the Smithsonian National Museum of Natural History and in the J. Longino Azteca collection. Azteca alfari Emery and A. ovaticeps Forel have been identified to the species level when queens are available. When only workers were available, identification was less certain so we decided to follow expert advise and pool all individuals from these two species into the alfari complex (J. Longino, pers. com.). J. Longino identified A. emeryi Forel and verified Azteca species that were not barcoded.

\section{Ant barcode analyses}

One of the main ant genera that interact with myrmecophytes in the Neotropics is Azteca. Because Azteca species frequently show little morphological differentiation (Longino 1989), ant samples from Ecuador and Costa Rica were sent to the Canadian Centre for DNA barcoding. Ants were barcoded by sequencing the cythochrome oxidase I gene (COI) which has been useful in sorting unidentified individuals to species or species groups, and has been especially useful with ants (Smith et al. 2005). A maximum of five individuals per species were used. A piece of a leg from each individual ant was collected and placed on a microplate with one drop of ethanol and all utensils sterilized with ethanol at $95 \%$ to avoid cross contamination. The microplates were sent to the Canadian Centre for DNA barcoding analyses. At the Center, ant leg pieces $\leq$ $1 \mathrm{~mm}$ long were used to extract DNA. The extraction proceedure followed the manufacture's protocol of the NucleoSpin ${ }^{\circledR} 96$ Tissue kit (Macherey-Nagel). DNA extracts were re-suspended in $30 \mu \mathrm{l}$ of $\mathrm{dH}_{2} \mathrm{O}$, and a 658-base bp region near the 5' terminus of the $\mathrm{CO} 1$ gene was amplified following Hebert et al. (2003). CO1 sequences were amplified using a variety of primers that 
have been previously published and are compiled by Smith et al. (2008). PCR reactions were carried out as in Smith et al. (2008). Sequence divergences were obtained using the Kimura 2 parameter distance model (Kimura 1980) and visualized with a neighbor-joining tree (Saitou and Nei 1987).

\section{Plant identification}

Branches from myrmecophytic trees were sampled by tree climbing, and/or with a pole pruner, or using a crossbow. Other myrmecophytes were collected by cutting a branch or leaves with domatia with a pruner or with a pole pruner. Resident ants were collected and preserved in $95 \%$ ethanol.

Plant species were photographed and identified in situ or with the help of local taxonomists or para-taxonomists. Only Cecropia species were collected, pressed and dried. Identification of species in the plant families Melastomataceae and Lauraceae were verified by sending photographs to D. Penneys, F. Michellangeli and H. van der Weff. Cecropia strigosa Trécul and $C$. distachya Huber were identified by Cornelis C. Berg after review of voucher specimens.

\section{Data analyses}

\section{Estimating asymptotic species richness and rarefaction}

We estimated the asymptotic species richness for the samples from Ecuador and Peru using a non-parametric method developed by Chao et al. (2009). Chao2, a non-parametric estimator, could not be used with samples from Costa Rica because these samples were not duplicated, having exactly two samples (Chao et al. 2009). This method allows the calculation of number of samples needed, "m", to reach the estimated number of species $\left(\mathrm{S}_{\mathrm{est}}\right)$. It is also 
possible to calculate the number of samples necessary to achieve any fraction of the total number of species estimated $\left(\mathrm{gS}_{\text {est }}\right)$.

To be able to determine which community in our study was more diverse, rarefaction analyses were performed because there were differences in sample sizes (Gotelli and Colwell 2001; Colwell et al. 2004; Gotelli and Colwell 2011). EstimateS 8.2.0 (Colwell 2005) was used to calculate the Mao Tau estimator and produce rarefaction curves. Mao Tau is a non-parametric estimator that provides the expected numbers of species after the empirical data samples were pooled (Colwell et al. 2004). In other words, it is the sum of the probabilities of a species not being absent from all sampling units, across species (Colwell et al. 2004). The sample obtained was without replacement after 500 runs. To produce a smooth curve it has been shown that 50 runs are sufficient (Colwell 2005).

\section{Network structure of plant-ant interactions}

Networks were graphed using the plotweb function in R (Dormann et al. 2008). Basic qualitative (presence and absence data) and quantitative metrics (frequency of interactions), were calculated using the bipartite package ver. 1.17 for $\mathrm{R}$ for the analyses of ecological networks using the "networklevel" function as the default Blüthgen method (Dormann et al. 2008). Niche for this study refers to the host plants available for an ant to use, and niche overlap calculations used the Horn's Similarity Index (Dormann et al. 2008). Horn's Index is not strongly affected by sample size (Krebs 1999). Values close to 0 indicate no overlap in host use, while 1 shows total overlap in host use (Dormann et al. 2008).

Plant dependence on each ant species was calculated as the fraction of interactions with a particular ant species over the total interactions of each plant species with all the ant species in the community (Bascompte et al. 2006). The same logic was used to calculate ant dependences 
on each plant species. Asymmetries in networks were calculated as the difference in dependences of the organisms interacting over the larger dependence between both of them (Bascompte et al. 2006). Asymmetries allow us to explore whether the dependences between organisms interacting were symmetric or not.

The strength of the interaction for plants and ants whose distributions overlapped in two or three locales was calculated by summing the dependences of plants relying on particular ant species or vice versa (Bascompte et al. 2006). Plant and ant dependences, asymmetries and strength of interactions were calculated to describe the frequency asymmetries of the organisms interacting (Blüthgen 2010). Networks can have compartments, also called modules (Olesen et al. 2007), which are subsets of species that interact only among themselves and not with other subsets of the community network (Lewinsohn et al. 2006). Some networks have sub-webs or isolated interacting species-pairs that are not connected with the rest of the network, as well (Guimarães et al. 2007).

The two-sample Kolmogorov-Smirnov (K-S) test was used to compare the link distribution found in our networks (Stuart et al. 1999; Crawley 2007). Three, two-sample comparisons were performed: Ecuador vs. Peru, Ecuador vs. Costa Rica and Costa Rica vs. Peru. Additionally, link distributions of ant species whose distribution overlapped in two or the three locales were compared with a K-S test. The distribution of asymmetries, where zero and nonzero values were used, found in the three networks were compared using a Pearson's Chi-square test. Fisher's exact test (Agresti 1996; Crawley 2007) was also performed only with the non-zero values. Statistical analyses were performed in R (TeamCoreDevelopment 2005) and SAS ${ }^{\circledR}$ software (StatisticalAnalysisSystem 2002-2012). 


\section{Degree of specialization in each network}

The $\mathrm{H}_{2}$, specialization index (Blüthgen et al. 2006; Blüthgen et al. 2007) was calculated using the bipartite package in R. We used the "vaznull" model to determine if the specialization indices observed were different from random expectation (Vazquez and Aizen 2003; Dormann et al. 2009). We generated 1,000 matrices with values conforming to random associations and compared these matrices with the observed data. The vaznull model function in $\mathrm{R}$ is characterized by maintaining the connectance found in the empirical networks and also constrains the total number of interactions observed. The vaznull model is the most conservative because it does not emphasize the dichotomy between data that have low value cells and data with higher values. $\mathrm{H}_{2}$ values vary from 0 (generalized) to 1 (specialized) (Blüthgen et al. 2006).

\section{Degree of species specialization}

The specialization index for each plant and ant species $\left(d^{\prime}{ }_{i}\right)$ interacting in each network was calculated with the bipartite package in $\mathrm{R}$. The index varies from 0 (generalized) to 1 (specialized) showing generalized interactions and 1 specialized ones (Blüthgen et al. 2006). The distribution of the specialization indices in plants and ants was compared across country of origin with Fisher's Exact test to determine if they were significantly different.

\section{Network resistance to species extinction}

Rarefaction was applied to entire networks because different total samples were obtained in each country (Blüthgen 2010). In Peru we had the lowest plant sample of 70 . Therefore, 70 samples were randomly obtained from the matrices in Ecuador and Costa Rica. The process of obtaining 70 plant samples from the matrices in Ecuador and Pere was repeated 250 times, the maximum number of replicates produced for the size matrices in the program. This procedure was performed with replacement, and mean matrices produced for Ecuador and Costa Rica were 
used in the simulation. Plant extinctions were simulated in each locale to determine the effect of the stepwise reduction of nesting places by ants in each community. One plant species was randomly removed stepwise without replacement, producing the null model with which to compare the other systematic removals. Two types of systematic removals were used: (1) beginning with less abundant plants and progressing to increasingly abundant, and, (2) beginning with highly connected plants towards increasingly less connected plants. The random and the “most connected" simulations were repeated 1000 times and averages were analyzed. Simulations were performed with the bipartite package, version 1.17 , in $\mathrm{R}$ and the fit of the resulting curves were verified. Robustness (R) was calculated in order to measure the area under the extinction curve (Burgos et al. 2007). This index represents the degree of network robustness to species extinction. Values of the $\mathrm{R}$ index close to one come from curves where the system is robust because the curve decreases slowly and a significant fraction of plants have to be eliminated to have an effect on animal populations (Burgos et al. 2007). Values close to zero are the result of curves where species death is abrupt and the system is not robust to even a mild loss of plant species (Burgos et al. 2007).

\section{Results}

\section{Estimating asymptotic ant species richness}

Generally, more ant species than plant species characterized the obligate interactions in these three locales. However, the number of hosts and ants were more similar in Peru than in the other two communities. This could be because not as many samples were obtained in Peru. More ant species were expected in Ecuador than in Peru and Costa Rica after rarefaction was applied (Fig. 1) demonstrating than Ecuador had greater ant species richness. 
Nine additional ant species were estimated to possibly occur in Ecuador and two more in Peru (Fig. 2, Table 2). The total number of samples that were needed to reach the species asymptote in Ecuador was 1000 and in Peru was 156. The sampling effort in Costa Rica did not allow the estimation of the sampling effort necessary to obtain an asymptote because we did not have duplicates (Chao pers.comm.). When the number of duplicates is zero, the algorithm breaks down because there was not sufficient sample size (Chao pers.comm.).

\section{Network structure of plant-ant interactions}

To describe the structure of the networks we selected commonly used qualitative and quantitative metrics (Table 3, Fig. 3). The link distribution of the networks showed that the majority of species were connected to others by less than 10 links (Fig. 4). In Ecuador, one of the ant species was connected to plants with 57 links, while the maximum links found at other locales was 22 in Peru, and 20 in Costa Rica. On average, more links per species were found in Ecuador and Costa Rica than in Peru potentially because we collected fewer samples in Peru (Table 3). However, the link distribution among countries was not significantly different among localities (Table 4) showing that overall network structure did not differ statistically among locales.

As expected for symbiotic mutualisms, these networks had compartments, subsets of species that interact only among themselves and not with other subsets of the community network. The Ecuador network had four more compartments than networks in Peru or Costa Rica (Fig. 3). Two sub-webs, isolated interacting species-pairs that were not connected with the rest of the network, were found in the network in Costa Rica, five in Ecuador and three in Peru (Fig. 3).

Compartment diversity, a measure of the heterogeneity in the size of the different compartments on networks (Tylianakis et al. 2007), showed that approximately six species form a compartment 
in Ecuador, while in Peru and Costa Rica, compartments have only three and four species, respectively.

Connectance is the metric that shows the proportion of realized interactions in networks relative to the total interactions possible (Blüthgen et al. 2008). Ecuador showed the lowest connectance while Peru and Costa Rica had similar proportions of realized interactions. Nestedness was not significantly different from random in the three networks $(P>0.05$, in each case), reinforcing the finding that these networks were not nested but compartmentalized.

When analyzing the number of links per node, we observed that a power law distribution pattern was found in the ant associations in Ecuador (Table 3). A power law distribution shows a few nodes (ant species) being more connected than expected by chance. The truncated power law distribution pattern was found to explain the link distribution in the plants found in Ecuador and in the ants in Peru and Costa Rica (Table 3) showing that there are fewer species than the number of ants found in Ecuador that have a high number of interactions.

Network interactions were more diverse in Ecuador than in Peru or Costa Rica as shown by Shannon diversity indices (Table 3) although interaction evenness showed that there was not much variation in the interaction frequencies in these three communities. Low values of interaction evenness, close to zero, were link to high variation in interaction frequencies (Blüthgen 2010). There was no niche overlap among species in each trophic level in all locales studied as suggested by Horn's Index (Krebs 1999; Dormann et al. 2009) (Table 3). The degree of specialization for the entire network in the three locales was significantly different from random $(\mathrm{P}<0.01$ in Ecuador and Costa Rica, $\mathrm{P}<0.05$ in Peru $)$, showing that these plant-ant interactions are highly specialized. 
Ant and plant dependences were skewed towards small values indicating that species that were observed less frequently interacted with species that were more frequently found in those networks (Fig. 5). Because the number of observations of ants and plants were similar in these networks, the interaction strength was symmetric $(\mathrm{P}=1)$ with very few asymmetries (Fig. 5). The distribution of asymmetries in the three countries did not differ regardless of whether zero values were included (Chi-square, $\mathrm{P}=0.11$ ) or excluded (Fisher's exact test $\mathrm{P}=0.26$ ).

The Azteca alfari complex and A. australis Wheeler were found more frequently in Ecuador than in Peru or Costa Rica (Fig. 6) while Allomerus ortoarticulatus and Camponotus balzani Emery were found more frequently in Peru than in Ecuador. Crematogaster sp. 1 was the only species found in all three locales and was more often seen in Costa Rica than elsewhere. Myrmelachista shumanni Emery and Pseudomyrmex dendroicus Forel were both found frequently in Ecuador and Peru. For the plants, only Cecropia engleriana Snethl. (Urticaceae) was found more frequently in Ecuador than in Peru (Fig. 7). Plant dependences revealed that species such as C. ficifolia Warb. ex Snethl. (Urticaceae), C membranacea Trécul (Urticaceae), and C. latiloba Miq. (Urticaceae), Cordia nodosa Lam. (Boraginaceae) and Ocotea cf. javitensis (Lauraceae) were more frequently found in Peru than in Ecuador. Cordia alliodora (Ruiz \& Pav.) Cham. (Boraginaceae) was found more frequently in Costa Rica than in Ecuador while Triplaris americana L. (Polygonaceae) was found in both Ecuador and Peru.

\section{Degree of species specialization}

The degree distribution of species specialization indices was not significantly different geographically in ant or plant species (Fisher's exact test; ants $\mathrm{P}=0.59$, plants $\mathrm{P}=0.11$ ) (Table 5, 6). Among the ants, the Azteca alfari complex was present at the three locales and in Costa Rica reached the highest level of specialization. Azteca australis had a higher specialization 
index in Ecuador than in Peru while Camponotus balzani had an index that showed more specialization in Peru than in Ecuador.

\section{Network resistance to species extinction}

The curves produced by random plant removals differed from the curves produced by the systematic removals in Peru and Costa Rica (Fig. 8). In Costa Rica and Peru, the random extinction simulation showed a slower decrease of ant species compared to the removal of the best-connected species first. Removal of the least abundant species first produced curves that had a stable number of ant species until an abrupt decrease occurred when ca. $60 \%$ of plant species were removed (Fig. 8). In Ecuador, random removals of plant species produced a curve roughly similar to the curve produced while the least abundant species were removed first (Fig. 8). However, the removal of the least abundant species produced a curve with slightly higher ant survivorship than random removal. Removal of the best-connected plant species produced the highest level of ant extinction in Ecuador as in the other two countries. The networks of these plant-ant interactions were not robust to the loss of plant species (Fig. 8, Table 7 and 8). The removal of the best-connected plant species had a slightly more severe impact on ant extinction in the three locales than the random and the least abundant plant removals.

When the extinction curves were analyzed by simulation procedure to search for differences among locales, the random removal of species produced almost identical curves in Costa Rica and Ecuador, and in Peru the shape was similar, but ant survivorship was lower in these simulations (Fig. 9). The "least abundant species" simulation showed that ant survivorship was higher in Ecuador than in Peru and Costa Rica until 50\% of the plant species were removed. Only then, ant species survivorship changed to less than $80 \%$ and continued to drop as in the other two locales (Fig. 9). The "best-connected species" simulations produced a similar pattern 
in Ecuador and Costa Rica (Fig. 9); ant species survival initially decreased less abruptly in Ecuador and Costa Rica than in Peru. Therefore, the removal of the best-connected plants in Peru initially resulted in $40 \%$ more ant extinctions than in Ecuador and Costa Rica. Apparently more ant species depend on the plant hosts in Peru than in the other two countries.

\section{Discussion}

Our study provides empirical evidence that network structure in symbiotic obligate mutualistic associations does not vary among different geographic areas. Our findings show that neither ant or plant identity nor richness had an effect on network topology. The structure of symbiotic obligate plant-ant communities was compartmentalized and had sub-webs independent of the geographic location of these associations. The networks of these obligate associations were highly specialized and some species forming those networks are also highly specialized. However, the degree distribution of specialization indices did not vary geographically indicating that a similar proportion of species showed a similar degree of specialization at all three sites. These obligate associations were not robust to plant extinctions, in general, and the removal of the best-connected plant species could have a substantially greater impact on ant species persistence.

Independently of the fact that our sampling effort did not reach an asymptote in these communities, the structural patterns that our sampling produced follow general patterns reported earlier (Guimarães et al. 2007). The patterns seen in obligate symbiotic ant-plant interactions have been shown to be independent of possible biases in sampling effort, whereas free-living mutualisms are not (Guimarães et al. 2007). The relative abundance of the species interacting in symbiotic obligate associations is thought not to influence the network structure in those obligate mutualisms as much as in free-living mutualisms, which are frequently characterized as "nested" 
(Krishna et al. 2008). This occurs because the relative abundance of species explains $60-70 \%$ of the nested patterns seen in free-living association networks (Krishna et al. 2008). That is why it is thought to be less influenced by the local abundance of the species (Krishna et al. 2008). In contrast, obligate symbiotic associations have high levels of specialization in which one ant species inhabits one tree, independent of the number of hollowed stems or domatia available. If two species of ants inhabiting a tree stem meet, in little time, the most aggressive and faster reproducing ant will take over (pers. observation). Additionally, network metrics describing symbiotic obligate associations generally do not have the problem of species aggregations (i.e. grouping organisms into order instead of species level) into trophic web studies, or issues with the taxonomic resolution of the species involved (Martinez 1993; Abarca-Arenas and Ulanowicz 2002; Arii et al. 2007). Those have been a concern in trophic food webs because of the effects on the calculated indices to analyze those webs.

The ant-plant interaction networks analyzed here had on average six more plant and ant species than networks in obligate ant-plant interactions analyzed previously (Guimarães et al. 2007). Network sizes were in the low range of species number found in non-symbiotic associations. The number of species interacting in the Ecuadorian network was similar to the 16 plants and 25 ant species found by Fonseca \& Granade in Brazil (1996). Connectance varied between $9.8-15 \%$, similar values to $12 \%$ connectance found in another ant-plant community (Fonseca and Ganade 1996), and decreased as the number of species increased (Table 3), a pattern observed in plant-pollinator networks (Olesen and Jordano 2002). The frequency distribution of the number of interactions per species, called also degree distribution, in each group (plants or ants) was described by a power or truncated power law distribution (Table 3). These degree distribution patterns have been generally found in mutualistic associations where 
the majority of species have few interactions and few species that have a larger number of interactions (Bascompte and Jordano 2007). One of the hubs, species strongly connected to others, was the Azteca alfari group (Fig. 3). This was particularly true for the Ecuador and Peru network.

The networks in these three communities were compartmentalized, having subgroups of species interacting only among themselves and not with others in the networks, and had subwebs, species pairs interacting isolated from others, and this general pattern was found in all three locales (Fig. 3)(Guimarães et al. 2007). The general network topology expected in symbiotic, obligate mutualisms was found in the three locales despite the identity of the species found in each community, as previously hypothesized (Thompson 2005). However, the frequency of interactions among some species in the three locales varied (Fig. 3) indicating that the ecological impact of the species forming these networks varied geographically (Blüthgen 2010). For example, the Azteca alfari complex seemed to play a more important role connecting several plant species in Ecuador and Peru than in Costa Rica. Similarly, the ecological impact of Crematogaster sp. 1 in Costa Rica where it interacts more frequently with myrmecophytes, may be different than in Ecuador and Peru (Figs. 3,6). This variation in the frequency of interactions shows that the relative ecological contribution of this complex of ant species varies among communities (Blüthgen 2010). Plant benefits from ant protection have been explored locally in other communities (Schupp 1986; Bruna et al. 2004; Frederickson 2005a; Trager et al. 2010), but possible geographic variation in the ecological services exhibited by ants due to change in the frequency of them interacting with plants has not been extensively studied.

Low niche overlap was observed among plant or ant species and all three networks had high levels of specialization (Table 3). However, Costa Rica had the most specialized network 
where the interactions were highly exclusive. The Network Specialization Index takes into consideration the proportional utilization and availability of species to interact with (Blüthgen et al. 2006). Even though Costa Rica had fewer ant and plant species than Ecuador and Peru (Table 3), the ant species partitioned their interactions differently making the network more specialized. Latitudinal variation in specialization levels in species interactions has not been well studied (Ollerton and Cranmer 2002) and apparent specialization trends in plant-pollinator interaction increasing from the temperate zones to the tropics have been the result of sampling bias (Ollerton and Cranmer 2002). However, it has been recently shown that biotic specialization in mutualistic networks of plant-pollinator and plant-seed disperser decreases towards the tropics and is higher in temperate zones (Schleuning et al. 2012). The specialization index used allows comparisons among networks with different sample sizes and showed that networks were more specialized while moving from Peru towards Costa Rica (Table 3) as Schleuning et al. (2012) found in plant pollinator and seed dispersers associations. This trend observed in these areas suggests that a higher percentage of ant species interacted more frequently with one plant species in Costa Rica, supporting the findings of Schleuning et al. (2012) that argues that biotic specialization decreased with the increment of local and regional plant diversity. Because we collected a fixed number of plant samples (10 individuals per species), we cannot state that they interacted more frequently with a rare resource. If we consider the percentage of ant species that interacted at least five times with only one plant species, then we see that this occurred in $41.6 \%$ of ant species in Costa Rica, $23.80 \%$ of the ant species in Ecuador and $7.69 \%$ of ant species in Peru. These observations support the idea that specialization in mutualistic interactions is a response of the ants, plant pollinators or seed dispersers to low plant diversity (Schleuning et al. 2012). This 
observed trend certainly requires further study. No relationship was found between number of plant species and percent mean occupancy.

Species specialization indices showed variation in a few species present in two or more communities. However, in some cases the index $\left(d_{i}{ }^{\prime}\right)$ values were low $(<0.3)$ showing that the frequencies of interactions observed were not different from the null model, i.e., that all the species are used in proportion to their availability (Blüthgen et al. 2006). In some cases, empirical specialization asymmetries, e.g., a rare species is specialized on a commonly visited partner, cannot be distinguished from the null model expectation. The Azteca alfari complex showed a clear geographical difference in its values of specialization (Table 5). Other species, such as Myrmelachista schumanni had the same value of specialization regardless of the community analyzed (Table 5). Plant species, for the most part, had low values of specialization and, when high, those values showed a difference among communities analyzed. For example, Cordia alliodora and Ocotea cf javitensis had higher value of specialization in Ecuador than in Costa Rica or Peru (Table 5). Cordia nodosa had a higher value in Peru than in Ecuador. Therefore, there was geographical variation in the specialization index of some species, but for others, the frequency of the interactions was not different from that expected by the null expectation (Table 6).

Sequential removal of plant species in these three locales produced roughly the same general patterns observed in plant-pollinator extinction studies (Memmott et al. 2004; KaiserBunbury et al. 2010). Random removals of plant species produced extinction curves with intermediate ant survivorship percentages in all the three locales relative to the best-connected and less abundant removal simulations. As in Memmott et al. (2004), the sequential removal of the best-connected to the least connected species resulted in the fastest rate of ant species lost 
while removal of the least abundant species resulted in the slowest loss rate. This pattern was maintained across the three locales. However, the curves produced in our study appeared to be more linear than the ones produced by Memmott et al. (2004). The removal of species such as Cecropia membranacea and Triplaris americana was predicted to produce an initial loss of $40 \%$ of ant species in Peru, compared to 0-20\% loss of species in Costa Rica and Ecuador. The ecological impact of these species loss is predicted to be more drastic than in the other two environments. These networks showed not to be robust to plant loss because of the high levels of specialization as similarly found by Aizen et al. (2012) in pollination networks in Argentina.

These simulations were performed after matrices with quantitative data, frequencies of interactions represented, corrected for using rarefaction methods (Blüthgen 2010). These approaches increase the reliability of our simulations by reducing the bias caused by different observation frequencies (Blüthgen 2010). Quantitative data, including interaction frequencies, have been shown to produce more realistic results in simulations than qualitative data sets where only the presence or absence of interactions are registered (Kaiser-Bunbury et al. 2010) and the metrics that use frequency of interactions to weight each link information are robust against differences in sample size and more informative than metrics that use only presence-absence data (Blüthgen et al. 2008).

Ant species removals were not simulated to analyze the effects on plant extinction because myrmecophytes can survive without ant associates (Fáveri and Vasconcelos 2004). Plants might suffer severe herbivory in the absence of ants (Schupp 1986), but their chemical and morphological defenses may help them survive. Ants have been thought to be more versatile allelopathic agents than chemicals (Janzen 1969a); however, no large scale analyses have been performed to asses mortality rates of myrmecophytes without their ants, suggesting that this 
should be tested. In the hypothetical case that plant species were extinct, the simulations allowed visualizing the consequences for the ant species. It is not very likely that myrmecophytes that are pioneers, such as Cecropia spp., would go extinct if disturbances in the environment occurred. However, species such as Tachigali formicarum (Fabaceae) Harms, Triplaris americana (Polygonaceae), Ocotea cf. javitensis might be more at risk by forest disturbances. Ant species seem more vulnerable to the lack of hosts especially in cases where food bodies are produced by the plants to maintain the ants inhabiting them relative to plants as a result of ant loss (Rickson 1971; Fischer et al. 2002; Valverde and Hanson 2011).

A new species of Camponotus was discovered during this study and was found interacting with Cecropia (Mackay and Barriga 2012). Cecropia Loelf. is probably one of the most common genera of myrmecophytes in the Neotropics and has been widely studied, yet our work demonstrates that new ant species are still being found, and thus taxonomic work is extremely important to understanding species' roles in ecosystems and variation in these roles across their distributions. This finding suggests that more collections, barcode analyses and taxonomic study are needed.

Evaluating the stability of ant-plant associations was conducted in this research from the perspective of static networks without regard to behavioral flexibility. Recent work in plantpollinator interactions has incorporated pollinator behavior in species extinction simulations. Pollinator behavior, measured as a switch in plant species pollinators interact with, was incorporated after analyzing the interactions in temporal snapshots and comparing them to longer periods of time (Kaiser-Bunbury et al. 2010). "Re-wiring" or the behavior of changing plant species increased network stability when strong plant associates were sequentially removed (Kaiser-Bunbury et al. 2010). Stability in this study was defined as the percentage of species and 
interactions that cause a 50\% secondary extinction (Kaiser-Bunbury et al. 2010) A more dynamic approach should increase our understanding of interaction dynamics because ant-plant interactions might be changing through the hosts' development and growth. Large spatial and long-term temporal observations of ant-plant interactions and experimentation may produce patterns that allow for greater understanding of ant competition for hosts and resources provided by the hosts. 


\section{Acknowledgements}

Funding for this project came from WWF's Russell E. Train Education for Nature Program, Organization for Tropical Studies (Glaxo Fund), and Dissertation Research Award, Fulbright College of Arts and Sciences, University of Arkansas to PB and NSF, Office of International Science and Education grant \# 0813594 to CS and N. Garwood. We acknowledge J. Trager, A. Wild, D. Donoso, J. Longino, W. Mackay for ant identifications/verifications. C. C. Berg, F. Michellangeli, D. Penneys, H. van der Weff, J. Gonzalez and J. P. Latorre for plant identification/verification. G. Alvia, E. Bellota and, R. Gonzales for field assistance. A. Smith for barcode cooperation. K. Kunn for her observations on Myrmelachista flavocotea at La Selva. A. Barragan, H. Navarrete, D. Brenes, OTS-Peru, M. Pires, P. Guimarães, P. Jordano, R. Colwell, C. Dormann, N. Blüthgen, S. Letcher, G. Petris, R. Vargas, A Dowling, staff Yasuni Research Station and N. Garwood for help with logistics, discussion, comment, equipment and advice. To Ministerio del Ambiente in Ecuador, Ministerio de Agricultura in Peru and to Ministerio de Ambiente y Energia in Costa Rica for the permits to do this research. 


\section{Literature cited}

Abarca-Arenas LG, Ulanowicz RE (2002) The effects of taxonomic aggregation on network analysis. Ecological Modelling 149:285-296

Agresti A (1996) An introduction to categorical data analysis. John Wiley \& Sons, Inc., New York

Aizen MA, Sabatino M, Tylianakis JM (2012) Specialization and rarity predict nonrandom loss of interactions from mutualist networks. Science 335:1486-1489

Arii K, Derome R, Parrott L (2007) Examining the potential effects of species aggregation on the network structure of food webs. Bulletin of Mathematical Biology 69:119-133

Bascompte J, Jordano P (2007) Plant-animal mutualistic networks: the architecture of biodiversity. Annual Review of Ecology, Evolution, and Systematics 38:567-593

Bascompte J, Jordano P, Melian CJ, Olesen JM (2003) The nested assembly of plant-animal mutualistic networks. Proceedings of the National Academy of Sciences 100:9383-9387

Bascompte J, Jordano P, Olesen JM (2006) Asymmetric coevolutionary networks facilitate biodiversity maintenance. Science 312:431-433

Blüthgen N (2010) Why network analysis is often disconnected from community ecology: a critique and an ecologist's guide. Basic and Applied Ecology 11:185-195

Blüthgen N, Frund J, Vazquez DP, Menzel F (2008) What do interaction network metrics tell us about specialization and biological traits. Ecology 89:3387-3399

Blüthgen N, Menzel F, Blüthgen N (2006) Measuring specialization in species interaction networks. Bio Med Central Ecology 6:1-12

Blüthgen N, Menzel F, Hovestadt T, Fiala B (2007) Specialization, constraints, and conflicting interests in mutualistic networks. Current Biology 17:341-346

Bruna EM, Lapola DM, Vasconcelos HL (2004) Interspecific variation in the defensive responses of obligate plant-ants: experimental tests and consequences for herbivory. Oecologia 138:558-565

Burgos E, Ceva H, Perazzo RPJ, Devoto M, Medan D, Zimmermann M, Delbue AM (2007) Why nestedness in mutualistic networks? Journal of Theoretical Biology 249:307-313

Cadol D, Wohl E (2010) Wood retention and transport in tropical, headwater streams, La Selva Biological Station, Costa Rica. Geomorphology 123:61-73 
Colwell RK (2005) EstimateS: Statistical estimation of species richness and shared species from samples. Version 8.02 User's Guide and application published at htt://purl.oclc.org/estimates. Robert K. Colwell.

Colwell RK, Mao CX, Chang J (2004) Interpolating, extrapolating, and comparing incidencebased species accumulation curves. Ecology 85:2717-2727

Crawley MJ (2007) The R book, 1st edn. John Wiley \& Sons Inc, West Sussex, England

Chao A, Colwell RK, Lin C, Gotelli NJ (2009) Sufficient sampling for asymptotic minimum species richness estimators. Ecology 90:1125-1133

Davidson DW (2005) Cecropia and its biotic defenses. In: Cecropia, vol Monograph 94. The New York Botanial Garden Press, New York, pp 214-226

Davidson DW, Snelling RR, Longino JT (1989) Competition among ants for myrmecophytes and the significance of plant trichomes. Biotropica:64-73

Diaz-Castelazo C, Guimarães Jr PR, Jordano P, Thompson JN, Marquis RJ, Rico-Gray V (2010) Changes of a mutualistic network over time: reanalysis over a 10-year period. Ecology 91:793-801

Donatti CI, Guimarães PR, Galetti M, Pizo MA, Marquitti FMD, Dirzo R (2011) Analysis of a hyper-diverse seed dispersal network: modularity and underlying mechanisms. Ecology Letters 14:773-781

Dormann CF, Frund J, Blüthgen N, Gruber B (2009) Indices, graphs and null models: analyzing bipartite ecological networks. The Open Ecology Journal 2:7-24

Dormann CF, Gruber B, Fr,nd J (2008) Introducing the bipartite package: analyzing ecological networks. R news 8:8-11

Ehrlich PR, Raven PH (1964) Butterflies and plants: a study in coevolution. Evolution 18:586608

Fáveri SB, Vasconcelos HL (2004) The Azteca-Cecropia association: are ants always necessary for their host plants? Biotropica 36:641-646

Fischer RC, Richter A, Wanek W, Mayer V (2002) Plants feed ants: food bodies of myrmecophytic Piper and their significance for the interaction with Pheidole bicornis ants. Oecologia 133:186-192

Fisher RC, Wolfgang W, Richter A, Mayer V (2003) Do ants feed plants? A N labelling study of nitrogen fluxes from ants to plants in the mutualism of Pheidole and Piper. Journal of Ecology 91:126-134 
Fonseca CR, Ganade G (1996) Asymmetries, compartments and null interactions in an Amazonian ant-plant community. Journal of Animal Ecology 65:339-347

Fortuna MA, Bascompte J (2006) Habitat loss and the structure of plant, animal mutualistic networks. Ecology Letters 9:278-283

Frederickson ME (2005) Ant species confer different partner benefits on two neotropical myrmecophytes. Oecologia 143:387-395

Gotelli NJ, Colwell RK (2001) Quantifying biodiversity: procedures and pitfalls in the measurement and comparison of species richness. Ecology Letters 4:379-391

Gotelli NJ, Colwell RK (2011) Estimating species richness. In: Magurran AE, McGill BJ (eds) Biological Diversity Frontiers in Measurement and Assessment. Oxford University Press, New York, pp 39-54

Guimarães PR, Rico-Gray V, Oliveira PS, Izzo TJ, dos Reis SF, Thompson JN (2007) Interaction intimacy affects structure and coevolutionary dynamics in mutualistic networks. Current Biology 17:1797-1803

Hamilton SK, Kellndorfer J, Lehner B, Tobler M (2007) Remote sensing of floodplain geomorphology as a surrogate for biodiversity in a tropical river system (Madre de Dios, Peru). Geomorphology 89:23-38

Hebert PDN, Cywinska A, Ball SL (2003) Biological identifications through DNA barcodes. Proceedings of the Royal Society of London. Series B: Biological Sciences 270:313-321

Heil M, Fiala B, Kaiser W, Linsenmair KE (1998) Chemical contents of Macaranga food bodies: adaptations to their role in ant attraction and nutrition. Functional Ecology $12: 117-122$

Ings TC, Montoya JM, Bascompte J, Bluthgen N, Brown L, Dormann CF, Edwards F, Figueroa D, Jacob U, Jones JI (2009) Ecological networks-beyond food webs. Journal of Animal Ecology 78:253-269

Janzen DH (1966) Coevolution of mutualism between ants and acacias in Central America. Evolution:249-275

Janzen DH (1969) Allelopathy by myrmecophytes: the ant Azteca as an allelopathic agent of Cecropia. Ecology 50:147-153

Jordano P (1987) Patterns of mutualistic interactions in pollination and seed dispersal: connectance, dependence asymmetries, and coevolution. The American Naturalist 129:657-677 
Kaiser-Bunbury CN, Muff S, Memmott J, Muller CB, Caflisch A (2010) The robustness of pollination networks to the loss of species and interactions: a quantitative approach incorporating pollinator behaviour. Ecology Letters 13:442-452

Kimura M (1980) A simple method for estimating evolutionary rates of base substitutions through comparative studies of nucleotide sequences. Journal of Molecular Evolution $16: 111-120$

Korning J, Thomsen K, Dalsgaard K, Nørnberg P (1994) Characters of three Udults and their relevance to the composition and structure of virgin rain forest of Amazonian Ecuador. Geoderma 63:145-164

Krebs CJ (1999) Ecological Methodology. Addison-Wesley Educational Publisher, Inc

Krishna A, Guimãraes Jr PR, Jordano P, Bascompte J (2008) A neutral-niche theory of nestedness in mutualistic networks. Oikos 117:1609-1618

Lewinsohn TM, Prado I, Jordano P, Bascompte J, Olesen JM (2006) Structure in plant-animal interaction assemblages. Oikos 113:174

Linsenmair KE, Heil M, Kaiser W, Fiala B, Koch T (2001) Adaptations to biotic and abiotic stress: Macaranga-ant plants optimize investment in biotic defense. Journal of Experimental Botany 52:2057-2065

Longino JT (1989) Geographic variation and community structure in an ant-plant mutualism: Azteca and Cecropia in Costa Rica. Biotropica 21:126-132

Longino JT (1991) Taxonomy of the Cecropia-inhabiting Azteca ants. Journal of Natural History 25:1571-1602

Longino JT (2007) A taxonomic review of the genus Azteca (Hymenoptera: Formicidae) in Costa Rica and a global revision of the aurita group. Zootaxa 1491:1-63

Mackay W, Barriga PA (2012) A new species of neotropical carpenter ant in the genus Camponotus (Hymenoptera: Formicidae), apparently without major workers. Psyche 2012, Article ID 382938, 5 pages, 2012. doi:10.1155/2012/382938

Martinez ND (1993) Effects of resolution on food web structure. Oikos 66:403-412

McDade LA, Harsthorn GS (1994) La Selva Biological Station. In: McDade LA, Bawa KS, Hespenheide HA, Harsthorn GS (eds) La Selva Ecology and natural history of a neotropical rain forest. The University of Chicago Press, Chicago

Memmott J, Gibson R, Carvalheiro LG, Henson K, Heleno RH, Lopezaraiza M (2007) The conservation of ecological interactions. In: Stewart AJA, Lewis OT, New TR (eds) Insect Conservation Biology. CABI Publishing, Wallingford, UK, pp 226-244 
Memmott J, Waser NM, Price MV (2004) Tolerance of pollination networks to species extinctions. Proceedings of the Royal Society of London. Series B: Biological Sciences 271:2605

Montoya JM, Pimm SL, Solé RV (2006) Ecological networks and their fragility. Nature 442:259-264

Olesen JM, Bascompte J, Dupont YL, Jordano P (2007) The modularity of pollination networks. Proceedings of the National Academy of Sciences 104:19891

Olesen JM, Jordano P (2002) Geographic patterns in plat-pollinator mutualistic networks. Ecology 83:2416-2424

Ollerton J, Cranmer L (2002) Latitudinal trends in plant-pollinator interactions: are tropical plants more specialised? Oikos 98:340-350

OrganizationforTropicalStudies (2012) La Selva Daily Rainfall, 1963-2010. In: Clark DA (ed) http://www,ots,ac,cr/meteoro/defaults.php?pestacion=2

Pitman NCA (2008) An overview of the Los Amigos watershed, Madre de Dios, southeastern Peru. August 2008 versions of an unpublished report available from the author at npitman@amazonconservation.org

Rezende EL, Lavabre JE, Guimar PR, Jordano P, Bascompte J (2007) Non-random coextinctions in phylogenetically structured mutualistic networks. Nature 448:925

Rickson FR (1971) Glycogen plastids in müllerian body cells of Cecropia peltata-a higher green plant. Science 173:344-347

Sagers CL, Ginger SM, Evans RD (2000) Carbon and nitrogen isotopes trace nutrient exchange in an ant-plant mutualism. Oecologia 123:582-586

Saitou N, Nei M (1987) The neighbor-joining method: a new method for reconstructing phylogenetic trees. Molecular biology and evolution 4:406-425

Schleuning M, Fründ J, Klein AM, Abrahamczyk S, Alarcón R, Albrecht M, Andersson GKS, Bazarian S, Böhning-Gaese K, Bommarco R, Dalsgaard B, Dehling DM, Gotlieb A, Hagen M, Hickler T, Holzschuh A, Kaiser-Bunbury CN, Kreft H, Morris RJ, Sandel B, Sutherland WJ, Svenning J-C, Tscharntke T, Watts S, Weiner CN, Werner M, Williams NM, Winqvist C, Dormann CF, Blüthgen N (2012) Specialization of mutualistic Interaction networks decreases toward tropical latitudes. Current Biology 22:1-7

Schupp EW (1986) Azteca protection of Cecropia: ant occupation benefits juvenile trees. Oecologia 70:379-385 
Smith MA, Fisher BL, Hebert PDN (2005) DNA barcoding for effective biodiversity assessment of a hyperdiverse arthropod group: the ants of Madagascar. Philosophical Transactions of the Royal Society B: Biological Sciences 360:1825-1834

Smith MA, Rodriguez JJ, Whitfield JB, Deans AR, Janzen DH, Hallwachs W, Hebert PDN (2008) Extreme diversity of tropical parasitoid wasps exposed by iterative integration of natural history, DNA barcoding, morphology, and collections. Proceedings of the National Academy of Sciences 105:12359-12364

StatisticalAnalysisSystem (2002-2012) SAS Institute Publication Copyright (c). In, 8 of the SAS system for [Unix] edn, Cary, NC, USA

Stuart A, Ord KJ, Arnold S (1999) Classical inference and the linear model. Kendall's advanced theory of Statistics, Sixth edn. Edward Arnold, London

TeamCoreDevelopment R (2005) R: a language and environment for statistical computing, R. Foundation for Statistical Computing. (http://www.R-project.org)

Thompson JN (2005) The Geographic Mosaic of Coevolution. The University of Chicago Press, Chicago

Trager MD, Bhotika S, Hostetler JA, Andrade GV, Rodriguez-Cabal MA, McKeon CS, Osenberg CW, Bolker BM (2010) Benefits for plants in ant-plant protective mutualisms: A meta-analysis. PloS one 5:e14308

Treseder KK, Davidson DW, Ehleringer JR (1995) Absorption of ant-provided carbon dioxide and nitrogen by a tropical epiphyte. Nature 375:137-139

Tuomisto H, Ruokolainen K, Poulsen AD, Moran RC, Quintana C, Cañas G, Celi J (2002) Distribution and diversity of Pteridophytes and Melastomataceae along edaphic gradients in Yasuni national park, Ecuadorian Amazonia. Biotropica 34:516-533

Tylianakis JM, Tscharntke T, Lewis OT (2007) Habitat modification alters the structure of tropical host-parasitoid food webs. Nature 445:202-205

Valencia R, Condit R, Foster RB, Romoleroux K, Villa Muñoz G, Svenning J-C, Magard E, Bass M, Losos EC, Balslev H (2004) Yasuni Forest Dymanics Plot, Ecuador. In: Losos EC, Leigh EG, Jr. (eds) Tropical Forest Diversity and Dynamism. Findings from a LargeScale Plot Network. The University Chicago Press, Chicago, pp 609-620

Valverde JP, Hanson P (2011) Parenchyma: a neglected plant tissue in the Cecropia/ant mutualism. Symbiosis 55:47-51

Vazquez DP, Aizen MA (2003) Null model analyses of specialization in plant-pollinator interactions. Ecology 84:2493-2501 
Table 1. Plant species collected in the three locales. Numbers of individuals collected are shown in each cell. Cells without numbers indicated that those species were not found in those locations.

\begin{tabular}{|c|c|c|c|}
\hline Plant species & Costa Rica & Ecuador & Peru \\
\hline Cecropia distachya Huber & & & 3 \\
\hline Cecropia engleriana Snethl. & & 11 & 1 \\
\hline Cecropia ficifolia Warb. ex. Snethl. & & 10 & 8 \\
\hline Cecropia herthae Diels & & 11 & \\
\hline Cecropia insignis Liebm. & 11 & & \\
\hline Cecropia latiloba Miq. & & 11 & 7 \\
\hline Cecropia litoralis Snethl. & & 3 & \\
\hline Cecropia marginalis Cuatrec & & 8 & \\
\hline Cecropia membranacea Trécul & & 12 & 13 \\
\hline Cecropia obtusifolia Bertol. & 16 & & \\
\hline Cecropia putumayonis Cuatrec. & & 10 & \\
\hline Cecropia strigosa Trécul & & & 1 \\
\hline Cinnamomum chavarrianum (Hammel) Kosterm. & 2 & & \\
\hline Clidemia crenulata Gleason & 10 & & \\
\hline Coccoloba "papel" & & 3 & \\
\hline Cordia alliodora (Ruiz \& Pavon) Cham. & 11 & 3 & \\
\hline Cordia nodosa Lam. & & 12 & 9 \\
\hline Duroia hirsuta (Poepp.) K. Schum. & & 12 & \\
\hline Ocotea cf. javitensis (Kunth)Pittier & & 9 & 9 \\
\hline Marmaroxylon basijugum (Duke)L. Rico & & 3 & \\
\hline Maieta guianensis Aubl. & & 10 & \\
\hline Ocotea atirrensis Mez \& Donn. Sm. & 10 & & \\
\hline Ocotea dendrodaphne Mez & 10 & & \\
\hline Pleurothyrium cf. cuneifolium Nees & & & 3 \\
\hline Piper cenocladum C. DC. & 10 & & \\
\hline Triplaris americana $L$. & & 9 & 10 \\
\hline Triplaris poeppigiana Wedd. & & & 5 \\
\hline Tachigali formicarum Harms & & 10 & \\
\hline Tococa guianensis Aubl. & & & 3 \\
\hline Zanthoxylum riedelianum Engl. & 9 & & \\
\hline
\end{tabular}


Table 2. Estimated sample effort to reach the asymptote in Ecuador and Peru. Calculations for the number of samples necessary to reach a fraction of the total asymptote have to consider $\mathrm{g}>$ 0.904 in Peru and $g>0.701$ in Ecuador.

\begin{tabular}{l|l|l|l|l|l|l|l|l|l|l|l}
\hline Country & $\mathrm{t}$ & $\mathrm{T}$ & $\mathrm{S}_{\text {obs }}$ & $\mathrm{S}_{\text {est }}$ & $\mathrm{Q}_{1}$ & $\mathrm{Q}_{2}$ & $\mathrm{q}_{\mathrm{o}}$ & $\mathrm{g}=1$ & $\mathrm{~g}=0.95$ & $\mathrm{~g}=0.90$ & $\mathrm{~g}=0.80$ \\
\hline Ecuador & 148 & 151 & 21 & 29.9 & 6 & 2 & 0.040 & 1005.16 & 394.93 & 241.743 & 88.56 \\
\hline Peru & 70 & 74 & 13 & 23.22 & 3 & 2 & 0.04 & 156.44 & 33.82 & NA & NA \\
\hline
\end{tabular}

Abbreviations correspond to: $t$, number of samples collected (trees); $\mathrm{T}$, total

number incidences; $\mathrm{S}_{\mathrm{obs}}$, observed species richness; $\mathrm{S}_{\text {est }}$, estimated species richness; $\mathrm{Q}_{1}$ number of uniques; $\mathrm{Q}_{2}$ number of duplicates. 
Table 3. Summary of select qualitative and quantitative metrics for Costa Rican, Ecuadorian and Peruvian ant-plant networks. Non-applicable (NA) has been used to mark values that were not analyzed due to the small size of the networks.

\begin{tabular}{|c|c|c|c|}
\hline $\begin{array}{l}\text { Metrics with un- } \\
\text { weighted links } \\
\text { (qualitative) }\end{array}$ & Costa Rica & Ecuador & Peru \\
\hline $\begin{array}{l}\text { Average number of } \\
\text { links per species }\end{array}$ & $0.76(4.24)$ & $0.89(3.86)$ & $0.92(2.88)$ \\
\hline Species richness & plants $=9$, ants $=12$ & $\begin{array}{l}\text { plants }=17, \text { ants }= \\
21\end{array}$ & $\begin{array}{l}\text { plants }=12, \text { ants }= \\
13\end{array}$ \\
\hline $\begin{array}{l}\text { Species richness } \\
\text { ratio (plants/ants) }\end{array}$ & 0.75 & 0.81 & 0.92 \\
\hline $\begin{array}{l}\text { Number of } \\
\text { compartments }\end{array}$ & 5 & 9 & 5 \\
\hline $\begin{array}{l}\text { Compartment } \\
\text { diversity }\end{array}$ & 4.03 & 6.77 & 3.63 \\
\hline Connectance & 0.15 & 0.095 & 0.15 \\
\hline $\begin{array}{l}\text { Number of isolated } \\
\text { sub-webs }\end{array}$ & 2 & 5 & 3 \\
\hline Nestedness & 25.10 & 15.34 & 25.02 \\
\hline $\begin{array}{l}\text { Degree distribution } \\
\text { plants }\end{array}$ & NA & $\begin{array}{l}\text { Truncated power } \\
\text { law }(-11.60)\end{array}$ & NA \\
\hline
\end{tabular}

\begin{tabular}{llll}
\hline Degree distribution & $\begin{array}{l}\text { Truncated power } \\
\text { law }(-31.94)\end{array}$ & Power law $(-13.17)$ & $\begin{array}{l}\text { Truncated power } \\
\text { law }(-24.73)\end{array}$ \\
ants & &
\end{tabular}

\begin{tabular}{llll}
\hline $\begin{array}{l}\text { Metrics based on } \\
\text { weighted links } \\
\text { (quantitative) }\end{array}$ & 3.21 & \\
\hline Interaction diversity & 2.43 & & \\
Shannon diversity & & & \\
\hline Interaction evenness & 0.88 & 0.91 & 0.90 \\
\hline Mean asymmetries & 0.06 & 0.05 & 0.075 \\
\hline Niche overlap plants & 0.05 & 0.16 & 0.16 \\
\hline
\end{tabular}




\begin{tabular}{llcc}
\hline Niche overlap ants & 0.10 & 0.07 & 0.09 \\
\hline $\mathrm{H}_{2}$ & 1 & 0.84 & 0.76 \\
\hline
\end{tabular}


Table 4. Kolmogorov-Smirnov tests for three countries.

\begin{tabular}{lll}
\hline Comparisons & D-value & $\begin{array}{l}\text { Exact P- } \\
\text { value }\end{array}$ \\
\hline Costa Rica vs. Peru & 0.28 & 0.46 \\
\hline Ecuador vs. Costa Rica & 0.27 & 0.38 \\
\hline Ecuador vs. Peru & 0.13 & 0.92 \\
\hline
\end{tabular}


Table 5. Degree specialization index values for individual ant species $\left(\mathrm{d}^{\prime}{ }_{\mathrm{i}}\right)$ for the three locales.

Values vary from 0-1 increasing from generalized to specialized species. Numbers in parenthesis are ant species codes used in Fig. 1.

\begin{tabular}{|c|c|c|c|}
\hline Ant species & Costa Rica & Ecuador & Peru \\
\hline Azteca australis (1) & & 0.43 & 0.19 \\
\hline Azteca alfari complex (2) & 0.96 & 0.77 & 0.69 \\
\hline Azteca "small"cf. beltii (25) & & & 1.0 \\
\hline Azteca "big"cf. beltii (27) & & & 0.14 \\
\hline $\begin{array}{l}\text { Azteca bequaerti Wheeler \& Bequaert } \\
\text { (24) }\end{array}$ & & & 1.0 \\
\hline Azteca depilis Emery (7) & & 0.56 & \\
\hline Azteca emeryi Forel (3) & & 0.31 & \\
\hline Azteca nigricans Forel (37) & 0.76 & & \\
\hline Azteca xanthochroa Roger (28) & 0.91 & & \\
\hline Azteca pittieri Forel (35) & 0.68 & & \\
\hline $\begin{array}{l}\text { Azteca cf. schumanni (19 Ecuador) ( } 26 \\
\text { Peru) }\end{array}$ & & 1.0 & 0.83 \\
\hline Azteca JTL-011 (23) & & & 0.65 \\
\hline Azteca sp.1 (8) & & 1.0 & \\
\hline Azteca sp. $2(15)$ & & 1.0 & \\
\hline Allomerus ortoarticulatus (11) & & 0.44 & 0.53 \\
\hline Camponotus balzani Emery (4) & & 0.21 & 0.36 \\
\hline Camponotus reburrus Mackay (5) & & 0.81 & \\
\hline Camponotus senex Smith (38) & 0.21 & & \\
\hline Cephalotes setulifer (32) & 0.48 & & \\
\hline Cephalotes multispinosus (33) & 0.21 & & \\
\hline Crematogaster sp.1 (6) & 0.48 & 0.12 & 0.35 \\
\hline Crematogaster sp. 2 (16) & & 0.56 & \\
\hline Crematogaster sp. 3 (17) & & 0.07 & \\
\hline Crematogaster sp. 4 (18) & & 0.07 & \\
\hline Crematogaster sp. 5 (20) & & 0.07 & \\
\hline Myrmelachista schumanni Emery (9) & & 0.77 & 0.78 \\
\hline $\begin{array}{l}\text { Myrmelachista flavocotea Longino } \\
\text { (36) }\end{array}$ & 1.0 & & \\
\hline Myrmelachista sp. 2 (10) & & 0.56 & \\
\hline Myrmelachista sp. 3 (21) & & 0.56 & \\
\hline Pachycondyla luteola Roger (22) & & & 0.23 \\
\hline Pachycondyla bugabensis Forel (34) & 0.75 & & \\
\hline Pseudomyrmex dendroicus Forel (12) & & 1.0 & 1.0 \\
\hline Pseudomyrmex tachigaliae Forel (13) & & 1.0 & \\
\hline Pheidole bicornis Forel (30) & 1.0 & & \\
\hline Pheidole sp. 1 (14) & & 0.85 & \\
\hline Pheidole sp. $2(31)$ & 1.0 & & \\
\hline
\end{tabular}


Table 6. Degree specialization index values for individual plant species $\left(\mathrm{d}^{\prime}{ }_{\mathrm{i}}\right)$ for the three locales. Values vary from 0 to 1 increasing from generalized to specialized species. Numbers in parentheses are plant species codes used in Fig 1.

\begin{tabular}{|c|c|c|c|}
\hline Plant species & Costa Rica & Ecuador & Peru \\
\hline Cecropia distachya Huber (18') & & & 0.12 \\
\hline Cecropia engleriana Snethl. (1') & & 0.29 & 0 \\
\hline Cecropia ficifolia Warb. ex. Snethl. (2') & & 0.28 & 0.35 \\
\hline Cecropia herthae Diels (3') & & 0.74 & \\
\hline Cecropia insignis Liebm. (23’) & 0.87 & & \\
\hline Cecropia latiloba Miq. (4') & & 0.30 & 0.32 \\
\hline Cecropia litoralis Snethl. (5') & & 0.16 & \\
\hline Cecropia marginalis Cuatrec (6') & & 0.24 & \\
\hline Cecropia membranacea Trécul (7') & & 0.30 & 0.48 \\
\hline Cecropia obtusifolia Bertol. (24') & 0.96 & & \\
\hline Cecropia putumayonis Cuatrec. (8') & & 0.33 & \\
\hline Cecropia strigosa Trécul (19’) & & & 0.37 \\
\hline $\begin{array}{l}\text { Cinnamomum chavarrianum (Hammel) Kosterm. } \\
\left(28^{\prime}\right)\end{array}$ & 0.70 & & \\
\hline Clidemia crenulata Gleason (26’) & 1.0 & & \\
\hline Coccoloba "papel" (15') & & 1.0 & \\
\hline Cordia alliodora (Ruiz \& Pavon) Cham. (10') & 0.91 & 1.0 & \\
\hline Cordia nodosa Lam. (9’) & & 0.74 & 0.81 \\
\hline Duroia hirsuta (Poepp.) K. Schum. (12') & & 0.77 & \\
\hline Ocotea cf. javitensis (Kunth)Pittier (11') & & 1.0 & 0.90 \\
\hline Marmaroxylon basijugum (Duke)L. Rico (16') & & 1.0 & \\
\hline Maieta guianensis Aubl. (17’) & & 1.0 & \\
\hline Ocotea atirrensis Mez \& Donn. Sm. (29') & 0.67 & & \\
\hline Ocotea dendrodaphne Mez (30’) & 0.67 & & \\
\hline Pleurothyrium cf. cuneifolium Nees (20') & & & 0.91 \\
\hline Piper cenocladum C. DC. (27') & 1.0 & & \\
\hline Triplaris americana L. (13') & & 1.0 & 1.0 \\
\hline Triplaris poeppigiana Wedd. (22') & & & 1.0 \\
\hline Tachigali formicarum Harms (14') & & 1.0 & \\
\hline Tococa guianensis Aubl. (21') & & & 1.0 \\
\hline Zanthoxylum riedelianum Engl. (25') & 0.89 & & \\
\hline
\end{tabular}


Table 7. Robustness to plant species extinctions. Values of 1 indicate that areas down the curve are reduced mildly. Values of 0 shows an abrupt decrease as soon as one species is removed

\begin{tabular}{llll}
\hline Country & $\begin{array}{l}\text { Least } \\
\text { abundant }\end{array}$ & Random & Best-connected \\
\hline Costa Rica & 0.503732 & 0.4327344 & 0.4299777 \\
Ecuador & 0.5610843 & 0.4515382 & 0.4419219 \\
Peru & 0.4497075 & 0.4170874 & 0.3622201 \\
\hline
\end{tabular}


Table 8. Extinction vulnerability. Larger values show an abrupt die-off of species.

\begin{tabular}{llll}
\hline Country & $\begin{array}{l}\text { Least } \\
\text { abundant }\end{array}$ & Random & Best-connected \\
\hline Costa Rica & 0.9898924 & 0.8117495 & 0.803421 \\
Ecuador & 1.412254 & 0.8592134 & 0.8300672 \\
Peru & 0.9852944 & 0.7873294 & 0.6165945 \\
\hline
\end{tabular}




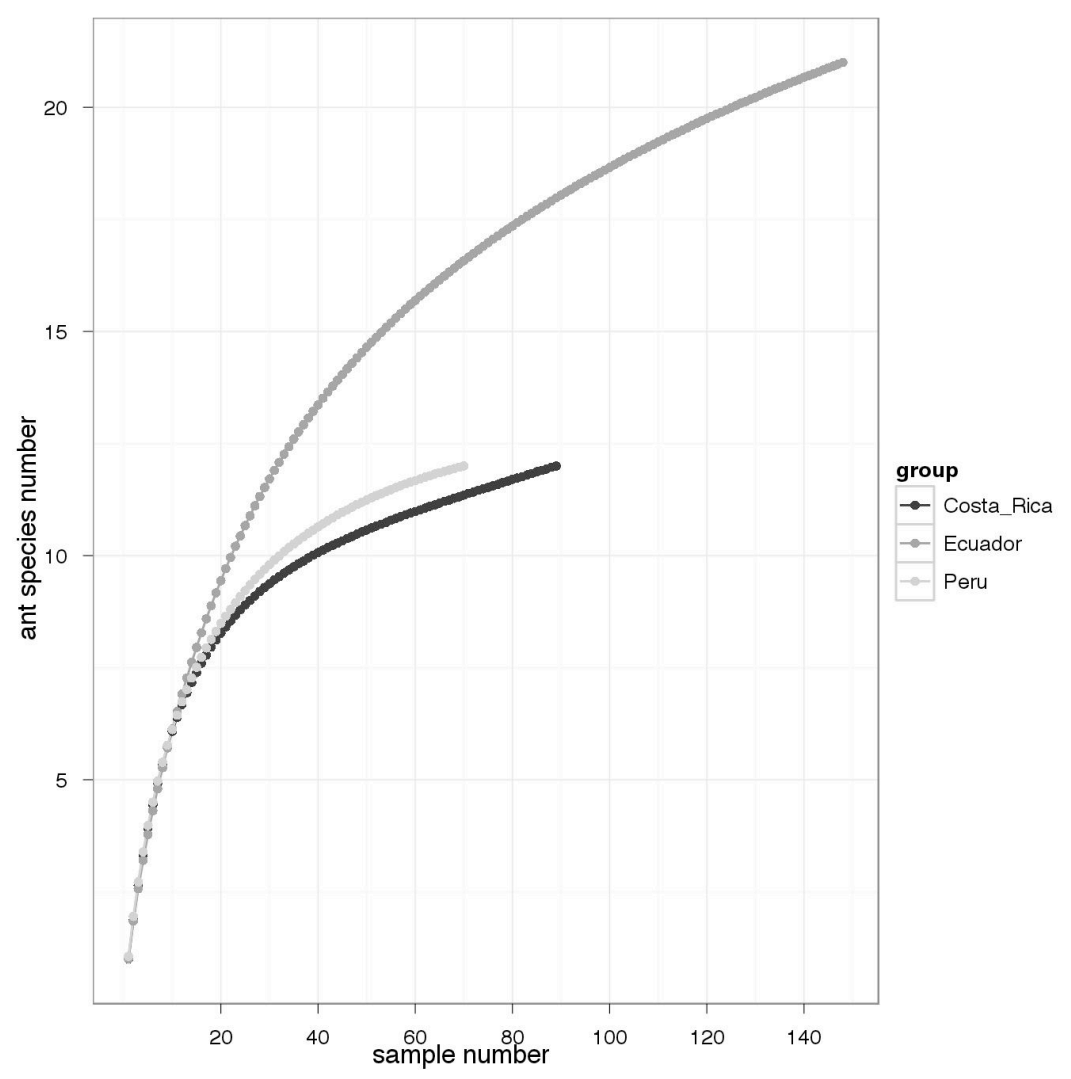

Figure 1. Rarefaction curves contrasting ant

species richness in three locales with different sampling

effort. 


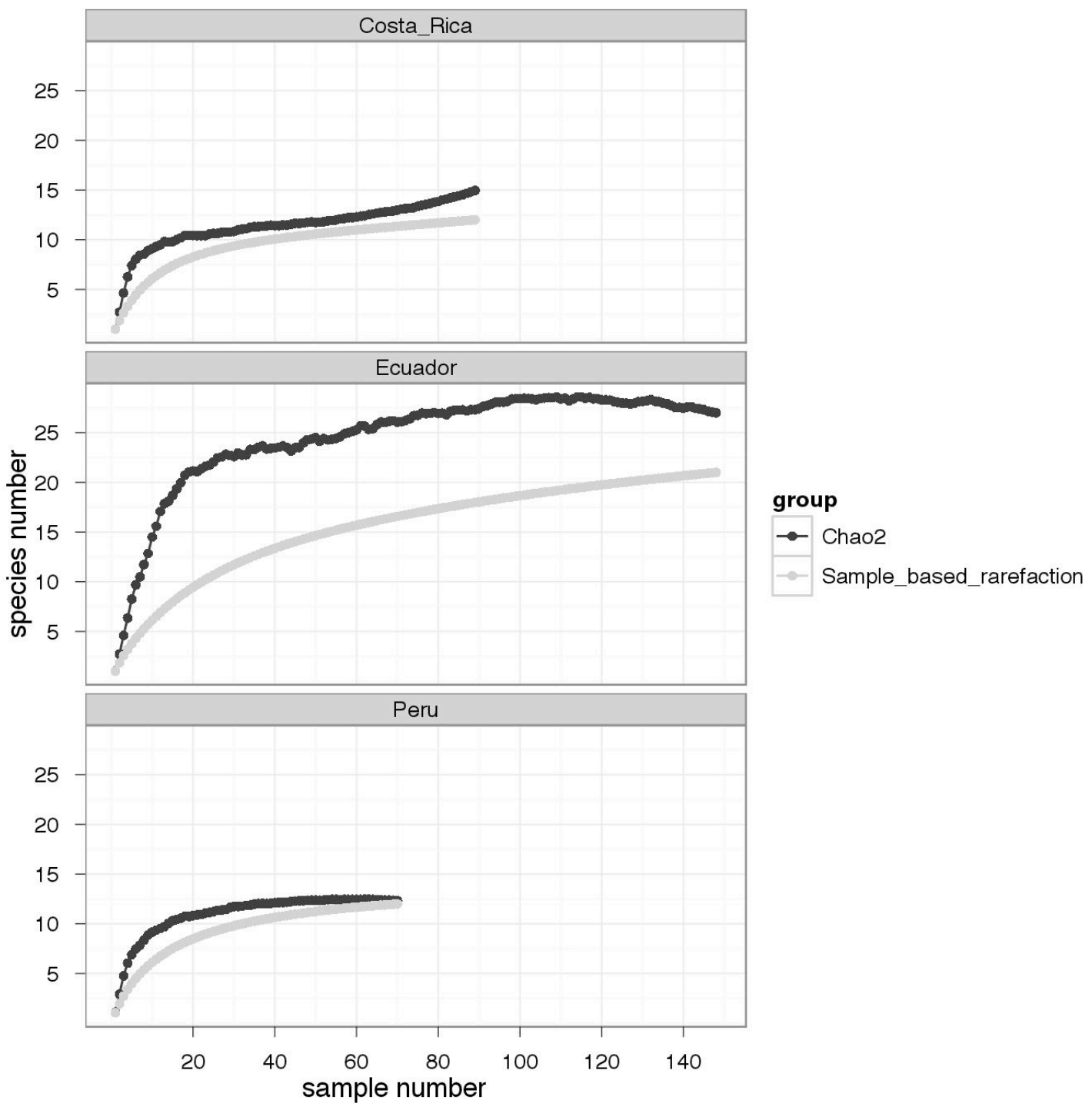

Figure 2. Sample based rarefaction, and asymptotic species richness curves for ants collected in Costa Rica, Ecuador and Peru, as estimated by Chao2. See text for details. 

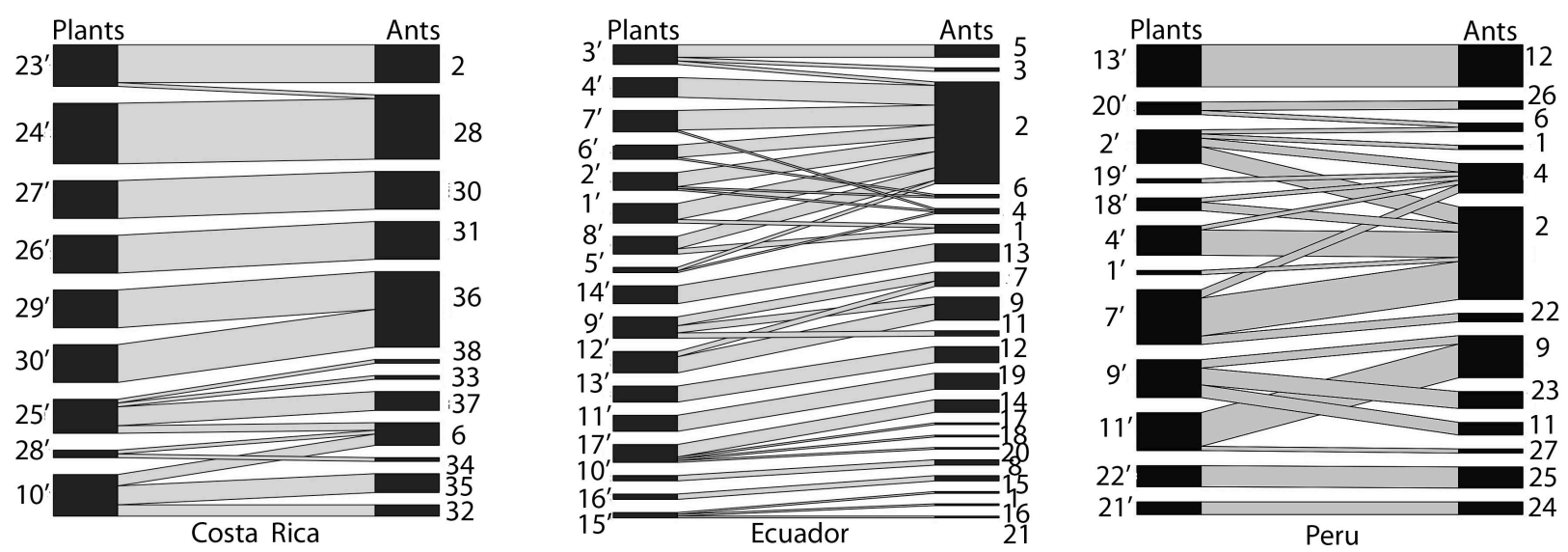

Figure 3. Ant-plant networks at La Selva (Costa Rica), Yasuni (Ecuador), and Los Amigos (Peru). Horizontal bars indicate pairwise species associations. Width of horizontal bars indicates relative frequency of the association. Numbers with apostrophes represent plant species.

Numbers without apostrophes represent ant species. Species names for ants can be found in Table 4 and for plants in Table 5. 


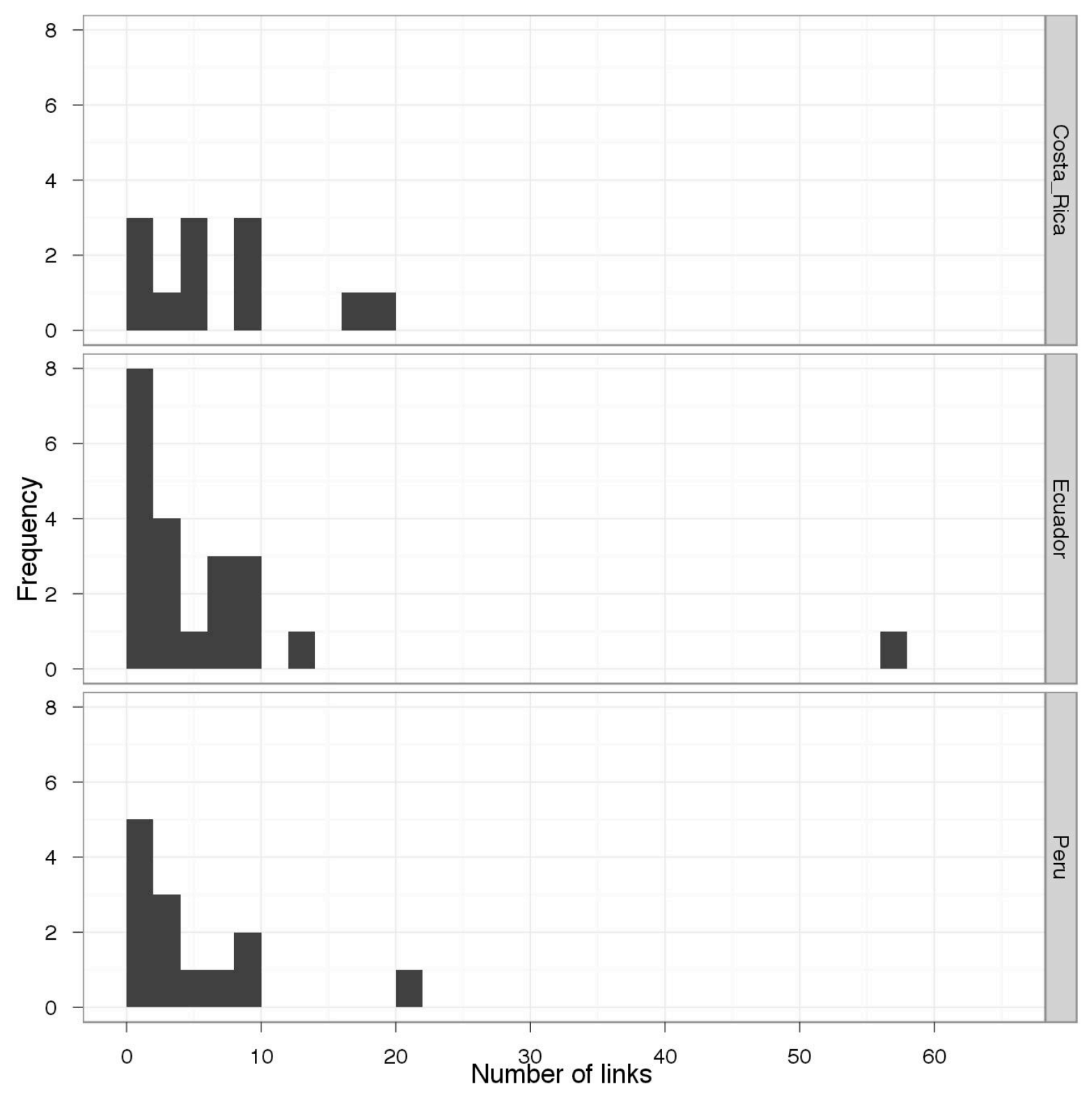

Figure 4. Link frequency distribution for the compartmentalized networks in Costa Rica, Ecuador and Peru. 


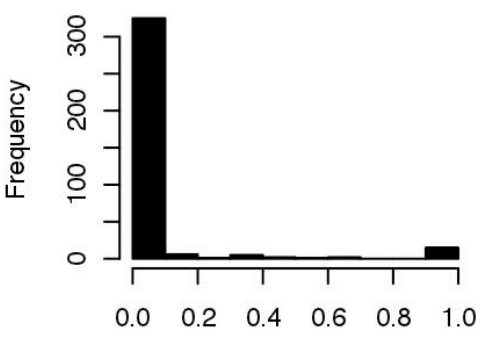

Ant dependence Ecuador
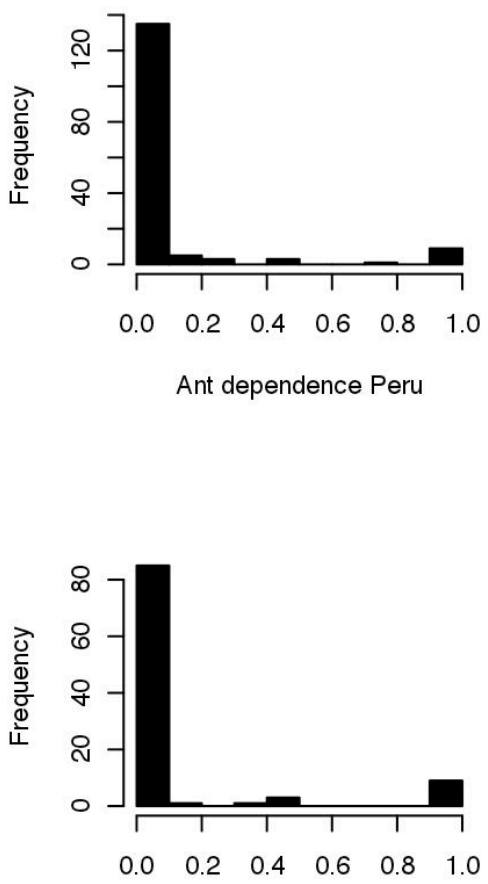

Ant dependences Costa Rica

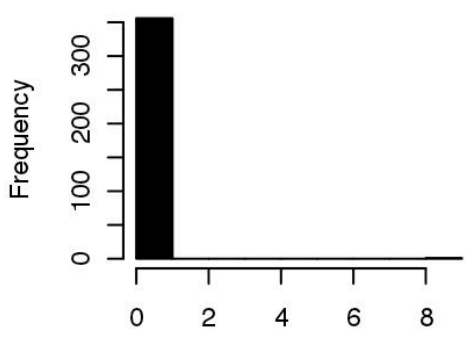

Plant dependence Ecuador
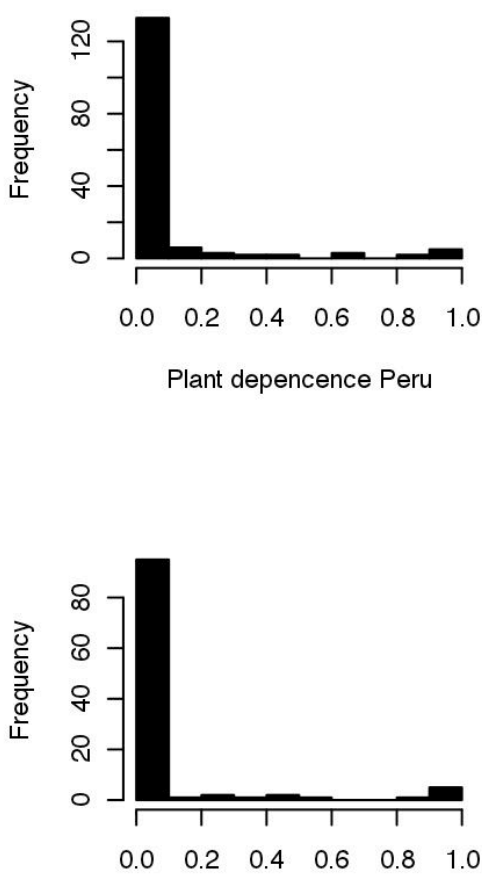

Plant dependence Costa Rica

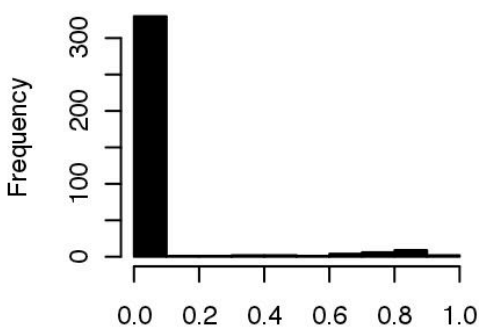

Asymmetry Ecuador
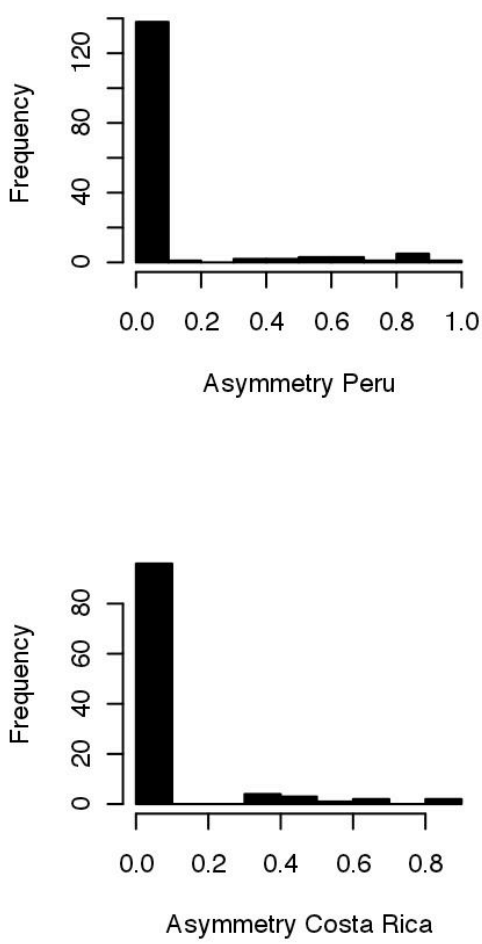

Figure 5. Ant and plant dependences, and interaction asymmetries for networks in Ecuador, Peru and Costa Rica. Values calculated following Bascompte et al. (2006). 


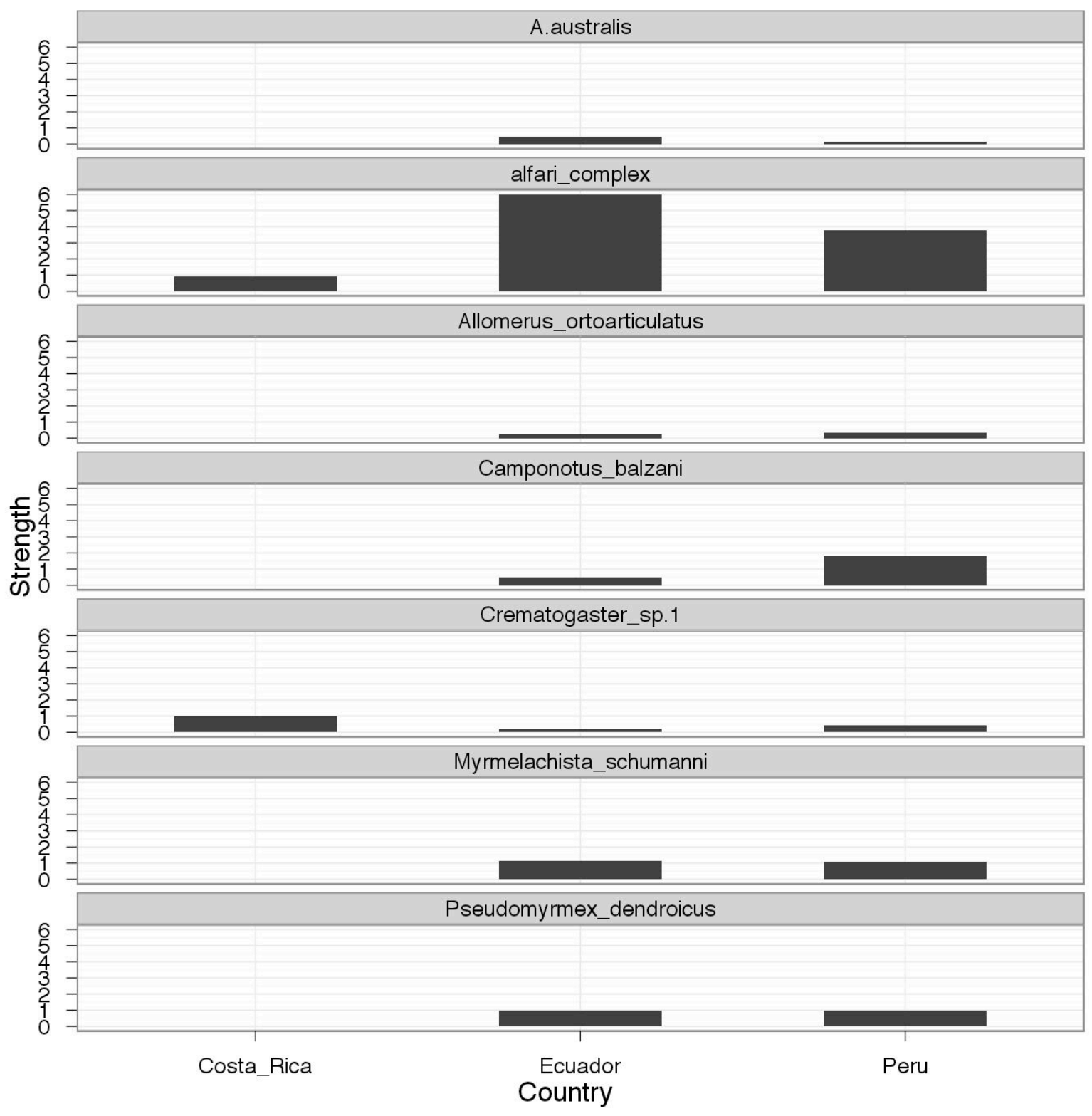

Figure 6. Strength of association for seven ant species that occurred in multiple sites. Ant strength is calculated as the sum of the plant dependences on ant species following Bascompte et al. (2006). 




Figure 7. Strength of association for eight plant species that occurred at multiple sites. Plant strength is calculated as the sum of the ant dependences on plant species following Bascompte et al.(2006) 


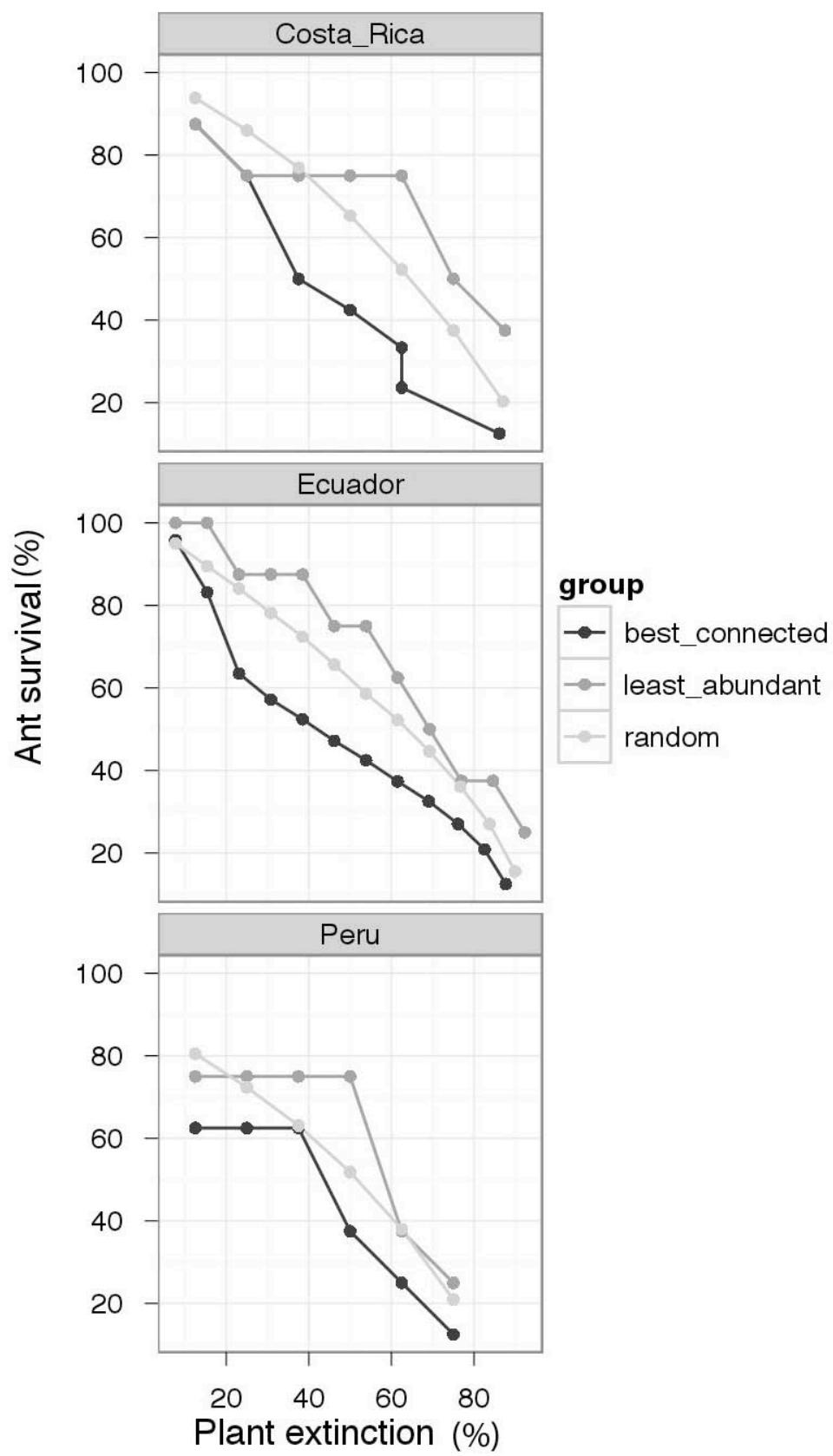

Figure 8. Simulation curves of ant survival (\%) following plant extinction in Costa Rica, Ecuador and Peru after rarefaction. Standard errors were very small and are not shown. 


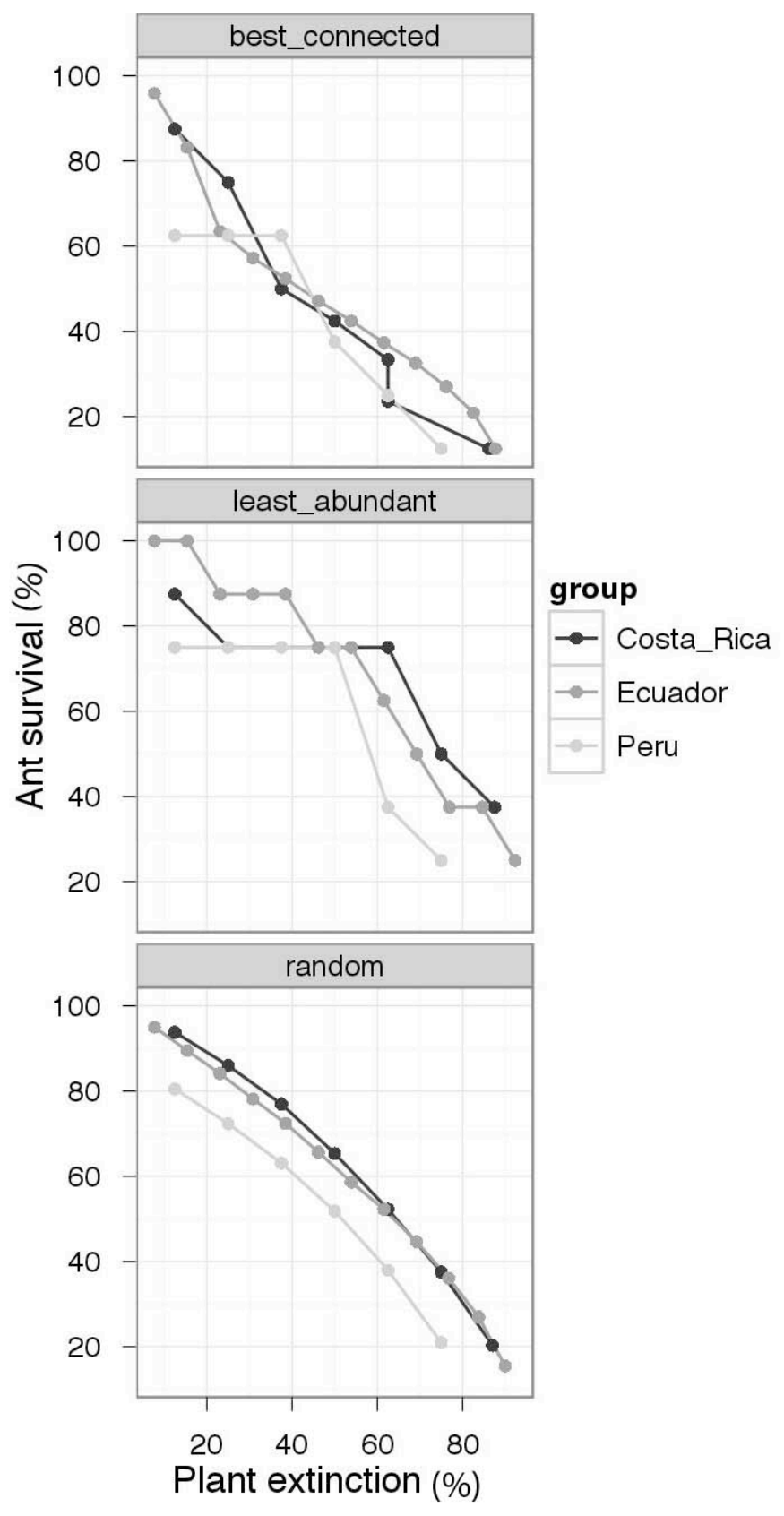

Fig 9. Simulation curves of ant survival (\%) following plant extinction for Costa Rica, Ecuador and Peru after rarefaction. Standard errors were very small and are not shown. 
Appendix 2.1 Neighbor-joining tree of ant COI barcode analysis results.




Appendix 2.2 Statement from major professor that certifies the main authorship of this chapter

To whom it may concern,

I can certify that Paola Barriga is the principal investigator in the chapter entitled "Community structure and ecological specialization in plant-ant interactions." As principal investigator she contributed to this chapter with more than $90 \%$ of the work required and she obtained funding to pursue this research. Please let me know if further information is required.

Sincerely,

Cynthia Sagers

Department of Biological Sciences

Professor 


\title{
3. FUNCTIONAL TRAIT VARIATION AND ANT SPECIALIZATION IN TWO PLANT- ANT SPECIES IN COSTA RICA
}

\author{
Barriga, Paola A.* and Sagers, Cynthia L.
}

Department of Biological Sciences,

University of Arkansas

Fayetteville, AR, USA

72701

*Corresponding author

email:pbarrig@uark.edu

phone: (479) 575-6349

Fax: (479) 575-3251 


\begin{abstract}
Plant functional traits, including traits important in interspecific interactions, vary among environments. In cases were plants and ants may have intimate associations and high levels of specialization, it is likely that the level of specialization will also show geographic shifts. However, it has been suggested that some symbioses (Cecropia-Azteca) are shaped by ecological sorting rather than by host-specific trait selection. We assessed how a suite of morphological and physiological traits of two common myrmecophytes (Cecropia) differ between a pre-montane forest and a lowland tropical wet forest, and how this variation affects the degree of specialization between ant and host. Cecropia obtusifolia and C. insignis are common at Las Cruces Biological station and La Selva Biological station in Costa Rica. Branches were collected from ten mature trees of each species at each site. Resident ants were collected in $95 \%$ ethanol and leaves collected and dried for subsequent analysis. In the lab, a series of plant traits were measured $(\% \mathrm{C}, \% \mathrm{~N}, \mathrm{C} / \mathrm{N}$, specific leaf area (SLA), trichome number, leaf thickness, $\%$ herbivory). Carbon and nitrogen stable isotopic ratios were measured for ants and plants at the University of Arkansas Stable Isotope Laboratory. We evaluated degree of host specialization two ways: 1) as $\mathrm{d}_{\mathrm{i}}$, a specialization index from network metrics, and, 2) as ant reliance on its host for food as calculated by the deviation in the stable isotopic composition between ant and host. We found rather strict pairwise associations of Cecropia and Azteca at both sites. Most plant traits differed between plant species and/or between locales. The di' values suggested high degree of specialization for both species pairs at both sites. In addition, nitrogen isotope deviation from host was similar for both ant species at both sites, providing further evidence that both species pairs are equally specialized at both sites. Herbivory rates were higher at the higher elevation site; however, there were no significant differences in herbivore damage between
\end{abstract}


species pairs. Our results reveal a high degree of specialization between Cecropia trees and associated ants at two sites in Costa Rica. Moreover, the level of specialization appears not to vary despite substantial variation in a suite of plant functional traits. We conclude that specialization at these sites may be driven by some plant traits not measured in this study, or perhaps by micro-environmental sorting of ant and plant species.

Key words plant traits, specialization, stable isotopes, hemipteran, herbivory 


\section{Introduction}

Plant morphologies, physiologies and behaviors are known to vary across habitats and along environmental gradients (Sandquist and Ehleringer 1997; Correia et al. 2008). Some of these traits are important in how plants interact with other species (Coley 1983). It is likely, then, that because these traits vary geographically, the nature of interspecific interactions will vary as well. As a result, the level of specialization between pairs of species should produce a geographic mosaic of specialization across the distributions of interacting species (Thompson 1994).

Specialization in species interactions also can be influenced by the predictability and complexity of resources (Schemske 1982; 1983). In the case of mutualisms, highly specialized interactions should increase with the completeness of resources offered by one of the species in the association (Schemske 1983). For example, in plant-ant interactions, plants offer resources to the ants such as nectar rich in amino acids (Inouye and Inouye 1980), food bodies with proteins and sugars (Rickson 1976; Folgarait et al. 1994; Heil et al. 1998), and spaces to nest or domatia (Janzen 1966). Different combinations of all these resources influence the range of specialization between ant and host. For example, plants that offer nectar through extra-floral nectaries, but provide no domatia are expected to be less specialized ants than plants that offer both (Schemske $1982 ; 1983)$. Because specialized ants tend to rely on their hosts for food, levels of ant specialization can be measured through dietary analysis of the ants (Trimble and Sagers 2004).

Analyses of nitrogen stable isotopes can reveal how resources provided by the host plant were used by ants (Trimble and Sagers 2004). If the isotopic composition of nitrogen found in the ant body resembles the nitrogen composition found in the host, it could be that the ants rely mainly on the host for food. As an indication of specialization by ants on their hosts, the smaller 
the isotope difference, the greater the reliance of ants on their hosts for food (Feldhaar et al. 2009).

Differences in benefits provided by each ant associate can be measured to understand the degree of specialization in the interaction (Suarez et al. 1998). Different ant species vary in the protection they offer to plants (Suarez et al. 1998; Gaume and McKey 1999; Bruna et al. 2004; Frederickson 2005a), and various measurements have been used in determining ant-provided benefits (Frederickson 2005a). Some species kill and clean away vegetation encroaching on the host (Janzen 1969; Davidson and McKey 1993; Frederickson 2005b), prey on herbivores that attack the plant (Schupp 1986; Frederickson 2005a), or provide ant debris and feces for plant assimilation (Treseder et al. 1995; Sagers et al. 2000; Solano and Dejean 2004; Dejean et al. 2012). By whatever measure, benefits are expected to be greater for specialist than for generalist ant associates.

An alternative route to specialization is thought to be the product of ant and host cospecialization to the micro-environments; where the interacting species are co-distributed (Davidson and McKey 1993; Yu and Davidson 1997). Ecological specialization has often been difficult to test because some myrmecophytes and their associated ant fauna have specific microhabitat affinities (Yu and Davidson 1997). Micro-habitat has been hypothesized to shape species interactions in the Cecropia-Azteca associations in tropical wet forests of Peru (Davidson and Fisher 1991; Davidson and McKey 1993; Yu and Davidson 1997). Yu and Davidson (1997) found that host plants grown outside of their normal distribution could be inhabited by ant species with which they were not normally associated.

The aim of this study is to explore the degree of specialization in Cecropia and Azteca species of the Atlantic slope forests of Costa Rica. If traits important in the interaction vary 
geographically in plants that host ants, and if this variation influences ant specialization as measured by ant isotopic composition and percent herbivory, then we expect to see level of specialization vary geographically, as well.

The Cecropia-Azteca association is the most common and conspicuous ant-plant interaction in the Neotropics (Longino 1989; Berg and Franco Rosselli 2005). Most species of Cecropia trees are associated with ants, and the most specialized associations are with ants in the genus Azteca (Janzen 1969; Longino 1991; Davidson 2005). These associations have reached a degree of specialization at the generic level, but there are few instances of strict specialization at the species level (Davidson et al. 1991). Azteca ants are very aggressive and protect the plant from herbivores (Schupp 1986) and from encroaching vegetation (Janzen 1969). Among the benefits Cecropia species offer to the ants are the hollowed stems used as nests and Müllerian bodies, specialized food bodies that contain glycogen, protein and lipids (Rickson 1971) that the ants use to feed their larvae (Janzen 1969).

We used both Cecropia species that grow in these forests, C. obtusifolia Bertol (Urticaceae) and C. insignis Liebem. (Urticaceae) to ask specifically:

1. Do Cecropia and Azteca species assort similarly at two forest sites?

2. Do leaf traits of these Cecropia species vary between locales?

3. Does the level of specialization of ant species to host vary between locales?

\section{Methods}

\section{Study sites and field collections}

This research was performed at the La Selva $\left(10^{\circ} 26^{\prime} \mathrm{N}, 83^{\circ} 59^{\prime} \mathrm{W}\right)$ and Las Cruces $\left(8^{\circ}\right.$ 47' 7" N, $82^{\circ} 57^{\prime} 32^{\prime \prime}$ W) Biological Stations in Costa Rica. These two stations are located in two different forest types: Las Cruces is in a pre-montane wet forest at an elevation of 1,200 m while 
La Selva is in a tropical wet forest at 35 m.a.s.l. (Holdridge et al. 1971). The annual average 1963-2010 rainfall at La Selva was $4375 \mathrm{~mm}$, with no apparent dry season (Cadol and Wohl 2010; OrganizationforTropicalStudies 2012) while the annual average rainfall at Las Cruces was ca. $3500 \mathrm{~mm}$ with a dry season from December to March (Cole et al. 2011).

Cecropia insignis and C. obtusifolia are naturally distributed in these locales (Longino 1989; Berg and Franco Rosselli 2005). We attempted to collect in each locale a minimum of 10 individuals separated by at least $100 \mathrm{~m}$ from each species in each locale. Cecropia branches were collected with the help of a crossbow expert and a pole pruner at La Selva or using a Sherrill "big shot" sling shot (Sherman Tree Company, NC, USA) at Las Cruces. Cecropia individuals were collected in disturbed areas, primary and secondary forests at La Selva, while places with secondary forest and a pasture undergoing forest restoration and secondary succession were sampled at Las Cruces. Cecropia voucher samples from La Selva were deposited at the National Herbarium of Costa Rica; no voucher specimens were collected at Las Cruces. Pieces of leaves from each individual tree were collected in coin envelopes and dried during two-three weeks in herbarium ovens at $\sim 60^{\circ} \mathrm{C}$.

\section{Ant collections}

Ants were collected into eppendorf tubes containing 95\% ethanol. Select individuals were pinned and identified using the J. Longino's on-line key for Costa Rican ants (http://academic.evergreen.edu/projects/ants/genera/azteca/key.html) and taxonomic revisions for Azteca in Costa Rica (Longino 1991; 2007).

\section{Stable isotope sample preparation}

Dried leaf fragments and ant samples were transported to laboratory facilities at the University of Arkansas in Fayetteville, USA. Plant samples were lyophilized for at least three 
days, and ground with a Wig-L Bug ${ }^{\circledR}$ Mixer MSD. Ants were removed from ethanol and abdomens from each sample were excised to avoid the influence of fresh food stored in the crop on stable isotope measurements (Blüthgen et al. 2003). In addition, including abdomen parts of adult workers underestimates $\delta^{15} \mathrm{~N}$ and overestimates C:N ratios (Blüthgen et al. 2003). The head, thorax and legs from each sample were dried in the lyophilizer for at least three days. Dried ants were ground with a glass rod inside an eppendorf tube. Ground samples were placed in tin capsules and weighed using a micro-balance digital scale. Samples and lab standards were processed in a mass spectrometer at the University of Arkansas Stable Isotope Laboratory (UASIL). Variables obtained from this analysis were: $\delta^{13} \mathrm{C}, \delta^{15} \mathrm{~N}, \% \mathrm{C}, \% \mathrm{~N}$ and $\mathrm{C}: \mathrm{N}$ ratio.

\section{Plant measurements}

\section{Leaf area, weight, specific leaf area, trichomes and leaf thickness}

To estimate specific leaf area (SLA), a $10 \mathrm{~cm}^{2}$ disk was cut from each leaf in the collection. Leaf disks were used to measure leaf area in a leaf area meter (Li-Cor, Inc., NE, USA) after a $10 \mathrm{~cm}^{2}$ calibration disk passed through the area meter. Five measurements for leaf area per disk were taken and the average obtained. Each disk was weighed two times on a Sartorius digital scale and the average weight was obtained. The specific leaf area per each sample was also calculated as dried disk area $\left(\mathrm{cm}^{2}\right) /$ dry disk weight (g) (Pringle et al. 2011).

Nine-millimeter diameter areas in plant vouchers or plant disks were examined for trichomes. The upper side on leaves was chosen for this analysis, and the main venation zone was avoided. Three haphazardly chosen areas of the disks or plant vouchers were examined, and the number of trichomes was counted on an Omano dissecting scope at 40X. An average of the three measurements was produced. 
With $\% \mathrm{C}$ and $\% \mathrm{~N}$ from stable isotope analyses, we calculated the $\mathrm{C}: \mathrm{N}$ ratio. The percent nitrogen per area was calculated as (leaf mass $\left.\mathrm{cm}^{2}\right) /($ leaf weight $\mathrm{g}) * \% \mathrm{~N}$.

A Crafstman dial micrometer was used to measure leaf thickness. Three dry leaves from each plant sample were used for the measurement. An average was calculated for each plant sample.

\section{Herbivory measurements}

Three young leaves from each collected individual were photographed with a 15 or $30 \mathrm{~cm}$ ruler for scale. The Image Processing and Analysis in Java or ImageJ were used to import leaf images (Schneider and Rasband 2012). Due to the large size of young Cecropia leaves and because they are lobed, only areas where the leaves were flat were considered. Leaf area was estimated and leaf holes or marks by herbivores were also estimated after magnifying photographs by $33 \%$, and the proportion of the area missing over total leaf area was obtained. Holes, mines, scraped sections of leaves, necrotic areas that could be the product of bacterial or fungal damage were all included as damage (Coley 1983) and identified with a guide for fossils (Labandeira et al. 2007).

\section{Data analyses}

The nine plant traits were analyzed in a Multivariate Analyses of Variance (MANOVA) (Quinn and Keough 2007). A Shapiro-Wilks normality test was run for each MANOVA analysis (Quinn and Keough 2007). Additionally, two-way ANOVAs were performed to detect differences in the traits measured, and between herbivory in the two locales. Two three-way ANOVAs were performed between ant carbon and nitrogen isotopic deviation from hosts. Normality was assessed for all variables using Bartlett tests for heteroscedasticity (Crawley 2007). While analyzing herbivory levels in the two locales, the analyses were performed on 
untransformed data, transformed data and a general linear model following a beta distribution. A beta distribution is commonly used instead of a normal distribution for proportions. All of these analyses gave the same result. Statistical analyses were performed with $\mathrm{R}$ (TeamCoreDevelopment 2005) and SAS ${ }^{\circledR}$ software (StatisticalAnalysisSystem 2002-2012). Principal Component Analyses (PCA) were performed with all nine plant variables (Quinn and Keough 2007). Two matrices were built to perform the PCAs. Those two matrices had as columns data on each plant trait measured, and as rows individuals analyzed, but varied depending upon how the data were categorized. For example, on the first matrix rows were plant species sorted by locale. The second matrix had rows where the plant traits were sorted by ant species that inhabit each plant species and by locale. The biplot produced by the data on the second matrix was imported into Adobe Photoshop (Knoll 1990-2007) and polygons were constructed. Polygons were formed with the data that encompassed each ant species. One-way MANOVAs were performed with data on the second matrix (Quinn and Keough 2007).

\section{Results}

\section{Ant-plant species associations at two sites}

We found regular associations of Azteca ants with Cecropia trees at our study sites in Costa Rica. Generally, C. obtusifolia was found interacting more often with A. xanthochroa and C. insignis with the A. alfari complex. Out of 29 observations of $C$. obtusifolia and $A$. xanthochroa, only in one occasion C. obtusifolia was observed with A. alfari complex. These ant species preferentially sorting by plant species was observed also by Longino (1989). We found no other ant species occupying mature stems of Cecropia trees at these sites. 


\section{Differences in plant traits between host species and communities}

MANOVA analyses showed that plant traits varied significantly by plant species and by locale $(\mathrm{P}<0.001)$ and that their interaction was significant $(\mathrm{P}<0.05)$ (Table 1$)$. The two-way ANOVA showed that the plant traits varied significantly between locations or between plant species $(\mathrm{P}>0.05$ for plant, locale and interaction), with the exceptions of trichome number, leaf

thickness and gram of nitrogen per leaf area. $\delta^{13} \mathrm{C}$ differed significantly between plant species (P $<0.05)$ and locales $(\mathrm{P}<0.001)$, but the interaction was not significant $(\mathrm{P}>0.08)$ (Fig. 1). Plant species had a significant effect on $\% \mathrm{~N}(\mathrm{P}<0.001)$, specific leaf area $(\mathrm{SLA})(\mathrm{P}<0.05)$ and $\mathrm{C}: \mathrm{N}$ ratio $(\mathrm{P}<0.001)$. Locale had a significant effect on $\delta^{15} \mathrm{~N}(\mathrm{P}<0.001)$. Percent carbon $(\mathrm{P}<0.05)$, $\% \mathrm{~N}(\mathrm{P}<0.05)$ and $\mathrm{C}: \mathrm{N}$ ratio $(\mathrm{P}<0.001)$ differed between and among location and plant species. In summary, $\delta^{13} \mathrm{C}$ and $\delta^{15} \mathrm{~N}$ differed between sites while the other traits showed important interactions between locale and species.

We also explored effects of host and locale on trait variation using a principle components analysis. The first and second principle component explained much of the plant trait variation (27\% and 16\%, respectively) (Fig. 2, Table 2$)$. Interestingly, the first component had no plant trait typically associated with plant defense, such as leaf thickness or trichome number, although trichome number becomes important in the second principal component (Fig. 2, Table 2).

The first component loadings (Table 2, Fig.2) showed that plant traits with higher values were traits in which the two-way ANOVA found significant differences for plant species, locale or plant by locale interaction. For example, $\mathrm{C}: \mathrm{N}$ and $\% \mathrm{~N}$ showed significant differences by plant species and the interaction of plant by locale. Cecropia obtusifolia mean values for C:N ratio at La Selva was $16.15( \pm 0.41)$ and at Las Cruces was $17.68( \pm 0.60)$, while C. insignis mean C:N 
value at La Selva was $24.55( \pm 0.40)$ and at Las Cruces $22.23( \pm 1.078)$. Nitrogen values were higher for C. obtusifolia at La Selva $(2.95 \pm 0.075)$ and Las Cruces $(2.74 \pm 0.092)$, than $C$. insignis at each locale (La Selva $1.96 \pm 0.026$; Las Cruces $2.16 \pm 0.13$ ). ANOVA results for SLA were significant only for plant species. SLA values were higher for C. obtusifolia (La Selva $126.58 \pm 19.12$; Las Cruces 100.18 \pm 4.34 ) than for C. insignis (La Selva $76.53 \pm 10.17$; Las Cruces $68.86 \pm 6.43)$.

Leaf $\delta^{15} \mathrm{~N}$ and $\delta^{13} \mathrm{C}$ explain the most variation in the second PCA axis. Plant species and locale were significant in the ANOVA for $\delta^{15} \mathrm{~N}$ and $\delta^{13} \mathrm{C}$ and their interaction term for $\delta^{13} \mathrm{C}$ was marginally significant $(\mathrm{P}=0.08)$. Plants at la Selva had higher $\delta^{15} \mathrm{~N}$ values on average $(C$. obtusifolia $4.65 \pm 0.48 ;$ C. insignis $5.88 \pm 0.71)$ than plants at Las Cruces (C. obtusifolia $1.40 \pm$ 0.32 ; C. insignis $2.16 \pm 0.36$ ).

Plant traits in the other principal components did not have values as high as $\delta^{15} \mathrm{~N}$ and $\delta^{13} \mathrm{C}$ with the exception of gram of nitrogen per leaf area and trichomes. These two variables explained an important fraction of the variability seen on the third component. However, neither gram of nitrogen nor trichome density differed significantly in a two-way ANOVA.

\section{Ant specialization interpreted as isotopic deviation from host plants}

The specialization index from network metrics showed that Azteca xanthochroa at $\mathrm{La}$ Selva had a value of 0.68 , while $A$. alfari complex had values of 0.9 . These indices were calculated only considering the data from the particular species of Cecropia and Azteca studied here. These results do not come from an entire ant community analyses. At Las Cruces $A$. xanthochroa had values of 0.2 while $A$. alfari complex had values of 0.55 . A. alfari complex was generally more specialized, had values closer to one, than A. xanthochroa in both locales. 
$\delta^{13} \mathrm{C}$ ant deviations from plant signatures were significantly different by plant and ant species and their interaction (Table 3$)$, and the plant by locale was significant also $(\mathrm{P}<0.1)$ (Table 3). The least specialized ant species at Las Cruces was A. alfari complex (Formicidae: Dolichoderinae) with a $\delta^{13} \mathrm{C}$ deviation of $2.99 \%$ ( \pm 0.05$)$ from $C$. insignis. Azteca xanthochroa Roger (Formicidae: Dolichoderinae) had a carbon deviation from C. obtusifolia of 1.57\%o $( \pm 0.65)$ at Las Cruces, and was more specialized in this environment than the A. alfari complex (Fig. 3). Azteca xanthochroa had a higher deviation from C. obtusifolia $(3.50 \% \pm \pm 0.22)$ (Fig. 3) than A. alfari complex $(3.35 \% \pm 0.15)$ at La Selva. The overall larger isotopic deviation from host was found in A. xanthochroa at La Selva. For carbon signatures, location did not have an effect (Table 3) indicating that specialization as measured by deviation in carbon isotopic signature did not vary geographically.

There were no significant differences between $A$. xanthochroa and the A. alfari complex in $\delta^{15} \mathrm{~N}$ deviation from host plants $(\mathrm{P}>0.1)$ (Table 4, Fig. 4). Therefore, both ant species are similarly specialized. Furthermore, there were no significant effects of plant, ant, or locale on deviation in $\delta^{15} \mathrm{~N}$ (Table 4). However, the plant by ant interaction was significant (Table 4). Tukey honest significant difference was run for this ANOVA (Quinn and Keough 2007). No significant interactions for any of the factors or their interactions were found. These three way ANOVAs have zero degrees of freedom for the three way interaction because ants are mainly observed in one tree species or the other and the rare associations were found once or were not observed. Generally, C. obtusifolia at La Selva was $1 \%$ more carbon depleted than C. insignis and plants at La Selva were 3.37-3.42 \% more nitrogen enriched than plants at Las Cruces (Fig. 5). Ants were carbon enriched in relation to plant tissues and not nitrogen enriched with the exception of $\sim 1 \%$ in A. xanthochroa at Las Cruces (Fig. 5). 


\section{Different levels of herbivory between ants in same locale and between locales}

Herbivory levels were significantly different between locales (Tukey's HSD, P < 0.05), but there were no significant differences by ant species (Tukey's HSD, P $>0.05$ ) or locale by ant interaction (Tukey's HSDP $>0.05$ ). These results showed that leaf damage by herbivores was significantly greater Las Cruces than at La Selva (Fig. 6).

\section{Ant specialization to habitat}

Polygons produced with the biplot obtained from PCA of plant traits showed that the traits that characterized the plants used by the two ant species' nests overlap in their variation (Fig. 7). MANOVA analyses with data of $A$. xanthochroa hosts showed that locale had a significant effect and that mean values of those traits differ between communities (Pillai $=0.81$, $\mathrm{P}<0.001)$. Similarly, A. alfari complex hosts' data showed a significant difference in mean values of plant traits between La Selva and Las Cruces (Pillai $=0.87, \mathrm{P}<0.05$ ). Plant traits differed significantly between host species and between locales. Nonetheless, ant species largely maintained rather strict specialization: $C$. obtusifolia was mainly interacting with $A$. xanthochroa and $C$. insignis interacts mainly with $A$. alfari complex.

\section{Discussion}

\section{Cecropia-Azteca associations}

We report regular associations of Azteca ants with Cecropia trees at our study sites in Costa Rica. Generally, C. obtusifolia was found interacting more often with A. xanthochroa and C. insignis with the A. alfari complex. This species-limited sorting was also observed in Costa Rica by Longino (1989). In general, Cecropia and Azteca species are thought to specialize at the generic, not at the species level (Davidson and McKey 1993). Therefore, this degree of assortment is somewhat unexpected, and suggests that the evolutionary ecology of Cecropia- 
Azteca species pairs in Costa Rica may differ fundamentally from more generalized associations in other parts of the distribution, as expected from the geographic mosaic theory of coevolution (Thompson 2004).

\section{Geographic variation of plant traits}

Within the native distribution of Cecropia insignis and C. obtusifolia, plant functional traits express substantial variation. We found that six of nine host traits varied significantly between the field sites and between species. These traits include morphological and physiological traits that may be important in interactions with other species. For example, $\delta^{13} \mathrm{C}$ and $\% \mathrm{~N} /$ area reflect important aspects of plant physiology. Morphological traits, such as leaf thickness, specific leaf area and trichome density, are often considered anti-herbivore defenses. PCA analysis clearly demonstrated plant species separation on Component 1 , and separation by locale on Component 2. Nonetheless, pairwise ant-plant associations were maintained across both sites. These results are not conclusive, but suggested that some plant traits are linked to ant association, either directly or indirectly if plant trait expression is the result of micro-habitat sorting. Further study that characterizes precisely the affinities of Cecropia hosts for particular forest habitats will be necessary to resolve this question.

\section{Evidence for specialization in A. xanthochroa and in the A. alfari complex}

The index of specialization $\left(\mathrm{d}_{\mathrm{i}}{ }^{\prime}\right)$ revealed higher levels of specialization in Azteca alfari complex than in A. xanthochroa. Azteca xanthochroa had an index value of 0.68 and 0.2 at $\mathrm{La}$ Selva and Las Cruces respectively. The A. alfari complex had values of 0.9 and 0.55 at La Selva and Las Cruces respectively. Values closer to 1 indicate highly specialized associations. (Add some text commenting on how these values compare to those found for Azteca in more diverse forests of Ecuador and Peru). 
Specialization measured as the deviation between the isotopic difference between ant and host showed no difference between species pairs. The deviation of ant nitrogen isotopic composition from its host plants did not differ between species pairs or between study sites, indicating that Azteca ants are equally reliant on their hosts for food at Las Cruces and La Selva. (Sagers et al. 2000; Davidson 2003).

We found significantly different levels of herbivory (Tukey's HSD, $\mathrm{P}<0.05$ ) across locales, with Las Cruces plants being more heavily affected. Commonly in obligate plant associations, different ant species provide different levels of plant defense. For example, Bruna et al. (2004) found that Tococa bullifera Mart. \& Schrank ex DC. (Melastomataceae) plants defended by Crematogaster laevis Mayr (Formicidae: Myrmicinae) had 4.5 times more damage by herbivores than plants defended by Azteca sp. Differences in ant defense were also shown in Toccoca while analyzing herbivory differences with age by ant species. Levels of herbivory in these two locations however (1-3\%), show relative high levels of protection by specialized ants. A pattern was observed in a meta-analysis where reductions in herbivory were seen in plants with domatia and that offer food bodies (Chamberlain and Holland 2009). The high levels of protection seen for Azteca xanthochroa and for the A. alfari complex are in agreement with the high specialization indices calculated for these two species in a community study (Barriga and Sagers unpubl. data).

\section{Conclusions}

If plant functional traits were driving specialization, it is expected those traits would differ between plant species, but vary only slightly between locales. However, plant traits differed significantly between species and locales (Table 1, Fig. 7). Nonetheless, Azteca species sorted predictably on to their Cecropia hosts. This result suggests additional variables, including 
micro-habitat selection, may contribute to the high degree of specialization observed in this study. Furthermore, stable isotope measures for specialization indicate that the pairwise associations between ant and plant are specialized in both species pairs. Therefore, trait variation, as predicated by the geographic mosaic theory of coevolution (Thompson 2005), is fully expressed in this cross-site comparison, but has little effect on species associations. It is conceivable that species sorting in this system is strictly tied to preferential use of forest microhabitats, but we know that ants of both species colonize saplings of both hosts. The importance of ecological sorting in the evolution of specialization merits further study, and in particular, comparative study among sites that vary in forest type and diversity. In our study, we found no evidence of a geographic variation in a highly specialized, symbiotic interaction. 


\section{Acknowledgements}

Funding for this project came from WWF's Russell E. Train Education for Nature

Program, Organization for Tropical Studies (Glaxo Fund), and a Dissertation Research Award, Fulbright College of Arts and Sciences, University of Arkansas to PB.

We acknowledge to J. Longino for ant identifications/verifications. R. Gonzales for

field assistance, the staff at the Stable isotope laboratory at the University of

Arkansas, Fayetteville and the Ministerio de Ambiente y Enegia in Costa Rica for the permits to do this research. 


\section{Literature cited}

Berg CC, Franco Rosselli P (2005) Cecropia. The New York Botanical Garden Press, New York

Blüthgen N, Gebauer G, Fiedler K (2003) Disentangling a rainforest food web using stable isotopes: dietary diversity in a species-rich ant community. Oecologia 137:426-435

Bruna EM, Lapola DM, Vasconcelos HL (2004) Interspecific variation in the defensive responses of obligate plant-ants: experimental tests and consequences for herbivory. Oecologia 138:558-565

Cadol D, Wohl E (2010) Wood retention and transport in tropical, headwater streams, La Selva Biological Station, Costa Rica. Geomorphology 123:61-73

Cole RJ, Holl KD, Keene CL, Zahawi RA (2011) Direct seeding of late-successional trees to restore tropical montane forest. Forest Ecology and Management 261:1590-1597

Coley PD (1983) Herbivory and defensive characteristics of tree species in a lowland tropical forest. Ecological Monographs 53:209-234

Correia I, Almeida MH, Aguiar A, Alía R, Soares David T, Santos Pereira J (2008) Variations in growth, survival and carbon isotope composition ( $\delta 13 \mathrm{C}$ ) among Pinus pinaster populations of different geographic origins. Tree Physiology 28:1545-1552

Crawley MJ (2007) The R book, 1st edn. John Wiley \& Sons Inc, West Sussex, England

Chamberlain SA, Holland JN (2009) Quantitative synthesis of context dependency in ant-plant protection mutualisms. Ecology 90:2384-2392

Davidson DW (2003) Explaining the abundance of ants in lowland tropical rainforest. Science 300:969-972

Davidson DW (2005) Cecropia and its biotic defenses. In: Cecropia, vol Monograph 94. The New York Botanial Garden Press, New York, pp 214-226

Davidson DW, Fisher BL (1991) Symbiosis of ants with Cecropia as a function of light regime. In: Huxley CR, Cutler DF (eds) Ant-plant interactions. Oxford Univ. Press, Oxford, pp 289-309

Davidson DW, Foster RB, Snelling RR, Lozada PW (1991) Variable composition of some tropical ant-plant symbioses. In: Plant-animal interactions: evolutionary ecology in tropical and temperate regions.Wiley, New York, pp 145-162 
Davidson DW, McKey D (1993) The evolutionary ecology of symbiotic ant-plant relationships. Journal of Hymenoptera Research 2:13-83

Dejean A, Petitclerc F, Roux O, Orivel J, Leroy C (2012) Does exogenic food benefit both partners in an ant-plant mutualism? The case of Cecropia obtusa and its guest Azteca plant-ants. Comptes Rendus Biologies 335:214-219

Feldhaar H, Gebauer G, Blüthgen N (2009) Stable isotopes: past and future in exposing secrets of ant nutrition (Hymenoptera: Formicidae). Myrmecol News 13:3-13

Folgarait PJ, Johnson HL, Davidson DW (1994) Responses of Cecropia to experimental removal of müllerian bodies. Functional Ecology 8:22-28

Frederickson ME (2005a) Ant species confer different partner benefits on two neotropical myrmecophytes. Oecologia 143:387-395

Frederickson ME (2005b) Devil's gardens bedevilled by ants. Nature 437:495-496

Gaume L, McKey D (1999) An ant-plant mutualism and its host-specific parasite: activity rhythms, young leaf patrolling, and effects on herbivores of two specialist plant-ants inhabiting the same myrmecophyte. Oikos 84:130

Heil M, Fiala B, Kaiser W, Linsenmair KE (1998) Chemical contents of Macaranga food bodies: adaptations to their role in ant attraction and nutrition. Functional Ecology:117122

Holdridge LR, Grenke WC, Hatheway WH, Liang T, Tosi JAJ (1971) Forest environments in tropical life zones: a pilot study. Pergamon Press, New York

Inouye DW, Inouye RS (1980) The amino acids of extrafloral nectar from Helianthella quinquenervis (Asteraceae). American Journal of Botany 67:1394-1396

Janzen DH (1966) Coevolution of mutualism between ants and acacias in Central America. Evolution 20:249-275

Janzen DH (1969) Allelopathy by myrmecophytes: the ant Azteca as an allelopathic agent of Cecropia. . Ecology. 50:147-153

Knoll T (1990-2007) Adobe Photoshop. In, 10.0 edn. Adobe systems incorporated, USA

Labandeira CC, IWilf P, Johnson KR, Marsh F (2007) Guide to insect (and other) damage types on compressed plant fossils. Smithsonian Institution, Washington, D.C.

Longino JT (1989) Geographic variation and community structure in an ant-plant mutualism: Azteca and Cecropia in Costa Rica. Biotropica 21:126-132 
Longino JT (1991) Azteca ants in Cecropia trees: Taxonomy, colony structure, and behaviour. In: Huxley C, R, Cutler D, F (eds) Ant-plant interactions. Oxford Univ. Press, Oxford, pp 271-288

Longino JT (2007) A taxonomic review of the genus Azteca (Hymenoptera: Formicidae) in Costa Rica and a global revision of the aurita group. Zootaxa 1491:1-63

OrganizationforTropicalStudies (2012) La Selva Daily Rainfall, 1963-2010. In: Clark DA (ed) http://www,ots,ac,cr/meteoro/defaults.php?pestacion=2

Pringle EG, Adams RI, Broadbent E, Busby PE, Donatti CI, Kurten EL, Renton K, Dirzo R (2011) Distinct Lea-trait syndromes of evergreen and deciduous trees in a seasonally dry tropical forest. Biotropica 43:299-308

Quinn GP, Keough MJ (2007) Experimental design and data analysis for biologists. Cambridge University Press, New York

Rickson FR (1971) Glycogen plastids in müllerian body cells of Cecropia peltata-a higher green plant. Science 173:344-347

Rickson FR (1976) Anatomical development of the leaf trichilium and Mullerian bodies of Cecropia peltata L. American Journal of Botany 63:1266-1271

Sagers CL, Ginger SM, Evans RD (2000) Carbon and nitrogen isotopes trace nutrient exchange in an ant-plant mutualism. Oecologia 123:582-586

Sandquist DR, Ehleringer JR (1997) Intraspecific variation of leaf pubescence and drought response in Encelia farinosa associated with contrasting desert environments. New Phytologist 135:635-644

Schemske DW (1982) Ecological correlates of a neotropical mutualism: Ant assemblages at Costus extrafloral nectaries. Ecology 63:932-941

Schemske DW (1983) Limits to specialization and coevolution in plant-animal mutualisms. In: Nitecki MH (ed) Coevolution. The University of Chicago Press Ltd., Chicago, pp 67-102

Schneider CA, Rasband WS (2012) NIH image to ImageJ: 25 years of image analysis. Nature Methods 9:671-675

Schupp EW (1986) Azteca protection of Cecropia: ant occupation benefits juvenile trees. Oecologia 70:379-385

Solano PJ, Dejean A (2004) Ant-fed plants: comparison between three geophytic myrmecophytes. Biological Journal of the Linnean Society 83:433-439 
StatisticalAnalysisSystem (2002-2012) SAS Institute Publication Copyright (c). In, 8 of the SAS system for [Unix] edn, Cary, NC, USA

Suarez AV, De Moraes C, Ippolito A (1998) Defense of Acacia collinsii by an obligate and nonobligate ant species: the significance of encroaching vegetation. Biotropica:480-482

TeamCoreDevelopment R (2005) R: a language and environment for statistical computing, $R$. Foundation for Statistical Computing. (http://www.R-project.org)

Thompson JN (1994) The Coevolutionary Process. University Of Chicago Press

Thompson JN (2005) The Geographic Mosaic of Coevolution. The University of Chicago Press, Chicago

Treseder KK, Davidson DW, Ehleringer JR (1995) Absorption of ant-provided carbon dioxide and nitrogen by a tropical epiphyte. Nature 375:137-139

Trimble ST, Sagers CL (2004) Differential host use in two highly specialized ant-plant association: evidence from stable isotopes. Oecologia 138:74-82

Yu DW, Davidson DW (1997) Experimental studies of species-specificity in Cecropia-ant relationships. Ecological Monographs 67:273-294 
Table 1. MANOVA results for plant physiological traits at La Selva and Las Cruces. $* \mathrm{P}<0.05$ and $* * * \mathrm{P}<0.001$. All $\mathrm{df}=7,37$.

\begin{tabular}{|l|c|c|c|}
\hline & Pillai's trace & $\mathrm{F}$ & $\mathrm{P}$ \\
\hline Plant & 0.700 & 12.343 & $5.05 \mathrm{e}-08^{* * *}$ \\
& & & \\
\hline Locale & 0.693 & 11.985 & $7.22 \mathrm{e}-08^{* * *}$ \\
\hline Plant x Locale & 0.308 & 2.36 & $0.04^{*}$ \\
& & & \\
\hline
\end{tabular}


Table 2. PCA results for plant physiological traits at La Selva and Las Cruces at the nine principal components found. Traits analyzed were $\% \mathrm{C}, \% \mathrm{~N}, \delta^{13} \mathrm{C}, \delta^{15} \mathrm{~N}, \mathrm{~g}$ N per area, $\mathrm{C}: \mathrm{N}$, trichome number, specific leaf area (SLA), and leaf thickness.

\begin{tabular}{|l|c|c|c|c|c|c|c|c|c|}
\hline & PCA1 & PCA2 & PCA3 & PCA4 & PCA 5 & PCA6 & PCA7 & PCA8 & PCA9 \\
\hline Standard & 1.56 & 1.18 & 1.07 & 1.03 & 0.9 & 0.93 & 0.76 & 0.71 & 0.10 \\
deviation & & & & & & & & & \\
\hline $\begin{array}{l}\text { Proportion of } \\
\text { variance }\end{array}$ & 0.27 & 0.15 & 0.12 & 0.11 & 0.10 & 0.09 & 0.06 & 0.05 & 0.001 \\
\hline $\begin{array}{l}\text { Cumulative } \\
\text { proportion }\end{array}$ & 0.27 & 0.43 & 0.55 & 0.67 & 0.77 & 0.87 & 0.94 & 0.99 & 1.0 \\
\hline
\end{tabular}

\begin{tabular}{|l|c|l|l|l|l|l|l|l|l|}
\hline Loadings & PCA1 & PCA2 & PCA3 & PCA4 & PCA & PCA6 & PCA7 & PCA8 & PCA9 \\
\hline$\% \mathrm{C}$ & 0.225 & -0.186 & -0.343 & -0.227 & 0.718 & -0.344 & -0.295 & 0.149 & \\
\hline$\% \mathrm{~N}$ & -0.575 & -0.218 & & & 0.138 & -0.239 & 0.257 & & -0.687 \\
\hline$\delta^{13} \mathrm{C}$ & 0.264 & -0.578 & 0.242 & -0.133 & & & 0.180 & -0.694 & \\
\hline$\delta^{15} \mathrm{~N}$ & 0.147 & 0.629 & -0.213 & & 0.181 & -0.265 & 0.532 & -0.385 & \\
\hline g nitrogen & & -0.111 & -0.704 & -0.136 & -0.559 & -0.220 & -0.239 & -0.237 & \\
per area & & & & & & & & & \\
\hline C:N & 0.598 & 0.187 & & & & 0.193 & -0.209 & & -0.720 \\
\hline Trichomes & & 0.175 & 0.502 & -0.491 & -0.248 & -0.613 & -0.189 & & \\
\hline SLA & -0.401 & 0.331 & & & 0.226 & 0.256 & -0.575 & -0.522 & \\
\hline Thickness & & & 0.135 & 0.1816 & & -0.477 & -0.254 & -0.122 & \\
\hline
\end{tabular}




\begin{tabular}{|l|l|l|l|l|l|l|l|l|l|}
\hline Eigenvalue & 2.458 & 1.414 & 1.157 & 1.072 & 0.912 & 0.871 & 0.591 & 0.5114 & 0.011 \\
\hline
\end{tabular}


Table 3. Three way ANOVA with ant deviation in $\delta^{13} \mathrm{C}$ values from plants. $* \mathrm{P}<0.05$ ** $\mathrm{P}<0.01,{ }^{* * *} \mathrm{P}<0.001$. Three way interaction term is zero because one combination of ant-plant species was not observed.

\begin{tabular}{|l|c|c|c|c|}
\hline & df & Type III SS & $F$ & $P$ \\
\hline Plant & 1 & 19.57 & 9.62 & $0.003^{* *}$ \\
\hline Ant & 1 & 10.09 & 4.96 & $0.031^{*}$ \\
\hline Locale & 1 & 3.94 & 1.94 & 0.171 \\
\hline Plant X Ant species & 1 & 10.82 & 5.32 & $0.026^{*}$ \\
\hline Plant X Locale & 1 & 10.46 & 5.15 & $0.028^{*}$ \\
\hline Ant X Locale & 1 & 5.12 & 2.52 & 0.120 \\
\hline Plant X Ant X Locale & 0 & 0 & & \\
\hline
\end{tabular}


Table 4. Three way ANOVA with ant deviation in $\delta^{15} \mathrm{~N}$ values from plants. ${ }^{*} \mathrm{P}<0.05$ ** $\mathrm{P}<0.01, * * * \mathrm{P}<0.001$. Three way interaction term is zero because one combination of ant-plant species was not observed.

\begin{tabular}{|l|c|c|c|c|}
\hline & df & Type III SS & $F$ & $P$ \\
\hline Plant & 1 & 2.50 & 0.80 & 0.37 \\
\hline Ant & 1 & 1.98 & 0.63 & 0.43 \\
\hline Locale & 1 & 0.15 & 0.046 & 0.83 \\
\hline Plant X Ant & 1 & 8.35 & 2.67 & 0.10 \\
\hline Plant X Locale & 1 & 0.57 & 0.18 & 0.67 \\
\hline Ant X Locale & 1 & 0.12 & 0.038 & 0.84 \\
\hline Plant X Ant X & 0 & 0 & & \\
Locale & & & & \\
\hline
\end{tabular}




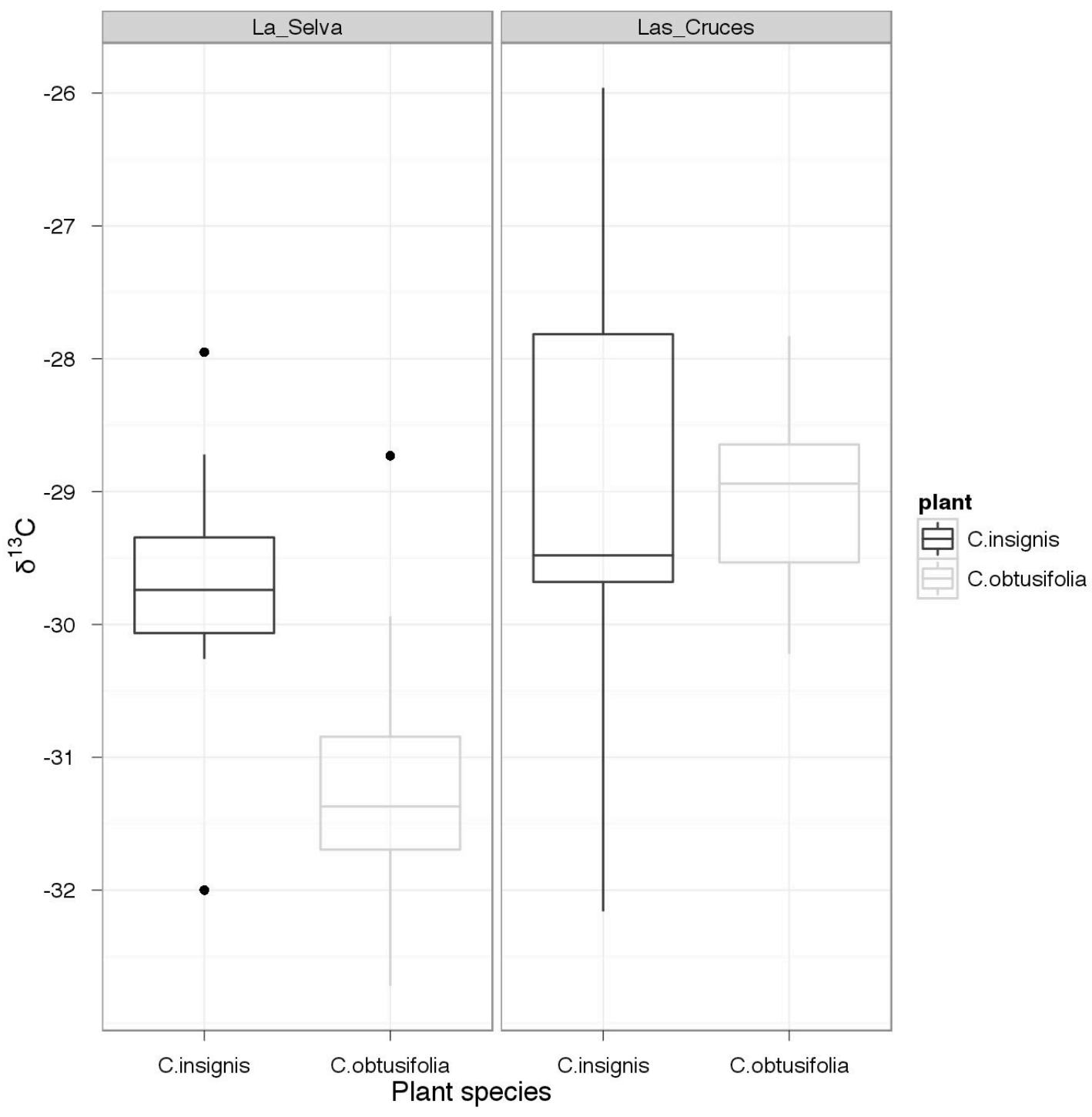

Figure 1. $\delta^{13} \mathrm{C}$ in Cecropia obtusifolia and C. insignis plants at La Selva and Las Cruces. Mean values and $25^{\text {th }}$ and $75^{\text {th }}$ percentiles are shown. 

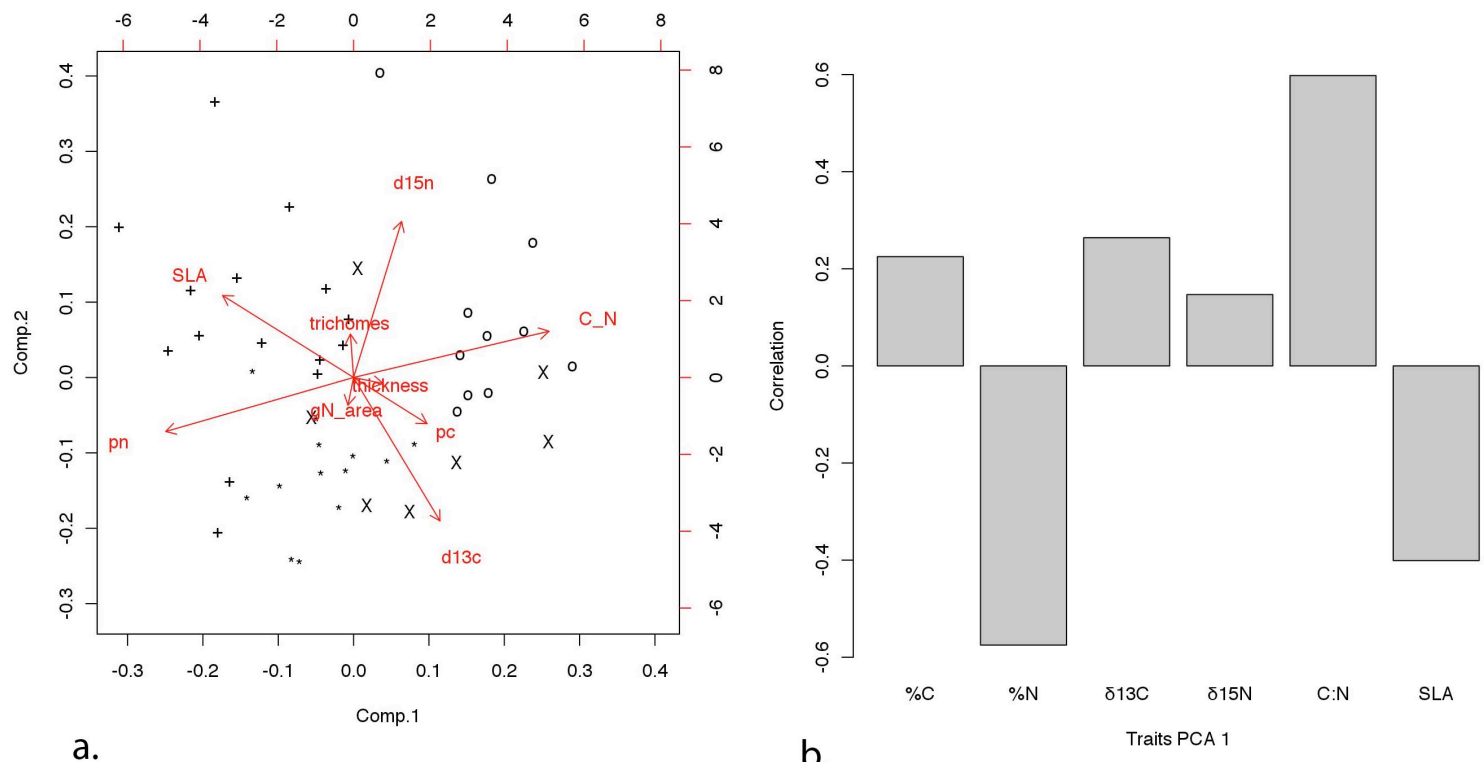

a.

b.

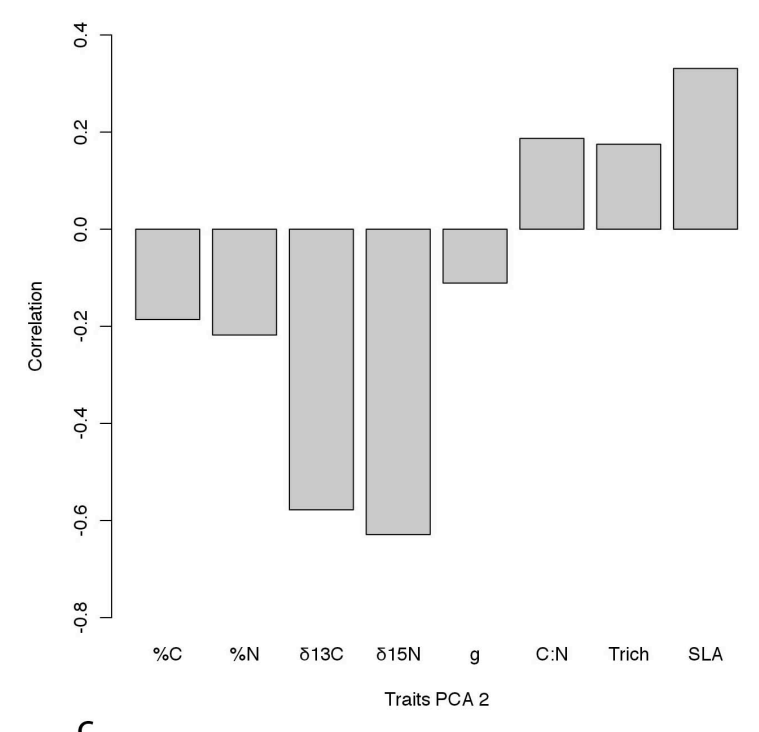

C.

Figure 2. a. PCA for nine plant traits obtained with analysis of matrix one. $(+)$ represents $C$. obtusifolia at La Selva, (o) C. insignis at La Selva, (*) C. obtusifolia at Las Cruces, and (X) C. insignis at Las Cruces. The length of the vector from the origin to the coordinates shows the variance of each variable. Small angles between variables represent high correlation between them. Correlation values obtained from b. PCA1 and c. PCA2 for nine plant traits. "g" shows the grams of Nitrogen per leaf area variable, "Trich" shows trichomes values and "SLA" specific leaf area. 


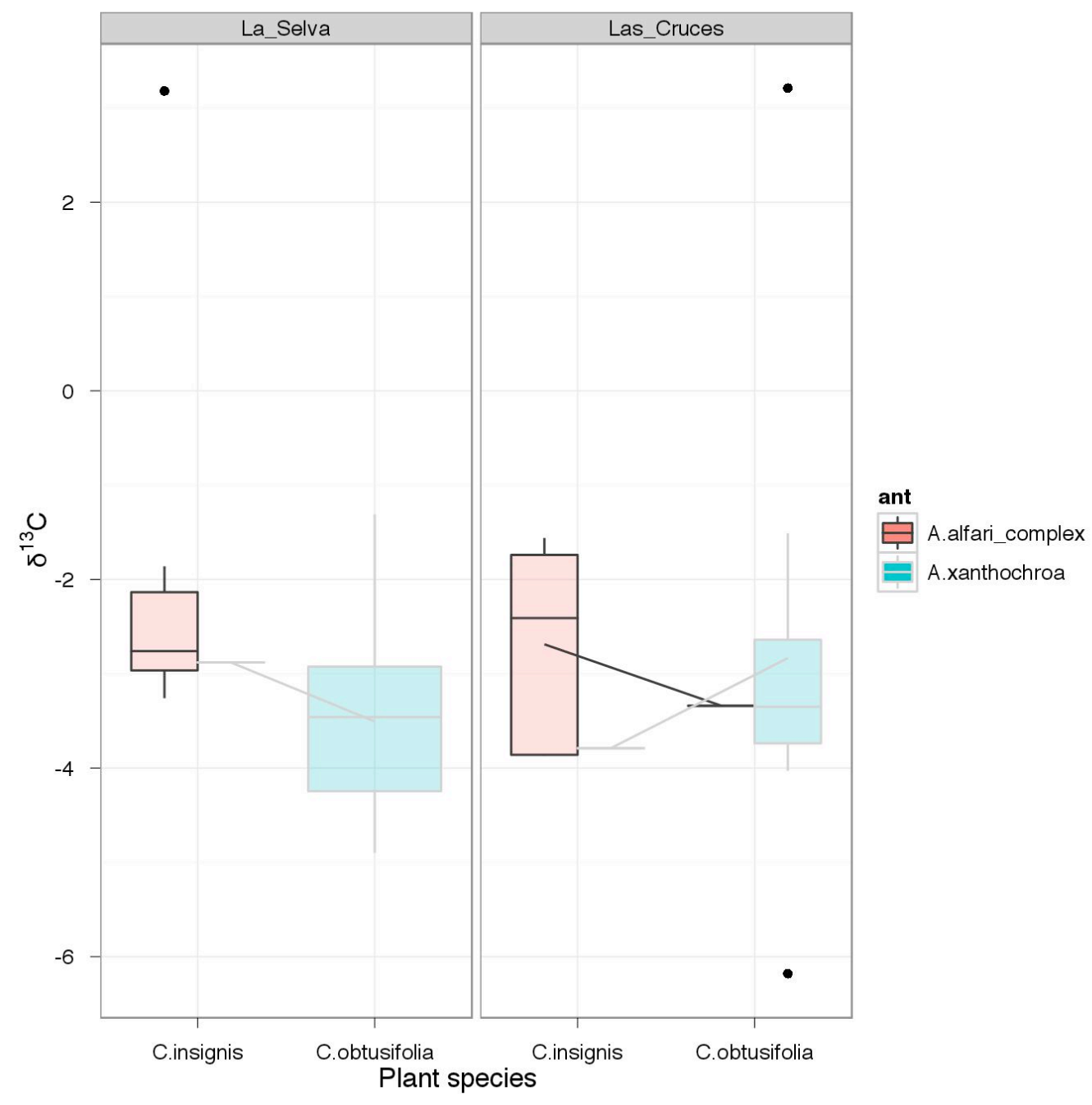

Figure 3. $\delta^{13} \mathrm{C}$ ant deviation from plants at La Selva and Las Cruces. Cecropia insignis mainly interacts with Azteca alfari complex ants and C. obtusifolia mainly interacts with A.xanthochora. At La Selva one plant of $C$. insignis interacted with $A$. xanthochroa represented as a grey line coming from $C$. obtusifolia to $C$. insignis. C. obtusifolia at La Selva was only found with $A$. xanthochora. Cecropia insignis at Las Cruces interacted with one $A$. xanthochroa represented as grey line from $C$. insignis to $C$. obtusifolia, and one $C$. insignis interacted with one $A$. xanthochroa. Mean values and $25^{\text {th }}$ and $75^{\text {th }}$ percentiles are shown. 


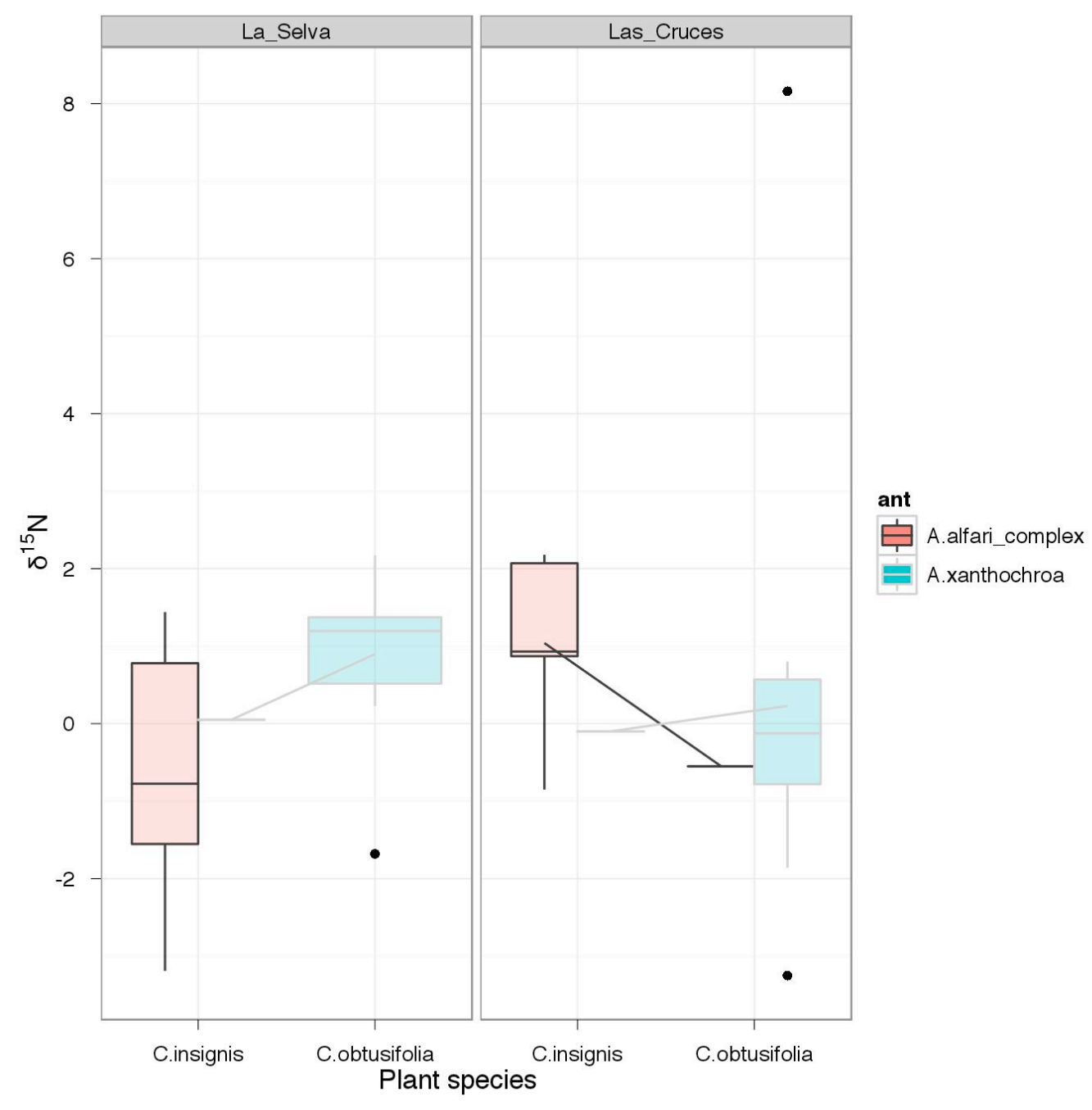

Figure 4. $\delta^{15} \mathrm{~N}$ ant deviation from plants at La Selva and Las Cruces. Cecropia insignis mainly interacts with Azteca alfari complex ants and C. obtusifolia mainly interacts with A.xanthochora. At La Selva one plant of $C$. insignis interacted with $A$. xanthochroa represented as a grey line coming from C. obtusifolia to C. insignis. C. obtusifolia at La Selva was only found with $A$. xanthochora. Cecropia insignis at Las Cruces interacted with one A. xanthochroa represented as grey line from $C$. insignis to $C$. obtusifolia, and one $C$. insignis interacted with one $A$. xanthochroa. Mean values and $25^{\text {th }}$ and $75^{\text {th }}$ percentiles are shown. 


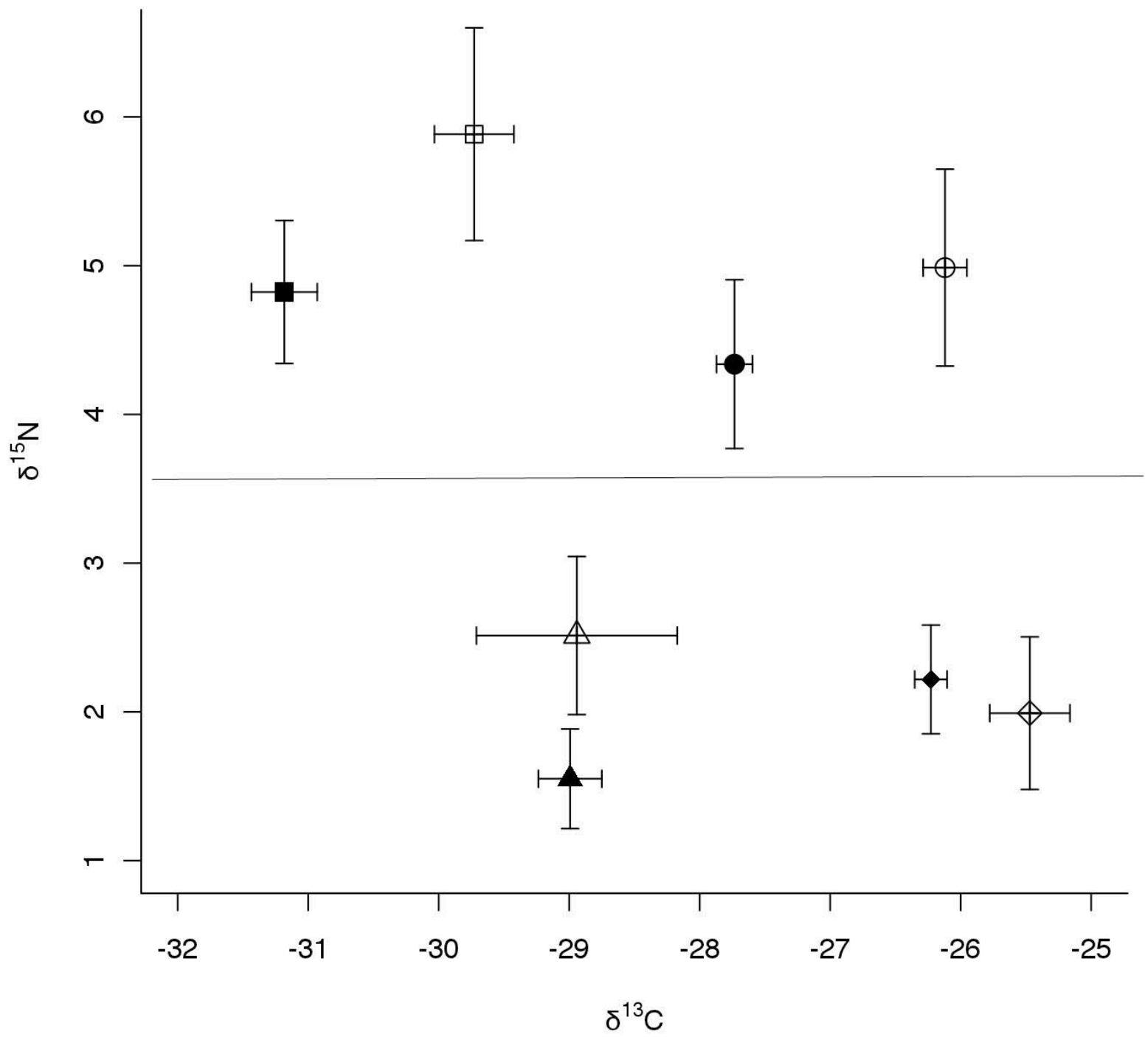

Figure 5. Plant ant ants in two locales. La Selva: $C$. obtusifolia= filled square, $C$. insignis= open square. A. xanthochroa $=$ filled circle, A. alfari complex= open circle. Las Cruces: $C$. obusifolia= filled triangle, $C$. insignis $=$ open triangle, . xanthochroa $=$ filled diamond, A. alfari complex $=$ open diamond. (Means \pm SE). 


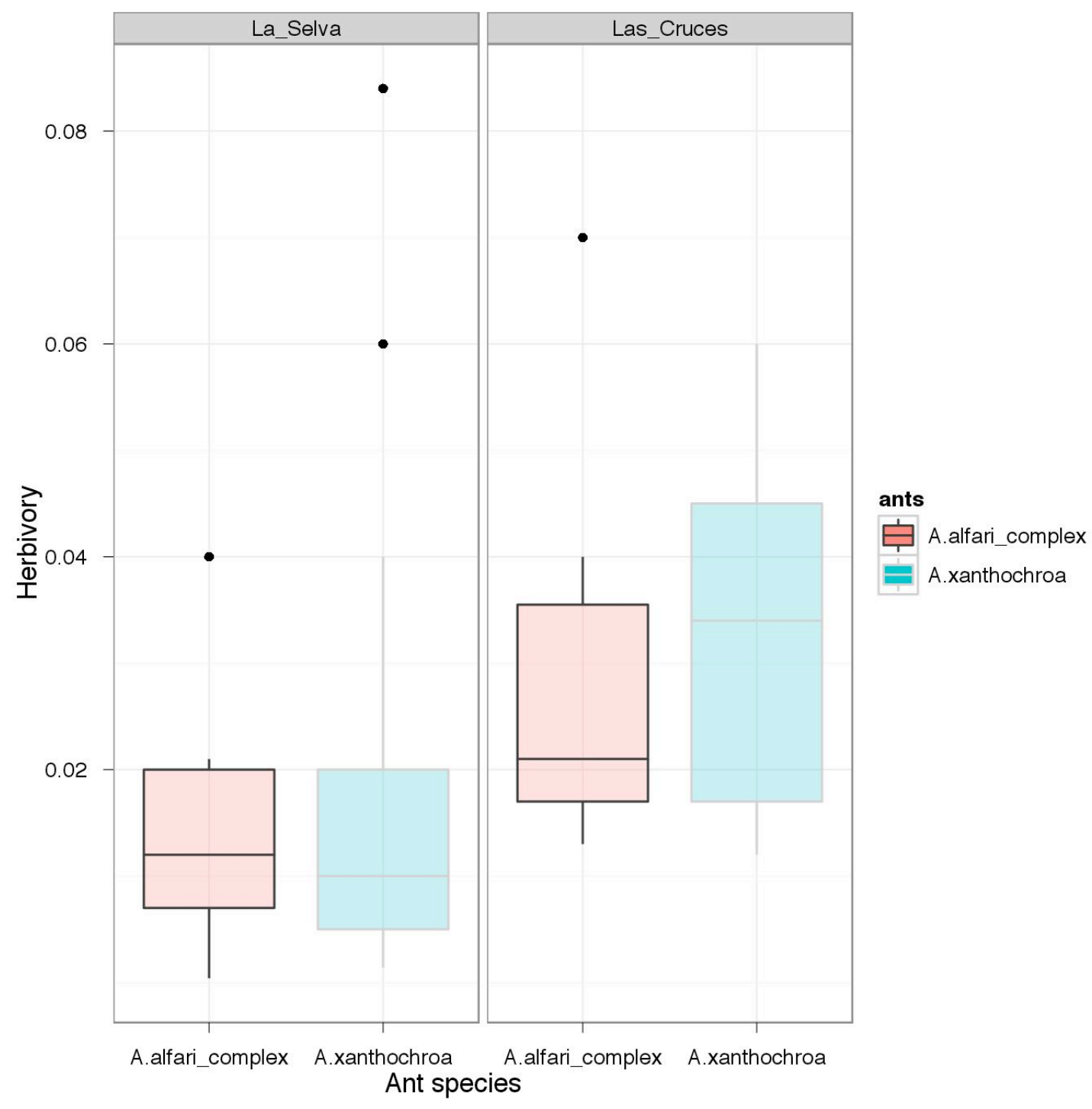

Figure 6. Herbivory measured as a proportion of area damaged over total leaf area for two locales. Mean values and $25^{\text {th }}$ and $75^{\text {th }}$ percentiles are shown. 


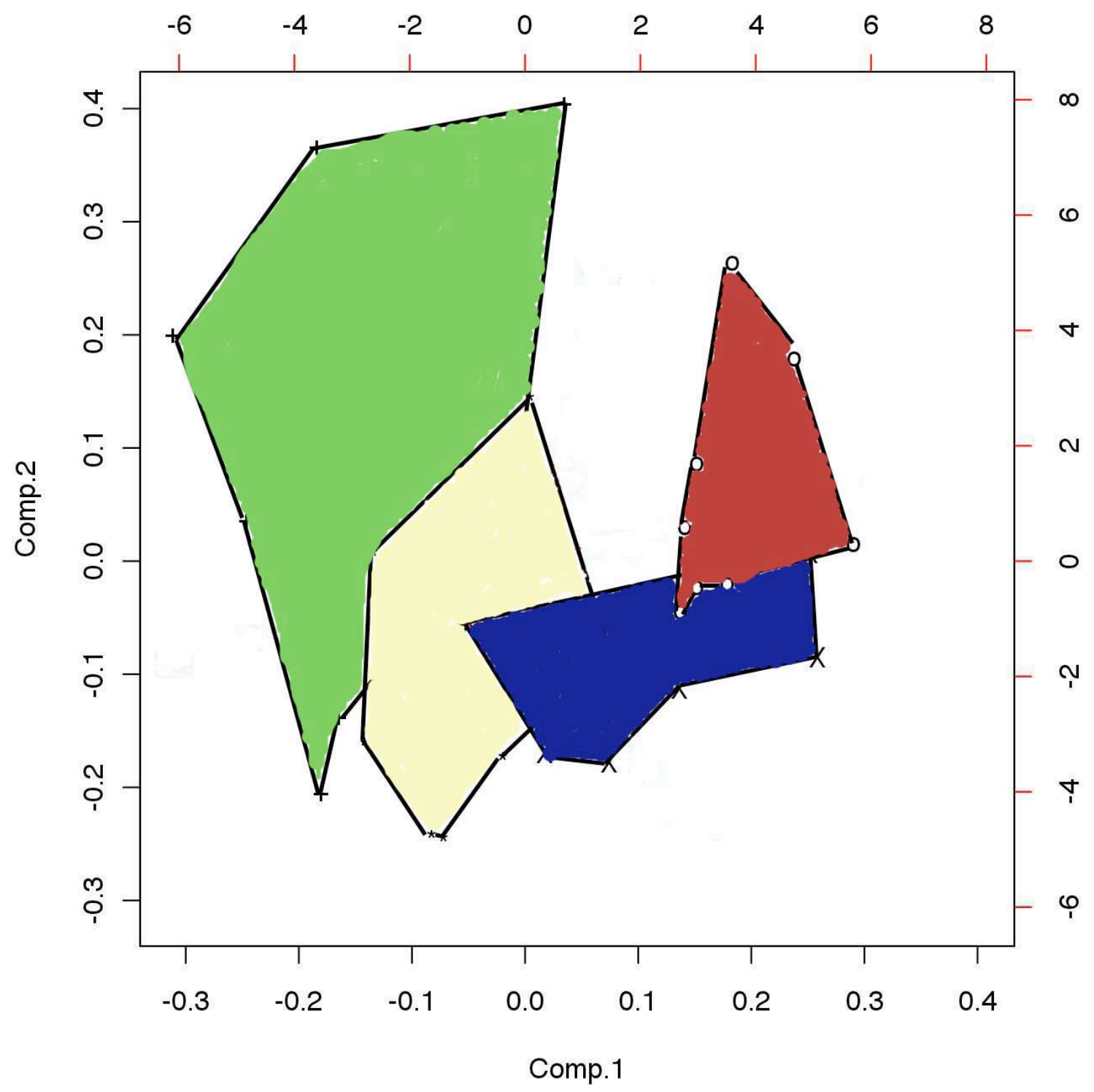

Figure 7. Polygons formed with the biplot product of the second matrix. Nine plant traits data were used to build these polygons. On the $\mathrm{x}$ axis the principal component one is shown and on the y axis, the second principal component is shown. From left to right: (+) represents $A$. xanthochroa at La Selva (green), (*) represents A. xanthochroa at Las Cruces (yellow), (X) represents $A$. alfari complex at Las Cruces (blue), (o) represents $A$ alfari complex at La Selva (red). 
Appendix 3.1 Statement from major professor that certifies the main authorship of this chapter

To whom it may concern,

I can certify that Paola Barriga is the principal investigator in the chapter entitled "Leaf trait variation and ant specialization in two plant-ant species." As principal investigator she contributed to this chapter with more than $50 \%$ of the work required. Additionally she obtained some of the funding needed to pursue this research. Please let me know if further information is required.

Sincerely,

Cynthia Sagers

Department of Biological Sciences

Professor 
4. Stable isotope enrichment in laboratory ant colonies: effects of metamorphosis, diet, and fat storage



${ }^{1}$ Department of Biological Sciences,

University of Arkansas

Fayetteville, AR, USA

72701

${ }^{2}$ USDA-ARS

Center for Medical, Agricultural and Veterinary Entomology

1600 SW $23^{\text {rd }}$ Drive, Gainesville, FL 32608, USA

*Corresponding author

Email: pbarrig@uark.edu

Phone: (479) 575-6349

Fax: (479) 575-4010

Physiological effects on stable isotope enrichment

Key words: fractionation, Hymenoptera, metamorphic enrichment, Solenopsis invicta 


\begin{abstract}
Holometabolous insects undergo complex physiological processes during metamorphosis, store and recycle carbon and nitrogen in a metabolically active exoskeleton, and store energy in as fat in fat body. Molting and changes in fat content both have the potential to shift the animal's stable isotope ratio from values expected by standard models of isotope fractionation and diet. We used laboratory-reared colonies of Solenopsis invicta Buren (Formicidae: Solenopsidini) to test the effects of metamorphosis, diet, and lipid storage on carbon and nitrogen stable isotope ratios. Effects of metamorphosis were examined in ant colonies maintained on a control diet of domestic crickets and sucrose solution. Effects of diet shift were evaluated by adding a tuna supplement to the diets of select experimental colonies. Effects of lipid storage were tested by treating worker ants from randomly selected control colonies with ethanol and hexaneisopropanol solutions. $\delta^{13} \mathrm{C}$ and $\delta^{15} \mathrm{~N}$ values of larvae, pupae, workers and queens were measured by mass spectrometry on whole animal preps. We found significant effects across time on $\delta^{13} \mathrm{C}$; larvae and pupae collected at 75 days were slightly depleted in ${ }^{13} \mathrm{C}$ relative to collections at 15 days. Metamorphosis had a significant effect on $\delta^{15} \mathrm{~N}$, but not $\delta^{13} \mathrm{C}$; tissues of each successive developmental stage were increasingly enriched in ${ }^{15} \mathrm{~N}$. Availability of tuna resulted in further shifts in isotope ratios for all developmental stages. Treatment with organic solvents had no effect on $\delta^{13} \mathrm{C}$, but resulted in enriched $\delta^{15} \mathrm{~N}$ values. Identifying regular patterns of isotopic enrichment as described here should improve the utility of stable isotopes in diet studies of insects. Specifically, researchers should be aware of ${ }^{15} \mathrm{~N}$ enrichment during metamorphosis when assessing trophic levels of fire ants.
\end{abstract}




\section{Introduction}

Stable isotopes have been used extensively to study the flow of energy and nutrients through a variety of biological systems (Ehleringer and Osmond 1989; Hobson et al. 1993; Hobson et al. 2000; Davidson 2003; Widga et al. 2010). Stable isotopes can act as tracers allowing the reconstruction of community trophic food webs (Layman et al. 2007) and analysis of trophic niche partitioning (Blüthgen et al. 2003). However, interpretation of isotope values have relied on several simplifying assumptions concerning isotopic enrichment with diet that have proven problematic in a variety of invertebrate systems (Post 2002; McCutchan Jr et al. 2003; Spence and Rosenheim 2005; Doi et al. 2007; Sagers and Goggin 2007; Tibbets et al. 2008). Here we evaluate a number of these assumptions, specifically the stability of isotopic composition through metamorphosis, diet manipulation, and lipid extraction, using captive colonies of the invasive red fire ant, Solenopsis invicta Buren (Hymenoptera: Formicidae). Our primary aim is to improve the utility of stable isotope ratios as trophic markers in the study of insect ecology. Perhaps the most important breakthrough in the adoption of stable isotope approaches was the finding that patterns of isotope enrichment occur predictably in a variety of animal systems (DeNiro and Epstein 1981; Fry and Sherr 1984). The $\delta^{13} \mathrm{C}$ and $\delta^{15} \mathrm{~N}$ values in animal tissues are enriched relative to those of their diets because lighter isotopes are lost at a higher rate through respiration or excretion leaving heavier isotopes to be incorporated into animal tissues (DeNiro and Epstein 1981; Spence and Rosenheim 2005). Typically, the carbon isotopic composition of an animal shows little enrichment from its diet (0-1\%o) (DeNiro and Epstein 1978; Peterson and Fry 1987) whereas nitrogen signatures are enriched by about 3\%o (DeNiro and Epstein 1981; Minagawa and Wada 1984; Post 2002). This pattern is consistent in a wide 
range of vertebrates independent of habitat, type of nitrogen excreted, and growth rate (Minagawa and Wada 1984). Although insects are likely to share with vertebrates some of the basic biochemical processes that result in isotope enrichment, other processes, are peculiar to arthropods such as carbon storage in fat bodies and molting which involves active re-assimilation and storage of nitrogen in the exoskeleton. Repeated reprocessing and recycling of biological molecules is likely to affect their stable isotope signature (Macko et al. 1986; Scrimgeour et al. 1995), yet the effects of these processes on isotopic composition of entire insects are largely unknown.

We have chosen to examine the effects of metamorphosis, diet and fat storage on the stable isotopic composition of ants. In holometabolous insects, larvae and adults are active feeding stages, whereas eggs and pupae are quiescent and non-feeding. Furthermore, among the eusocial hymenoptera, larvae and queens are largely sessile and their diet determined by workers who are tasked with provisioning them. As a result, workers are the only active foragers. Worker ants have been shown in observational studies to rely on liquid sugar resources which are low in protein while selectively provisioning larvae with solid foods which are high in proteins and fats. Queens are generally fed larval excretions, which are high in proteins. Therefore, differences in $\delta^{13} \mathrm{C}$ and $\delta^{15} \mathrm{~N}$ between quiescent feeding stages and workers may be due, at least partially, to preferential feeding of high protein items and by the metabolic effects of metamorphosis.

The imported red fire ant, Solenopsis invicta Buren (Formicidae), has become a serious pest in the southeastern United States (Trager 1991). Solenopsis invicta was first introduced to the USA from South America in the 1930s (Callcott and Collins 1996; Vinson 1997). Since then, populations have successfully expanded to 12 U.S. states and Puerto Rico (Callcott and Collins 1996; Wojcik et al. 2001) and other parts of the world (Ascunce et al. 2011). Because of its 
economic importance, and because the species is easily cultured in the laboratory, the imported fire ant has emerged as a model organism for ecological and evolutionary research (Ross and Shoemaker 2008). Several recent studies have used carbon and nitrogen isotope ratios to examine the trophic ecology of fire ants in native South American habitats and in North American habitats invaded by S. invicta fire ants (LeBrun et al. 2007; Wilder et al. 2011). We chose this species to explore some of the assumptions commonly used in stable isotope studies. Based on previous research (Blüthgen et al. 2003; Patt et al. 2003; Tillberg et al. 2006; Doi et al. 2007; Tibbets et al. 2008), we expect that developmental stage, diet, and lipid storage will influence isotopic composition of S. invicta. Specifically, we predict that:

1) Later developmental stages will be enriched relative to earlier developmental stages, as lighter isotopes will be lost at a higher rate during metamorphosis;

2) Availability of diet items rich in protein should be more evident in larval than worker diet, as workers selectively provision larvae with solid high quality diet;

3) Carbon, but not nitrogen, signatures will become heavier following extraction of stored lipids, because lipids are isotopically lighter than other compounds.

These studies, by evaluating patterns of enrichment in laboratory conditions, should improve the resolution and aid the interpretation of isotopic values of field-collected specimens.

\section{Materials and Methods}

Stable isotope terminology

Stable isotopic composition is frequently expressed in delta $(\delta)$ notation as the ratio of the heavier to the lighter isotopes of an element as the deviation per mil (\%) from an arbitrary standard (Peterson and Fry 1987) as:

$$
\delta \mathrm{X}=\left[\left(\mathrm{R}_{\text {sample }} / \mathrm{R}_{\text {standard }}\right)-1\right] \times 1000 \%
$$


where $\mathrm{R}$ is the absolute isotopic ratio and $\mathrm{R}_{\text {sample }}$ and $\mathrm{R}_{\text {standard }}$ are the molar ratios of the heavier to the lighter isotope of the sample and standard, respectively (Peterson and Fry 1987). The standards for carbon and nitrogen are PeeDee Belemnite carbonate and atmospheric air, respectively (Ehleringer \& Osmond, 1989).

Laboratory colony conditions

Founding colonies of S. invicta were provided by S.D. Porter. Thirty-one laboratory colonies were established at the University of Arkansas in Jul-2008. Every colony was initially comprised of one queen and approximately 15 workers. Colonies were maintained in $8 \times 15 \times 30 \mathrm{~cm}$ plastic containers rimmed with Fluon ${ }^{T M}$ to prevent ant escape (Banks et al. 1981). Water was available ad lib from glass tubes filled with water and stoppered with a wad of cotton. Colonies were fed one cricket and $7 \mathrm{ml}$ of $2 \mathrm{M}$ sucrose solution each day and were maintained in a room at $26.3 \pm$ $0.5^{\circ} \mathrm{C}(\mathrm{N}=98)$. 


\section{Effects of metamorphosis and diet}

Beginning May-2009, 10 active colonies were selected haphazardly to examine the effects of time and diet on isotopic composition. Each day, five control colonies were fed a diet of $6 \mathrm{~g}$ of crickets and $7 \mathrm{ml}$ of $2 \mathrm{M}$ solution of cane sugar. In control colonies, crickets provided the only extraneous source of nitrogen as cane sugar consists solely of sucrose. Five experimental colonies received the control diet plus a diet supplement of $6 \mathrm{~g}$ of tuna in water. Tuna is a rich source of fat and protein and its carbon and nitrogen isotope ratios differ substantially from both crickets and cane sugar (Table 1). If ants in experimental colonies feed on tuna, we expect to see differences between experimental and control colonies in $\delta^{13} \mathrm{C}$ and $\delta^{15} \mathrm{~N}$. If workers in the experimental colonies preferentially feed tuna to larvae, we expect isotopic enrichment in both larvae and pupae relative to workers.

Larvae, pupae, and workers from control and experimental colonies were collected every fifteen days for two months. Because eggs and pupae at $26^{\circ} \mathrm{C}$ complete development in approximately 10 and 15 days, respectively (Porter 1988), samples collected during the course of our study likely included several cohorts of lab-reared animals. When sampling was terminated, colonies were growing vigorously with 800-1,200 workers, abundant brood, major workers and some alates.

Effects of fat storage

Sixteen of the 31 laboratory colonies were sacrificed on 16-Dec-2008 and preserved in sealed vials at $-2^{\circ} \mathrm{C}$ for use in the fat body experiment. Colonies had approximately $200-400$ workers and were growing vigorously when harvested. Fifteen to twenty minor workers were haphazardly selected from each of the sixteen colonies and assigned to one of three treatments: 
control, extraction with $95 \%$ ethanol (a polar solvent), or extraction with a $1: 1(\mathrm{v} / \mathrm{v})$ mixture of hexane-isopropanol (a non-polar solvent). Specimens were thawed, air-dried and treated with $0.5 \mathrm{ml}$ of solvent. Ten days later, solutes were decanted and samples were lyophilized for $96 \mathrm{~h}$, and then homogenized with a Dentsply Wigg-L-Bug Mixer Amalgamator ${ }^{\mathrm{TM}}$. Dried homogenate was weighed into tin capsules using a Sartorius SC-2 microbalance and analyzed using a Finnegan Delta + mass spectrometer at the University of Arkansas Stable Isotope Laboratory (UASIL), Fayetteville, AR, USA. Outputs include $\delta^{13} \mathrm{C}, \delta^{15} \mathrm{~N}, \% \mathrm{C}$, and $\% \mathrm{~N}$. Over the course of these analyses, internal standards exhibited less than $0.5 \%$ variation from the mean $\delta^{13} \mathrm{C}$ or $\delta^{15} \mathrm{~N}$ isotopic value.

\section{Mixing models}

Stable isotope signatures can provide a measure of the amount of diet made up by a particular food item if the number of diet items is small, and if all items differ in their isotopic signature (Treseder et al. 1995). To estimate the fraction of ant nitrogen derived from crickets, we used the two end-member mixing model:

$$
\% \mathrm{~N}_{\text {from cricket }}=\frac{\delta^{15} \mathrm{~N}_{\text {ants }}}{\delta^{15} \mathrm{~N}_{\text {crickets }}-\delta^{15} \mathrm{~N}_{\text {tuna }}}
$$

Where $\delta^{15} \mathrm{~N}_{\text {ants }}$ and $\delta^{15} \mathrm{~N}_{\text {tuna }}$ are the isotopic composition of $S$. invicta and a homogenized sample of commercially available tuna, respectively. 


\section{Data analyses}

Bartlett's and Flinger's tests for heteroscedasticity were used to test homogeneity of variances (Crawley 2007; Dalgaard 2008). An ANOVA of a complete randomized block design was used to evaluate the effects of time and ant developmental stages (e.g. larvae, pupae and workers) on $\delta^{13} \mathrm{C}$ and $\delta^{15} \mathrm{~N}$ ratios. The main plot effect was time and the subplot effect was developmental stages. We used an ANOVA with a randomized complete block design to determine the effects of metamorphosis and diet on $\delta^{13} \mathrm{C}$ and $\delta^{15} \mathrm{~N}$ ratios where diet was the factor applied to the blocks (split-plot design) and the subplot effect was developmental stages. Tukey honestly significant difference (HSD) post hoc multiple comparisons procedure was used to compare treatment means. An ANOVA of a complete randomized block design was used to analyze the effects of solvents on $\delta^{13} \mathrm{C}$ and $\delta^{15} \mathrm{~N}$ ratios where colony was the block effect. These statistical analyses were performed using R (TeamCoreDevelopment 2005) and JMP (SAS Institute, 19892010).

\section{Results}

\section{Time}

Time had no significant effect on $\delta^{15} \mathrm{~N}$, nor was there a significant interaction between time and developmental stage in a two-way ANOVA (Table 2). In contrast, the $\delta^{13} \mathrm{C}$ of colonies collected at 75 days was slightly depleted relative to colonies collected at 15 days $\left(\Delta \delta^{13} \mathrm{C}=-0.27 \%\right.$, and the effect was significant $(F=6.51, P=0.03, \mathrm{~N}=10$, Table 2$)$. Furthermore, there was no significant interaction between time and developmental stage for $\delta^{13} \mathrm{C}(F=2.80, P=0.10)$. In summary, the effects of time or colony age were limited to a slight depletion in $\delta^{13} \mathrm{C}$ as colonies 
matured, and the effect was similar for all developmental stages. We decided arbitrarily to conduct the remaining analyses on colonies collected at 15 days.

\section{Effects of metamorphosis}

To evaluate the effects of metamorphosis on isotopic signature, we randomly selected colonies from those that had received a control diet and also consistently produced all the developmental stages. Among these colonies, variances were homogeneous for $\delta^{15} \mathrm{~N}$ (Bartlett test $\mathrm{K}$-squared $=2.96, P=0.23)$ and $\delta^{13} \mathrm{C}($ Bartlett test $\mathrm{K}$-squared $=0.29, P=0.86)$. A one-way ANOVA of a randomized complete block design showed a significant effect of developmental stage on $\delta^{15} \mathrm{~N}(F=45.40, P<0.001, \mathrm{~N}=10$; Fig. 1, Table 3). Nitrogen isotopic composition of workers was enriched by $2.0 \%$ relative to larvae (Tukey HSD: $P<0.001$ ) and by $1.4 \%$ relative to pupae (Tukey HSD: $P<0.001$ ) (Fig. 1, Table 4). A similar analysis showed no effect of developmental stage on $\delta^{13} \mathrm{C}(F=1.81, P=0.19, \mathrm{~N}=10$, Table 3,4).

Queens were isotopically similar to workers for $\delta^{15} \mathrm{~N}$ (Fig.1). Curiously, the queen variability for $\delta^{13} \mathrm{C}$ was too great to make any comparison with workers; partly this was because of small sample size, but queen signatures may also be carried over from a previous diet (Fisher et al. 1990; O'Brien et al. 2002), a strong possibility in this study. 


\section{Effects of diet}

Isotope ratios differed substantially among diet items. In this study, cane sugar, crickets and tuna differed significantly in both carbon and nitrogen isotopic composition (Table 1). Based on C:N ratios, quality of diet items can be ranked from high to low as tuna, cricket and sucrose (no nitrogen) (Table 1).

The nitrogen isotopic composition of larvae in control colonies matched the $\delta^{15} \mathrm{~N}$ of crickets, the only source of nitrogen available to them (Fig. 1), suggesting there is no trophic enrichment in larvae. Pupae in control colonies were significantly enriched relative to larvae, and workers were enriched relative to pupae (Tukey HSD $<0.01$, in each case, Fig. 1). Because pupae are non-feeding and there are no alternative sources of nitrogen, enrichment through subsequent developmental stages must result solely from metamorphosis. The intermediate $\delta^{13} \mathrm{C}$ values in this figure suggest that larvae on control diets use both sucrose and crickets for energy.

Among the experimental colonies, the addition of tuna had little effect on $\delta^{13} \mathrm{C}(F=1.28$, $P=0.27, \mathrm{~N}=10$, Fig. 1$)$, but a significant effect on $\delta^{15} \mathrm{~N}(F=34.89, P<0.0001, \mathrm{~N}=10$, Fig. 1$)$. Furthermore, we found a significant interaction effect between developmental stage and $\operatorname{diet}(F=$ 3.52, $P=0.05, \mathrm{~N}=10$, Fig. 1). If we assume patterns of fractionation due to metamorphosis are similar for ants in both control and experimental fed tuna colonies, we can modify a two endmember mixing model to incorporate metamorphic enrichment to assess diet composition of each developmental stage. The mixing model for $\% \mathrm{~N}$ must include a new term, metamorphic enrichment, calculated from control colonies above as:

$$
\% \mathrm{~N}_{\text {from cricket }}=\frac{\delta^{15} \mathrm{~N}_{\text {ants }} \frac{-\delta^{15} \mathrm{~N}_{\text {tuna }}}{\delta^{15} \mathrm{~N}_{\text {larvae }}+\delta^{15} \mathrm{~N}_{\text {metamorphic enrichment }}-\delta^{15} \mathrm{~N}_{\text {tuna }}}}{\text {. }}
$$


With a correction for metamorphic enrichment, we find that pupal diet matches larval diet, as would be expected for the, non-feeding pupal phase. Moreover, incorporating metamorphic enrichment, we find that in experimental tuna-fed colonies crickets form a larger proportion of assimilated $\mathrm{N}$ of workers $(96.0 \%)$ than of larvae (85.6\%) (Table 4). (Details of analyses provided in Supplemental information 1.)

The results of the mixing model corrected for metamorphic enrichment differ substantially from the uncorrected results (Table 4).Without correction, the simple mixing model suggests that workers received only $70.6 \%$ of their nitrogen diet from crickets rather than $96.0 \%$, a difference from the corrected value of $25.4 \%$. Furthermore, the larger absolute values of $\delta^{15} \mathrm{~N}$ of workers relative to larvae in both control (6.7\%o vs. $4.8 \%$, respectively) and experimental colonies (7.0 \%o vs. 5.8\%o respectively) might otherwise be interpreted to mean that workers feed at a higher trophic level than larvae when the reverse is likely true.

\section{Fat body dissolution experiment}

Sample variances were unequal between treatments for percent carbon (Fligner test $(\chi 2=6.1524$, $d f=2, P=0.05$; Bartlett test $(\mathrm{K}$-squared $=20.2541, d f=2, P<0.001)$ and percent nitrogen (Fligner test $(\chi 2=12.2374, d f=2, P<0.05$; Bartlett test $(\mathrm{K}$-squared $=14.565, d f=2, P<0.001)$. Treatment with solvents had a significant effect on the amount of carbon and nitrogen in the sample. An ANOVA showed that control samples had 7\% and 17\% more carbon than samples in ethanol and hexane-isopropanol, respectively $(F=209.92, P<0.001, \mathrm{~N}=16)$. Ethanol samples had $2.28 \%$ and $2.54 \%$ more nitrogen than control and hexane-isopropanol samples $(F=18.45, P$ $<0.001, \mathrm{~N}=16$ ), respectively.

Sample variances were homogeneous among treatments for $\delta^{13} \mathrm{C}$ (Bartlett's K-squared = $0.29, P=0.86)$ and $\delta{ }^{15} \mathrm{~N}$ (Bartlett's $\mathrm{K}$-squared $\left.=2.11, P=0.34\right)$. Carbon isotopic composition 
did not differ significantly among treatments $(F=3.12, P=0.06, \mathrm{~N}=16)$, but nitrogen isotopic composition $\operatorname{did}(F=18.45, P<0.001, \mathrm{~N}=16)$ (Table 5). A Tukey HSD multiple comparison test showed a significant difference in $\delta{ }^{15} \mathrm{~N}$ between the control group and the hexaneisopropanol group $(P=0.03)$; samples treated with hexane-isopropanol were enriched by $2.63 \%$ o relative to control. The $\delta^{15} \mathrm{~N}$ values of ethanol-treated samples were not significantly different from controls.

\section{Discussion}

Questions about utility of stable isotope analysis of field collected insects are not yet fully resolved as few studies have systematically examined patterns of enrichment and depletion on standardized diets in laboratory colonies. Our study finds that isotopic composition is influenced by development and feeding ecology, but deviations from expected values can be measured, modeled and predicted.

Effects of time on colonies were limited in this study to the depletion of ${ }^{13} \mathrm{C}$. This finding may be related to the natural fat storage variation observed in fire ants whereby worker fat content increases with body size and colony size. Tschinkel (1993) found that percent fat in wild workers from colonies can increase $2-4 \%$ for each worker size class. Consequently colonies would be expected to become isotopically lighter as they mature and more major workers are produced because fats tend to be isotopically lighter than whole animal signatures (Macko et al. 1986; Macko et al. 1987; Post 2002; Post et al. 2007).

Our study found significant differences in $\delta^{15} \mathrm{~N}$ among developmental stages, with increasing enrichment through developmental stages. Most notably, the step between the actively feeding larvae to the quiescent pupa was similar in magnitude for control and experimental diets $(0.5 \%)$, an indication that the metamorphic enrichment may be a predictable. Nitrogen 
enrichment with metamorphosis has been reported previously (Doi et al. 2007; Tibbets et al. 2008). Several studies have observed isotopic variation among developmental stages in field collected samples (Mihuc and Toetz 1994; Blüthgen et al. 2003; Spence and Rosenheim 2005) including Argentine ants (Menke et al. 2010). Controlled feeding trials in the lab have identified similar levels of metamorphic enrichment in Neuroptera (Patt et al. 2003), Diptera (Doi et al. 2007, Tibbets et al. 2008), Lepidoptera, and Coleoptera (Tibbets et al. 2008). Replicating these studies with additional invertebrate systems will reveal whether holometabolous insects and perhaps even hemimetabolous insects make a standard and predictable enrichment step with each metamorphic stage.

The diet portion of this study was revealing. A peculiar finding from control colonies was that larvae showed no trophic enrichment over their only available nitrogen source, and subsequent developmental stages were enriched even though no new diet items were available. In other words, the mostly herbivorous workers (Tennant and Porter 1991) were isotopically enriched in $\mathrm{N}$ compared to larvae which consume all of an ant colony's prey items and enriched to pupae which do not consume anything.

The addition of a novel diet item (tuna) affected nitrogen isotopic signatures for all developmental stages: the $\delta^{15} \mathrm{~N}$ of larvae, pupae and workers shifted toward tuna when it was available. When metamorphic enrichment is taken into account, pupal diet composition matched that of larval diet (approx. 86\% crickets), as expected for the non-feeding pupal stage. We conclude, then, that enrichment between larval and pupal developmental stages is due to pupation. With correction for metamorphic enrichment, we find workers' diet nitrogen composed almost entirely of crickets (96.0\%) rather than tuna, which supports the prediction that workers choose a nitrogen poor diet while selectively feeding larvae a diet richer in protein and fat. This 
finding is consistent with direct observations of selective feeding behaviors by S. invicta workers (Cassill and Tschinkel 1999).

We predicted that carbon, but not nitrogen, signatures will become heavier following extraction of stored lipids, because lipids are isotopically lighter than other compounds. Hexaneisopropanol extractions had no effect on $\delta^{13} \mathrm{C}$ values, suggesting that the fat content of those workers did not bias the stable isotope analysis (Post et al. 2007). In contrast, our results showed a significant effect of lipid extraction on $\delta^{15} \mathrm{~N}$ values (Fig. 1). Differences in the mean values of workers with lipids and workers that received hexane-isopropanol were $0.37 \%$ in $\delta^{15} \mathrm{~N}$ (Fig. 1), slightly more than the $0.25 \%$ found by Post et al. (2007). Other authors working mainly with fish found a similar result (Pinnegar and Polunin 1999; Sotiropoulos et al. 2004). Differences in the mean values of workers with lipids and workers that received hexane-isopropanol were $0.37 \%$ in $\delta^{15} \mathrm{~N}$ (Fig. 1), slightly than the $0.25 \%$ found by Post et al. (2007).

The utility of stable isotopes in insect ecology has been widely recognized (Davidson 2003; Tillberg et al. 2006). Interpreting patterns of isotopic discrimination have been questioned due to a lack of lab controlled feeding studies (Scrimgeour et al. 1995; Spence and Rosenheim 2005; Sagers and Goggin 2007). Our findings suggest that stable isotope approaches can be developed through additional study to provide insights to the feeding ecology of natural populations. 


\section{Acknowledgements}

Funding for this project was provided by WWF's Russell E. Train Education for Nature Program and Sigma Xi Grants-in-Aid to PB. We acknowledge E Gbur, JL Hamrick, L Hart, S Lehnen, J Ludlam, G Petris and J Stenken for discussion, comment and advice, to K Polansky for taking care of the colonies and to our colleagues of the University of Arkansas Stable Isotope Lab for sample processing and to E. LeBrun for peer review. 


\section{Literature cited}

Ascunce MS, Yang CC, Oakey J, Calcaterra L, Wu WJ, Shih CJ, Goudet J, Ross KG \& Shoemaker DW (2011) Global invasion history of the fire ant Solenopsis invicta. Science 331: $1066-1068$.

Banks WA, Lofgren CS, Jouvenaz DP, Stringer CE, Bishop PM, Williams DF, Wojcik DP \& Glancey BM (1981) Techniques for collecting, rearing, and handling imported fire ants. Advances in Agricultural Technology, Science and Education Administration, United States Department of Agriculture USDA SEA. AATS-S-21: 1-9.

Blüthgen N, Gebauer G \& Fiedler K (2003) Disentangling a rainforest food web using stable isotopes: dietary diversity in a species-rich ant community. Oecologia 137: 426-435.

Callcott AMA \& Collins HL (1996) Invasion and range expansion of imported fire ants (Hymenoptera: Formicidae) in North America from 1918-1995. Florida Entomologist 79: 240-251.

Cassill DL \& Tschinkel WR (1999) Regulation of diet in the fire ant, Solenopsis invicta. Journal of Insect Behavior 12: 307-328.

Crawley MJ (2007) The R book. 1st edn. John Wiley \& Sons Inc, West Sussex, England.

Dalgaard P (2008) Introductory statistics with R. 1st edn. Springer Verlag, Copenhagen, Denmark.

Davidson DW (2003) Explaining the abundance of ants in lowland tropical rainforest. Science 300: 969-972.

DeNiro MJ \& Epstein S (1978) Influence of diet on the distribution of carbon isotopes in animals. Geochimica et Cosmochimica Acta 42: 495-506.

DeNiro MJ \& Epstein S (1981) Influence of diet on the distribution of nitrogen isotopes in animals. Geochimica et Cosmochimica Acta 45: 341-351.

Doi H, Kikuchi E, Takagi S \& Shikano S (2007) Changes in carbon and nitrogen stable isotopes of chironomid larvae during growth, starvation and metamorphosis. Rapid Communications in Mass Spectrometry 21: 997-1002.

Ehleringer JR \& Osmond CB (1989) Stable isotopes: Plant physiological ecology field methods and instrumentation (ed. by RW Pearcy, JR Ehleringer, HA Mooney \& PW Rundel) Chapman and Hall Ltd., London, pp. 281-300.

Fisher BL, Silveira Lobo Sternberg L \& Price D (1990) Variation in the use of orchid extrafloral nectar by ants. Oecologia 83: 263-266. 
Fry B \& Sherr EB (1984) $\delta 13 C$ measurements as indicators of carbon flow on marine and freshwater ecosystems. Contributions in Marine Science 27: 13-47.

Hobson KA, Alisauskas RT \& Clark RG (1993) Stable-nitrogen isotope enrichment in avian tissues due to fasting and nutritional stress: implications for isotopic analyses of diet. Condor 95: 388-394.

Hobson KA, McLellan BN \& Woods JG (2000) Using stable carbon $\left(\delta^{13} \mathrm{C}\right)$ and nitrogen $\left(\delta^{15} \mathrm{~N}\right)$ isotopes to infer trophic relationships among black and grizzly bears in the upper Columbia River basin, British Columbia. Canadian Journal of Zoology 78: 1332-1339.

JMP (1989-2010): Version 8.0.2 (ed. SAS Institute Inc., Cary, NC.

Layman CA, Arrington DA, Montana CG \& Post DM (2007) Can stable isotope ratios provide for community-wide measures of trophic structure? Ecology 88: 42-48.

LeBrun EG, Tillberg CV, Suarez AV, Folgarait PJ, Smith CR \& Holway DA (2007) An experimental study of competition between fire ants and Argentine ants in their native range. Ecology 88: 63-75.

Macko SA, Estep MLF, Engel MH \& Hare PE (1986) Kinetic fractionation of stable nitrogen isotopes during amino acid transamination. Geochimica et Cosmochimica Acta 50: 21432146.

Macko SA, Fogel ML, Hare PE \& Hoering TC (1987) Isotopic fractionation of nitrogen and carbon in the synthesis of amino acids by microorganisms. Chemical Geology: Isotope Geoscience section 65: 79-92.

McCutchan Jr JH, Lewis Jr WM, Kendall C \& McGrath CC (2003) Variation in trophic shift for stable isotope ratios of carbon, nitrogen, and sulfur. Oikos 102: 378-390.

Menke SB, Suarez AV, Tillberg CV, Chou CT \& Holway DA (2010) Trophic ecology of the invasive Argentine ant: spatio-temporal variation in resource assimilation and isotopic enrichment. Oecologia 164: 763-771.

Mihuc T \& Toetz D (1994) Determination of diets of alpine aquatic insects using stable isotopes and gut analysis. American Midland Naturalist 131: 146-155.

Minagawa M \& Wada E (1984) Stepwise enrichment of ${ }^{15} \mathrm{~N}$ along food chains: Further evidence and the relation between $\delta^{15} \mathrm{~N}$ and animal age. Geochimica et Cosmochimica Acta 48: 1135-1140.

O'Brien DM, Fogel ML \& Boggs CL (2002) Renewable and nonrenewable resources: amino acid turnover and allocation to reproduction in Lepidoptera. Proceedings of the National Academy of Sciences 99: 4413. 
Patt JM, Wainright SC, Hamilton GC, Whittinghill D, Bosley K, Dietrick J \& Lashomb JH (2003) Assimilation of carbon and nitrogen from pollen and nectar by a predaceous larva and its effects on growth and development. Ecological Entomology 28: 717-728.

Peterson BJ \& Fry B (1987) Stable isotopes in ecosystem studies. Annual Review of ecology and Systematics 18: 293-320.

Pinnegar JK \& Polunin NVC (1999) Differential fractionation of $\delta^{13} \mathrm{C}$ and $\delta^{15} \mathrm{~N}$ among fish tissues: implications for the study of trophic interactions. Functional Ecology 13: 225231.

Porter SD (1988) Impact of temperature on colony growth and developmental rates of the ant, Solenopsis invicta. Journal of Insect Physiology 34: 1127-1133.

Post DM (2002) Using stable isotopes to estimate trophic position: models, methods, and assumptions. Ecology 83: 703-718.

Post DM, Layman CA, Arrington DA, Takimoto G, Quattrochi J \& Montana CG (2007) Getting to the fat of the matter: models, methods and assumptions for dealing with lipids in stable isotope analyses. Oecologia 152: 179-189.

Ross KG \& Shoemaker DD (2008) Estimation of the number of founders of an invasive pest insect population: the fire ant Solenopsis invicta in the USA. Proceedings of the Royal Society B: Biological Sciences 275: 2231.

Sagers CL \& Goggin FL (2007) Isotopic enrichment in a phloem-feeding insect: influences of nutrient and water availability. Oecologia 151: 464-472.

Scrimgeour CM, Gordon SC, Handley LL \& Woodford JAT (1995) Trophic levels and anomalous ${ }^{15} \mathrm{~N}$ of insects on raspberry (Rubus idaeus L.). Isotopes in Environmental and Health Studies 31: 107-115.

Sotiropoulos MA, Tonn WM \& Wassenaar LI (2004) Effects of lipid extraction on stable carbon and nitrogen isotope analyses of fish tissues: potential consequences for food web studies. Ecology of Freshwater Fish 13: 155-160.

Spence KO \& Rosenheim JA (2005) Isotopic enrichment in herbivorous insects: a comparative field-based study of variation. Oecologia 146: 89-97.

TeamCoreDevelopment R (2005) R: a language and environment for statistical computing, R. Foundation for Statistical Computing. (http://www.R-project.org).

Tennant LE \& Porter SD (1991) Comparison of diets of two fire ant species (Hymenoptera: Formicidae): solid and liquid components. Journal of Entomological Science 26: 450465. 
Tibbets T, M, Wheeless L, A. \& Martínez del Río C (2008) Isotopic enrichment without change in diet: an ontogenetic shift in $\delta^{15} \mathrm{~N}$ during insect metamorphosis. Functional Ecology 22: 109-113.

Tillberg CV, McCarthy DP, Dolezal AG \& Suarez AV (2006) Measuring the trophic ecology of ants using stable isotopes. Insectes sociaux 53: 65-69.

Trager JC (1991) A revision of the fire ants, Solenopsis geminata group (Hymenoptera: Formicidae: Myrmicinae). Journal of the New York Entomological Society 99: 141-198.

Treseder KK, Davidson DW \& Ehleringer JR (1995) Absorption of ant-provided carbon dioxide and nitrogen by a tropical epiphyte. Nature 375: 137-139.

Tschinkel WR (1993) Sociometry and sociogenesis of colonies of the fire ant Solenopsis invicta during one annual cycle. Ecological Monographs: 425-457.

Vinson SB (1997) Insect Life: Invasion of the red imported fire ant (Hymenoptera: Formicidae). American Entomologist 43: 23-39.

Widga C, Walker JD \& Stockli LD (2010) Middle holocene bison diet and mobility in the eastern Great Plains (USA) based on $\delta^{13} \mathrm{C}, \delta^{18} \mathrm{O}$, and ${ }^{87} \mathrm{Sr} /{ }^{86} \mathrm{Sr}$ analyses of tooth enamel carbonate. Quaternary Research 73: 449-463.

Wilder SM, Holway DA, Suarez AV, LeBrun EG \& Eubanks MD (2011) Intercontinental differences in resource use reveal the importance of mutualisms in fire ant invasions. Proceedings of the National Academy of Sciences 108: 20639-20644.

Wojcik DP, Allen CR, Brenner RJ, Forys EA, Jouvenaz DP \& Lutz RS (2001) Red imported fire ants: impact on biodiversity. American Entomologists 47: 16-23. 
Fig. 1 Mean $\delta^{13} \mathrm{C}$ values $\left( \pm\right.$ SE) versus mean $\delta^{15} \mathrm{~N}$ values $( \pm \mathrm{SE})$ for ants reared under control and experimental diets $($ closed symbols $=$ control colonies, open symbols $=$ experimental colonies fed tuna; circle $=$ larvae, triangle $=$ pupae, square $=$ workers, diamond $=$ queens $).$ Values within quadrangles are not significantly different (Tukey HSD, $P>0.5$, in each case). 
Fig. 1




Table 1. Carbon and nitrogen contents in diet items used for control and experimental colonies.

\begin{tabular}{|l|c|c|c|c|c|}
\hline & $\begin{array}{c}\delta^{13} \mathrm{C} \\
(\%)\end{array}$ & $\begin{array}{c}\delta^{15} \mathrm{~N} \\
(\%)\end{array}$ & $\% \mathrm{C}$ & $\% \mathrm{~N}: \mathrm{N}$ \\
\hline Cane sugar & -11.80 & - & 44.10 & - & - \\
\hline Cricket & -21.70 & 4.74 & 50.60 & 11.19 & 4.52 \\
\hline Tuna & -16.62 & 12.34 & 45.39 & 13.23 & 3.43 \\
\hline
\end{tabular}


Table 2. ANOVA of the effects of developmental stage and time on $\delta^{13} \mathrm{C}$ (above) and $\delta^{15} \mathrm{~N}$ (below) of Solenopsis invicta.

\begin{tabular}{|l|c|c|c|c|}
\hline & $\mathrm{df}$ & SSE & $F$ & $P$ \\
\hline Stage & 2 & 1.34 & 6.02 & 0.02 \\
\hline Block & 12 & 1.305 & 0.98 & 0.52 \\
\hline Time & 1 & 0.72 & 6.51 & 0.03 \\
\hline Stage*Time & 2 & 0.62 & 2.80 & 0.11 \\
\hline
\end{tabular}

\begin{tabular}{|l|c|c|c|c|}
\hline & df & SSE & $F$ & $P$ \\
\hline Stage & 2 & 16.44 & 117.30 & $<0.01$ \\
\hline Block & 12 & 1.52 & 1.80 & 0.17 \\
\hline Time & 1 & 0.03 & 0.45 & 0.52 \\
\hline Stage*Time & 2 & 0.44 & 3.15 & 0.08 \\
\hline
\end{tabular}


Table 3. ANOVA of the effects of diet and developmental stage on $\delta^{13} \mathrm{C}$ (above) and $\delta^{15} \mathrm{~N}$ (below) on Solenopsis invicta.

\begin{tabular}{|l|c|c|c|c|}
\hline & df & SSE & $F$ & $P$ \\
\hline Diet & 1 & 0.98 & 1.28 & 0.27 \\
\hline Block & 10 & 3.60 & 2.33 & 0.06 \\
\hline Stage & 2 & 0.56 & 1.81 & 0.19 \\
\hline Stage*Diet & 2 & 0.71 & 2.31 & 0.13 \\
\hline
\end{tabular}

\begin{tabular}{|l|c|c|c|c|}
\cline { 2 - 5 } \multicolumn{1}{c|}{} & $\mathrm{df}$ & SSE & $F$ & $P$ \\
\hline Diet & 1 & 5.37 & 34.89 & $<0.01$ \\
\hline Block & 10 & 3.36 & 2.18 & 0.07 \\
\hline Stage & 2 & 13.96 & 45.40 & $<0.01$ \\
\hline Stage*Diet & 2 & 1.08 & 3.52 & 0.05 \\
\hline
\end{tabular}


Table 4. Model estimates for fire ant colonies fed only crickets and sugar water (control) and colonies with tuna supplemental (experimental) with and without correction from metamorphic enrichment of $\delta^{15} \mathrm{~N}$, assuming no isotopic enrichment by larvae and incorporating levels of metamorphic enrichment measured experimentally. $\left(\delta^{15} \mathrm{~N}( \pm 1 \mathrm{SE})\right.$ for control and experimental colonies)

\begin{tabular}{|l|c|c|c|c|c|}
\hline & $\begin{array}{c}\delta^{15} \mathrm{~N}_{\text {control }} \\
(\%)\end{array}$ & $\begin{array}{c}\delta^{15} \mathrm{~N}_{\text {experimental }} \\
(\%)\end{array}$ & $\begin{array}{c}\text { \%crickets } \\
(\text { w/o } \\
\text { correction) }\end{array}$ & $\begin{array}{c}\text { \%crickets (w/ } \\
\text { correction) }\end{array}$ & $\begin{array}{c}\text { Difference } \\
(\%)\end{array}$ \\
\hline larvae & $4.8( \pm 0.2)$ & $5.8( \pm 0.1)$ & $\mathrm{NA}$ & 86.7 & 0.0 \\
\hline pupae & $5.3( \pm 0.2)$ & $6.4( \pm 0.32)$ & 78.8 & 85.6 & 6.8 \\
\hline workers & $6.7( \pm 0.06)$ & $7.0( \pm 0.06)$ & 70.6 & 96.0 & 25.5 \\
\hline
\end{tabular}


Table 5. ANOVA for the effect of ethanol and hexane-isopropanol on $\delta^{15} \mathrm{~N}$ of Solenopsis invicta.

\begin{tabular}{|l|c|c|c|c|}
\hline & df & SSE & $F$ & $P$ \\
\hline Treatment & 2 & 1.28 & 18.45 & $<0.01$ \\
\hline Block & 15 & 5.08 & 9.75 & $<0.01$ \\
\hline Residuals & 23 & 0.80 & & \\
\hline
\end{tabular}


Appendix 4.1 Calculations with the corrections for stable isotope values for each developmental stage

$\% N_{\text {crickets }}$ - larvae: $(5.8-12.34) /(4.8-12.34)=0.867$

$\% N_{\text {crickets }}$ - pupae $(6.4-12.34) /(4.8+.6-12.34)=0.788$

$\% N_{\text {crickets }}-$ workers $(7.02-12.34) /(4.8+2.0-12.34)=0.706$ 
Appendix 4.2 Statement from major professor that certifies the main authorship of this chapter

To whom it may concern,

I can certify that Paola Barriga is the principal investigator in the chapter entitled "Stable isotope enrichment in laboratory ant colonies: effects of metamorphosis, diet, and fat storage." As principal investigator she contributed to this chapter with more than $50 \%$ of the work required. Additionally she obtained the majority of the funding needed to pursue this research. Please let me know if further information is required.

Sincerely,

Cynthia Sagers

Department of Biological Sciences

Professor 


\section{CONCLUSION}

Plant-ant interactions have been an ideal model systems for a variety of ecological and evolutionary biology studies of inter-specific interactions (Heil and McKey 2003). Symbiotic plant-ant associations are of particular interest in the study of specialization (Heil and McKey 2003) because the ant partners stay in intimate contact with their host plants during the ant colonies' life. Such intimate interactions are also called obligate associations and have been catalogued as highly specialized to their host. I chose to study the obligate plant-ant associations in Yasuni (Ecuador), Los Amigos (Peru) and La Selva (Costa Rica) to explore the role of geographic location, ant species composition and richness on the structure of these associations. Simulations of sequential plant extinction in each network were performed to determine if resistance of these networks to host loss varies geographically and if these systems are robust to plant loss.

It has been hypothesized that even though the species composition in locales has an impact into the outcome of species associations (i.e. in one locale being mutualistic and in another parasitic), it does not have an impact on the structure of obligate mutualistic associations. Network theory is a tool that has been used to explore hypotheses like this because entire communities of interacting organisms can be depicted as nodes and their interactions as links. Obligate mutualistic associations are expected to display a compartmentalized network, a network where subsets of species interact only among themselves and not with other species that are part of the network. Additionally, sub-webs or isolated species of interacting pairs that are not connected with other parts of the network are expected in obligate mutualisms. 
This dissertation has produced empirical evidence that shows that obligate plant-ant associations have network structures that do not vary geographically. These obligate plantant associations have a compartmentalized network structure with sub-webs. Plant or ant identity or ant richness did not influence the network topology observed in Yasuni (Ecuador), Los Amigos (Peru), and La Selva (Costa Rica). Networks produced in each locale were highly specialized and the degree of specialization of plant and ant species, nodes, in those networks had values all over the range of the species index from 0 , generalists, to 1 , specialists. The distribution of values of the species specialization index did not vary geographically either. Plant removal simulations showed that the disappearance of bestconnected plant species creates the most impact on ant survivorship and that these interactions are not robust to the loss of plant hosts independently of the type of plant removal simulated. The results of random, less abundant plant species and best-connected plant species removals' did not vary geographically.

Even though the general community structure of interactions may evolve to a specific structure (Thompson 2005), the interactions among species are very dynamic. Species levels of specialization change geographically producing what is known as a geographic mosaic of specialization (Thompson 1994). Individual species can have different levels of specialization across their distributional gradient (Thompson 1994).

A factor that could be driving this dynamic change in interaction outcomes could be traits that organisms have. For example, traits in plants are known to vary across habitats and environmental gradients (Sandquist and Ehleringer 1997; Correia et al. 2008). Because different levels of specialization result as the product of the genetics of the interacting 
individuals and ecological opportunity (Thompson 1994), it is clear that population variation in traits in interacting species and the environment in which they occur will have an effect on the final level of specialization observed.

Specialization levels in symbiotic plant-ant associations can additionally be influenced by the completeness of the resources provided by the hosts (Janzen 1966b; Schemske 1983); for example, when plants provide domatia, nest spaces to ants, and food bodies that are highly nutritious, highly specialized associations usually result. Plant hosts that have the less amount of herbivory are going to be associated with ants that provide the most beneficial association. Therefore, we can measure ant specialization by the benefits plants receive and a geographic mosaic of those benefits can be expected if the completeness of those resources also vary.

In symbiotic obligate plant-ant interactions where food rewards are offered it is possible to measure how dependent ants are on the food provided by the host. Stable isotope analysis is an important tool that helps to determine the carbon and nitrogen signature that is characteristic of the host. If ants living inside plants depend mainly of host food for living, carbon and nitrogen plant signatures can be tracked in the ant body composition. The smaller the carbon and nitrogen deviation in the ant body, the more dependence ants have on their hosts for food.

The Cecropia-Azteca association is the most common and conspicuous interaction in the Neotropics (Berg and Franco Rosselli 2005). Cecropia Loelf. (Urticaceae) trees have the most specialized associations with ants in the genus Azteca (Formicidae: Hymenoptera) (Janzen 1969b; Longino 1991a; Davidson 2005). Even though this association has reached a degree of specialization at the generic level, there are few instances of strict specialization at the species level (Davidson et al. 1991). To test if plant physiology has an effect on the 
specialization seen in the Cecropia-Azteca interaction, Cecropia insignis and Cecropia obtusifolia were studied in a pre-montane forest and a lowland tropical wet forest. Nine plant traits were analyzed using analyses of variance to determine if plant traits vary geographically. Trichome number, leaf thickness, specific leaf area, grams of nitrogen per area, $\delta^{13} \mathrm{C}, \delta^{15} \mathrm{~N}, \% \mathrm{C}, \% \mathrm{~N}$ and $\mathrm{C}: \mathrm{N}$ ratio were explored. Trichome number, leaf thickness and grams of nitrogen per area were the only traist that did not vary by plant species or locale. A Principal Components Analyses (PCA) showed that $27 \%$ of the variation seen in plant traits was explained by all the traits except grams of nitrogen per area, number of trichomes and leaf thickness. Only $\delta^{13} \mathrm{C}$ had variation between plant species and locales, but not in their interaction. $\delta^{15} \mathrm{~N}$ was the only trait that showed variation between locales, but not between plant species or the interaction between locales and plant species. Plant species isotopic signatures have been seen to vary in different rainfall regimes. Temperature, light, salinity and their genotypes also influence these variations (Farquhar et al. 1982; Cregg and Zhang 2001; Xu et al. 2003), but it is unknown which factor caused the variation seen in these two locations and further exploration is required.

Because plant traits varied between locales and species, $\delta^{13} \mathrm{C}$ ant deviations from plant signatures were significantly different by locale. However, no significant differences were found between ant species' deviations from their hosts indicating that these two ants are similarly specialized. These observations suggest that plant trait variation is high between locales and that other factors such as micro-environment might be playing a role in the levels of specialization observed on these plant-ant associations.

While exploring percent herbivory plant hosts had in each locale, no significant differences by ant species were found. Significantly different percentages were found for locale 
what may result from differences in leaf age (Coley 1983). At Las Cruces older leaves were sampled than at La Selva. Herbivory at Las Cruces was $0.015 \mathrm{~cm}^{2}$ higher than at La Selva, showing that the area affected by herbivory is very small. In general these ants are efficiently protecting the trees from herbivory.

Ant bodies were carbon enriched in comparison to plant carbon signatures. However, no nitrogen enrichment was observed on these ants. Symbiotic ants that use honeydew from hemipterans are depleted in $\delta^{15} \mathrm{~N}$ in comparison to ants that predate other organisms and that live in the same environment (Davidson 2003). Ants additionally, have endo-symbionts and/or bacteria in their guts that might provide the ant host with amino acids that are $\delta^{15} \mathrm{~N}$ depleted (Macko et al. 1986). The processes that produce a final nitrogen depletion or enrichment in bacteria are influenced by ratios of metabolic pathways, initial amino acid concentration and how many reactions in which a particular amino acid is involved (Macko et al. 1986). Probably different amounts of glutamate (Davidson 2003) were used in each locale and those also could have varied between plant species. Azteca has been observed using fungus and it is likely that fungi may recycle nutrients such as nitrogen (Defossez et al. 2010). However, the influence of this on the plant, ant and fungi stable isotopic signatures is not fully understood.

To determine which diet items form the body of organisms, studies that have tracked carbon and nitrogen from the food sources to the feeder have been performed. Such studies have provided general conclusions that have guided interpretations to determine the most important food sources in an organisms' diet. Among those generalizations it is that carbon isotopic signatures are not very different in the organism that ingested it and in their food item. In other words, there is not carbon enrichment between the food item and the organism that ate it. On the other hand, nitrogen signatures increase in a 3\%o fashion with every trophic level. Physiological 
changes in animals have shown to alter isotopic signatures influencing the final interpretation of isotopic signatures seen if those are not accounted for.

I examined the effect of ant metamorphosis on isotopic signatures because stable isotopes are an important tool in the study of symbiotic plant-ant associations. I explored also if the removal of fat bodies from ants had an effect on stable isotope values and provided tuna as an extra source of protein to determine the impact of diet. I used laboratory reared fire ant colonies because they are invasive species in the United States and there are well-developed protocols to maintain them. Metamorphosis had a significant effect on $\delta^{15} \mathrm{~N}$, but not $\delta^{13} \mathrm{C}$; tissues of each successive developmental stage were increasingly enriched in ${ }^{15} \mathrm{~N}$. Tuna availability resulted in further shifts in isotope ratios for all developmental stages. Treatment with organic solvents had no effect on $\delta^{13} \mathrm{C}$, but resulted in enriched $\delta^{15} \mathrm{~N}$ values. These results show the impact of physiological factors on stable isotope values and suggest that both laboratory and field studies should be performed when possible to allow more accurate interpretations. 


\section{Literature cited}

Berg CC, Franco Rosselli P (2005) Cecropia. The New York Botanical Garden Press, New York

Coley PD (1983) Herbivory and defensive characteristics of tree species in a lowland tropical forest. Ecological Monographs 53:209-234

Correia I, Almeida MH, Aguiar A, Alía R, Soares David T, Santos Pereira J (2008) Variations in growth, survival and carbon isotope composition $(\delta 13 \mathrm{C})$ among Pinus pinaster populations of different geographic origins. Tree Physiology 28:1545-1552

Cregg BM, Zhang JW (2001) Physiology and morphology of Pinus sylvestris seedlings from diverse sources under cyclic drought stress. Forest Ecology and Management 154:131139

Davidson DW (2003) Explaining the abundance of ants in lowland tropical rainforest. Science 300:969-972

Davidson DW (2005) Cecropia and its biotic defenses. In: Cecropia, vol Monograph 94. The New York Botanial Garden Press, New York, pp 214-226

Davidson DW, Foster RB, Snelling RR, Lozada PW (1991) Variable composition of some tropical ant-plant symbioses. In: Plant-animal interactions: evolutionary ecology in tropical and temperate regions. . Wiley, New York, pp 145-162

Defossez E, Djieto-Lordon C, McKey D, Selosse MA, Blatrix R (2010) Plant-ants feed their host plant, but above all a fungal symbiont to recycle nitrogen. Proceedings of the Royal Society B: Biological Sciences 278:1419-1426

Farquhar GD, O'Leary MH, Berry JA (1982) On the relationship between carbon isotope discrimination and the intercellular carbon dioxide concentration in leaves. Aust. J. Plant Physiol. 9:121-137

Heil M, McKey D (2003) Protective ant-plant interactions as model systems in ecological and evolutionary research Annual Review of Ecology, Evolution, and Systematics 34:425553

Janzen DH (1966) Coevolution of mutualism between ants and acacias in Central America. Evolution:249-275

Janzen DH (1969) Allelopathy by myrmecophytes: the ant Azteca as an allelopathic agent of Cecropia. . Ecology. 50:147-153

Longino JT (1991) Azteca ants in Cecropia trees: Taxonomy, colony structure, and behaviour. In: Huxley C, R, Cutler D, F (eds) Ant-plant interactions. Oxford Univ. Press, Oxford, pp $271-288$ 
Macko SA, Estep MLF, Engel MH, Hare PE (1986) Kinetic fractionation of stable nitrogen isotopes during amino acid transamination. Geochimica et Cosmochimica Acta 50:21432146

Sandquist DR, Ehleringer JR (1997) Intraspecific variation of leaf pubescence and drought response in Encelia farinosa associated with contrasting desert environments. New Phytologist 135:635-644

Schemske DW (1983) Limits to specialization and coevolution in plant-animal mutualisms. In: Nitecki MH (ed) Coevolution. The University of Chicago Press Ltd., Chicago, pp 67-102

Thompson JN (1994) The Coevolutionary Process. University Of Chicago Press

Thompson JN (2005) The Geographic Mosaic of Coevolution. The University of Chicago Press, Chicago

Xu Z, Prasolova N, Lundkvist K, Beadle C, Leaman T (2003) Genetic variation in branchlet carbon and nitrogen isotope composition and nutrient concentration of 11-year-old hoop pine families in relation to tree growth in subtropical Australia. Forest Ecology and Management 186:359-371 